\title{
Conjugated Microporous Polymers via Solvent-Free Ionothermal Cyclotrimerization of Methyl Ketones
}

Jaehwan Kim, ${ }^{a}+$ Casandra M. Moisanu, ${ }^{a},{ }^{\ddagger}$ Cara N. Gannett, ${ }^{a}$ Arjun Halder, ${ }^{a}$ José J. FuentesRivera, ${ }^{a}$ Sean H. Majer, ${ }^{a}$ Kyle M. Lancaster, ${ }^{a}$ Alexander C. Forse, ${ }^{b}$ Héctor D. Abruña, ${ }^{a}$ Phillip J. Milner ${ }^{a, *}$

${ }^{a}$ Department of Chemistry and Chemical Biology, Cornell University, Ithaca, NY, 14850, United States

${ }^{b}$ Department of Chemistry, University of Cambridge, Cambridge, CB2 1EW, U.K. *pjm347@cornell.edu

These authors contributed equally.

\section{Supporting Information}

Table of Contents.

1. General procedures. 2

2. Synthesis and characterization of monomers. 4

a. Tetraphenylmethane. 4

b. Tetrakis(4-acetylphenyl)methane (TAPM). $\quad 6$

c. 1,3,5-tris(4-acetylphenyl)benzene (TAPB). $\quad 8$

d. 1,3,5-tris(4-acetylphenyl)triazine (TAPT). 10

3. General procedure for the synthesis of polymeric materials. 12

4. Synthesis and characterization of trimerized materials. 13

a. 1,3,5-triacetylbenzene trimerization. 13

b. Tetrakis(4-acetylphenyl)methane trimerization. 29

c. 1,4-diacetylbenzene trimerization.

d. 4,4'-diacetylbiphenyl trimerization.

e. 1,3,5-tris(4-acetylphenyl)benzene trimerization. $\quad 51$

f. 1,3,5-tris(4-acetylphenyl)-triazine trimerization.

5. Electrochemical Measurements of TAB-CMP-400 ${ }^{\circ} \mathrm{C}, 5.0$ eq. 59

6. Synthesis and characterization of OFC-1b. 64

7. Synthesis and characterization of tri-PPN. 69

8. Control experiments 73

a. Attempted trimerization of 1,3,5-triethylbenzene. 73

b. Solid state ${ }^{1} \mathrm{H}$ NMR comparison with other carbon materials. 73

9. Calculated Structural Models of CORN-CMP-1 and CORN-PAF-1. 76

$\begin{array}{ll}\text { 10. References. } & 78\end{array}$ 


\section{General procedures.}

The reagents 1,4-diacetylbenzene (DAB, 97\%, Alfa Aesar), 4,4'-diacetylbiphenyl (DABP, 98\%, Alfa Aesar), 1,3,5-triphenylbenzene (98\%, Alfa Aesar), aqueous hypophosphorous acid (50 w/w\%, Alfa Aesar), methanesulfonic acid (98\%, Alfa Aesar), 1,3,5-triacetylbenzene (TAB, 96\%, Tokyo Chemical Industry), cyanuric chloride (98\%, Tokyo Chemical Industry), potassium carbonate (99.7\%, Fisher Scientific), anhydrous aluminum chloride (99\%, Acros), carbon disulfide (99\%, Acros), hydrochloric acid (37\%, Aldrich), acetyl chloride (98\%, Aldrich), anhydrous zinc chloride (99.6\%, Aldrich), 4-acetylphenylboronic acid (97\% Aldrich), XPhos Pd G3 (95\%, Aldrich), 1,3,5-triethylbenzene (97\%, Aldrich), XPhos (95\%, Astatech Inc), tetraethylammonium tetrafluoroborate (99\%, Millipore Sigma), polytetrafluoroethylene (preparation, 60 wt\% dispersion in water, Millipore Sigma), and aniline (99\%, Fluka Chemical) were purchased from commercial vendors and used without additional purification. Super P carbon (Imerys Graphite \& Carbon) was dried overnight in a vacuum oven at $60{ }^{\circ} \mathrm{C}$ before use. Supercapacitor Activated Carbon was purchased from MTI Corporation and used without further purification. All solvents were purchased from commercial vendors and used without further purification unless otherwise noted. Anhydrous acetonitrile (MeCN) (HPLC Grade) was purchased from Fisher Chemical and dried over activated $4 \AA$ molecular sieves (Mallinckrodt Chemicals) for at least two days before use.

Infrared spectra were collected on a Bruker Tensor II IR spectrometer with a diamond Attenuated Total Reflectance (ATR) attachment. Surface area data were collected on a Micromeritics 3-flex gas sorption analyzer using ultrapure $\mathrm{N}_{2}(99.999 \%)$ and a liquid $\mathrm{N}_{2}$ bath. Brunauer-Emmett-Teller (BET) and Langmuir surface areas were determined by linear least squares regression analysis using the linearized forms of the BET and Langmuir equations, respectively. Powder X-ray diffraction (PXRD) patterns were collected on a Rigaku Ultima IV diffractometer equipped with a $\mathrm{Cu} \mathrm{K}_{\alpha}$ source $(\lambda=1.5406 \AA)$ and were baseline-corrected using OriginPro. Solution-state NMR data were collected on a Bruker INOVA $500 \mathrm{MHz}$ spectrometer and are referenced to residual solvent. Magic angle spinning solid-state NMR (MAS SSNMR) measurements at Cornell University were carried out using a Phoenix NMR HX NB Probe (3.2 $\mathrm{mm}$ ) located within a Varian INOVA $500 \mathrm{MHz}$ spectrometer. All MAS SSNMR experiments were carried out using samples packed within $35 \mu \mathrm{L}$ rotors at a spinning speed of $20 \mathrm{kHz}$. Solid-state NMR measurements at the University of Cambridge were carried out at either 16.4 (700 MHz for ${ }^{1} \mathrm{H}$ ) or $9.4 \mathrm{~T}\left(400 \mathrm{MHz}\right.$ for $\left.{ }^{1} \mathrm{H}\right)$, with $3.2 \mathrm{~mm}$ and $4 \mathrm{~mm}$ MAS probes, respectively. Unless otherwise stated, ${ }^{13} \mathrm{C}$ NMR spectra were recorded with cross polarization. ${ }^{1} \mathrm{H}$ spectra were recorded using a spin echo sequence with a single rotor period used as the spin echo delay. Spectral deconvolution was carried out in the SOLA package in Topspin software (Bruker). ${ }^{1} \mathrm{H}$ and ${ }^{13} \mathrm{C}$ NMR spectra were referenced relative to adamantane at 1.8 and $38.5 \mathrm{ppm}$ (left hand resonance), respectively. Mass spectral (MS) data were obtained on Advion Mass Spectrometer equipped with an APCI (Atmospheric Pressure Chemical Ionization) module. Solid-state UV-Vis absorption spectra were collected using a Shimattadzu UV-2600i UV-Vis Spectrophotometer equipped with an ISR-2600 Plus Integrating Sphere. Decomposition profiles were collected on a TA Instruments 
Q500 V6.7 thermogravimetric analyzer using a temperature ramp of $5.00{ }^{\circ} \mathrm{C} / \mathrm{min}$ from room temperature to $600.00{ }^{\circ} \mathrm{C}$. Scanning electron microscopy (SEM) images were taken at between $1.0-10 \mathrm{kV}$ using a Zeiss Gemini 500 scanning electron microscope. The powder samples were immobilized on carbon tape mounted on an aluminum stub. The samples were blown using compressed air to remove excess material not stuck to the tape and then coated with a carbon layer. Energy dispersive X-ray spectroscopy (EDS) data were collected at $10.0 \mathrm{kV}$ using a Zeiss Gemini 500 scanning electron microscope equipped with an Oxford Instruments Ultima Max 170 detector (detector type X-max) and processed using the AZtec software. The samples were similarly prepared as SEM samples but were not coated with a carbon layer. Tunneling electron microscopy (TEM) images were taken on a ThermoFischer Scientific F20 STEM at 200kV. The images were acquired on a Gatan Orius 2k x 2k CCD camera, and processed using ImageJ. The sample was embedded in EmBed 812 at room temperature and left to settle in a BEEM capsule for $8 \mathrm{~h}$ to allow the material to aggregate at the tip of the capsule. The BEEM capsule was then transferred to a 70 ${ }^{\circ} \mathrm{C}$ oven for polymerization overnight for $12 \mathrm{~h}$. The sample is removed from the oven and ultramicrotomed on a Leica Ultracut 7 using a Diatome 45 degree diamond knife. The sections are $70 \mathrm{~nm}$ in thickness and picked up on a 300 mesh copper TEM grid. X-ray photoelectron spectroscopy samples were analyzed using a Scienta Omicron ESCA-2SR with operating pressure ca. $1 \times 10^{-9}$ Torr. Monochromatic Al K $\alpha$ X-rays $(1486.6 \mathrm{eV})$ were generated at $250 \mathrm{~W}(15 \mathrm{kV}$; $20 \mathrm{~mA}$ ) with photoelectrons collected from a $2 \mathrm{~mm}$ diameter analysis spot. Photoelectrons were collected at a $0^{\circ}$ emission angle with source to analyzer angle of $54.7^{\circ} \mathrm{A}$ hemispherical analyzer determined electron kinetic energy, using a pass energy of $200 \mathrm{eV}$ for wide/survey scans, and 50 $\mathrm{eV}$ for high resolution scans. A flood gun was used for charge neutralization of non-conductive samples. The data was then processed with CasaXPS. Raman spectra were collected using a homebuilt spectrometer. Samples were excited using a SpectraPhysics Stabilite $1800 \mathrm{Ar} / \mathrm{Kr}$ mixed-gas laser set to $\lambda=458 \mathrm{~nm}$. Incident laser excitation was passed through Semrock MaxLine laser cleanup filters and focused to a ca. $2 \mathrm{~mm}$ point using a spherical lens (ThorLabs). Samples were held in a $180^{\circ}$ backscattering geometry and continuously spun at room temperature using an NMR tube spinner for power dissipation. All Raman data were collected at room temperature. Incident laser power at the sample was measured using a ThorLabs digital power meter. The laser power was ca. $20 \mathrm{~mW}$ for all measurements. Scattered light was collected using a $50 \mathrm{mM}$ Canon F/1.2 FD macro lens and focused through a $10 \mu \mathrm{m}$ slit into a Princeton Instruments IsoPlane SCT320 spectrograph using an F-matched achromatic doublet lens. Semrock Razoredge long-pass filters were used to remove Rayleigh scattering. Scattered, filtered light was energy dispersed using a $1200 \mathrm{~g} / \mathrm{mm}$ grating onto a Pixis 100B eXcelon digital CCD held thermoelectrically at $-60{ }^{\circ} \mathrm{C}$. Data were recorded and processed using the Lightfield software package (Princeton Instruments). Spectra were centered at $500 \mathrm{~nm}$. Acetaminophen was used as a Raman shift calibrant. Sample spectra were collected at 30-45 second exposures and summed over 50 frames. Electrochemical tests were performed with a Biologic SP150 potentiostat. Idealized structural models were constructed using BIOVIA Materials Studio 2020 (extended structures) or Avogadro (molecular fragments). C/H combustion elemental analysis was performed by Atlantic Microlab Inc. 


\section{Synthesis and characterization of monomers.}

\section{a. Tetraphenylmethane.}

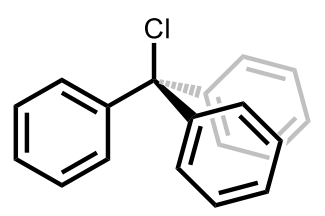

1) $\mathrm{PhNH}_{2}, \Delta$,

2) $\mathrm{HCl}, \mathrm{MeOH}$

3) $\mathrm{H}_{2} \mathrm{SO}_{4}$, isoamylnitrite

4) $\mathrm{H}_{3} \mathrm{PO}_{2}$

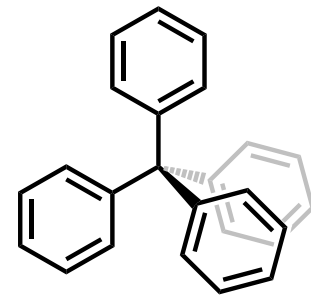

Figure S1. Synthesis of tetraphenylmethane.

Tetraphenylmethane was prepared according to the literature procedure. ${ }^{1}$ A mixture of trityl chloride ( $25 \mathrm{~g}, 0.089 \mathrm{~mol}, 1.0$ eq.) and aniline (22 mL, $0.23 \mathrm{~mol}, 2.8$ eq.) was stirred for 15 min at $190{ }^{\circ} \mathrm{C}$ in a $500 \mathrm{~mL}$ round bottom flask. The mixture was cooled to room temperature, at which time $2 \mathrm{M} \mathrm{HCl}(100 \mathrm{~mL})$ and $\mathrm{MeOH}(150 \mathrm{~mL})$ were added. The addition of solvents resulted in precipitation of a purple solid. The solid was broken up into smaller pieces using a spatula. The mixture was heated for $30 \mathrm{~min}$ at $80{ }^{\circ} \mathrm{C}$ and again allowed to cool to room temperature. The light purple solid was filtered and washed with water $(250 \mathrm{~mL})$ before being dried under reduced pressure $\left(<100 \mathrm{mTorr}, 70^{\circ} \mathrm{C}\right)$ for $16 \mathrm{~h}$. The solid was then suspended in DMF $(250 \mathrm{~mL})$, and this mixture was cooled to $-20{ }^{\circ} \mathrm{C}$ using an ice water bath containing $\mathrm{NaCl}$. Concentrated sulfuric acid $(27.5 \mathrm{~mL})$ and isoamyl nitrite $(19.9 \mathrm{~mL})$ were added to the reaction mixture slowly. The reaction mixture was then stirred for $1 \mathrm{~h}$ at $0{ }^{\circ} \mathrm{C}$. At this time, $50 \%$ hypophosphorous acid $(140 \mathrm{~mL})$ was added dropwise, causing the solution to bubble. The mixture was heated to $50{ }^{\circ} \mathrm{C}$ until gas stopped evolving. The reaction mixture was cooled to room temperature and filtered. The solid was washed with DMF $(2 \times 250 \mathrm{~mL})$, water $(2 \times 250 \mathrm{~mL})$, and $\mathrm{EtOH}(2 \times 250 \mathrm{~mL})$. The resulting light brown solid was dried under reduced pressure $\left(<100 \mathrm{mTorr}, 70{ }^{\circ} \mathrm{C}\right)$ for $18 \mathrm{~h}$ to afford the final product (20 g, $69 \%$ yield) as a light brown solid.

${ }^{1} \mathrm{H}$ NMR (500 MHz, $\left.\mathrm{CDCl}_{3}\right): \delta 7.19-7.30(\mathrm{~m}, 20 \mathrm{H}) \mathrm{ppm} .{ }^{13} \mathrm{C} \mathrm{NMR}\left(125 \mathrm{MHz}, \mathrm{CDCl}_{3}\right): \delta$ $146.8,131.2,127.5,125.9,65.0 \mathrm{ppm}$. These spectra are consistent with those reported in the literature. $^{1}$ 


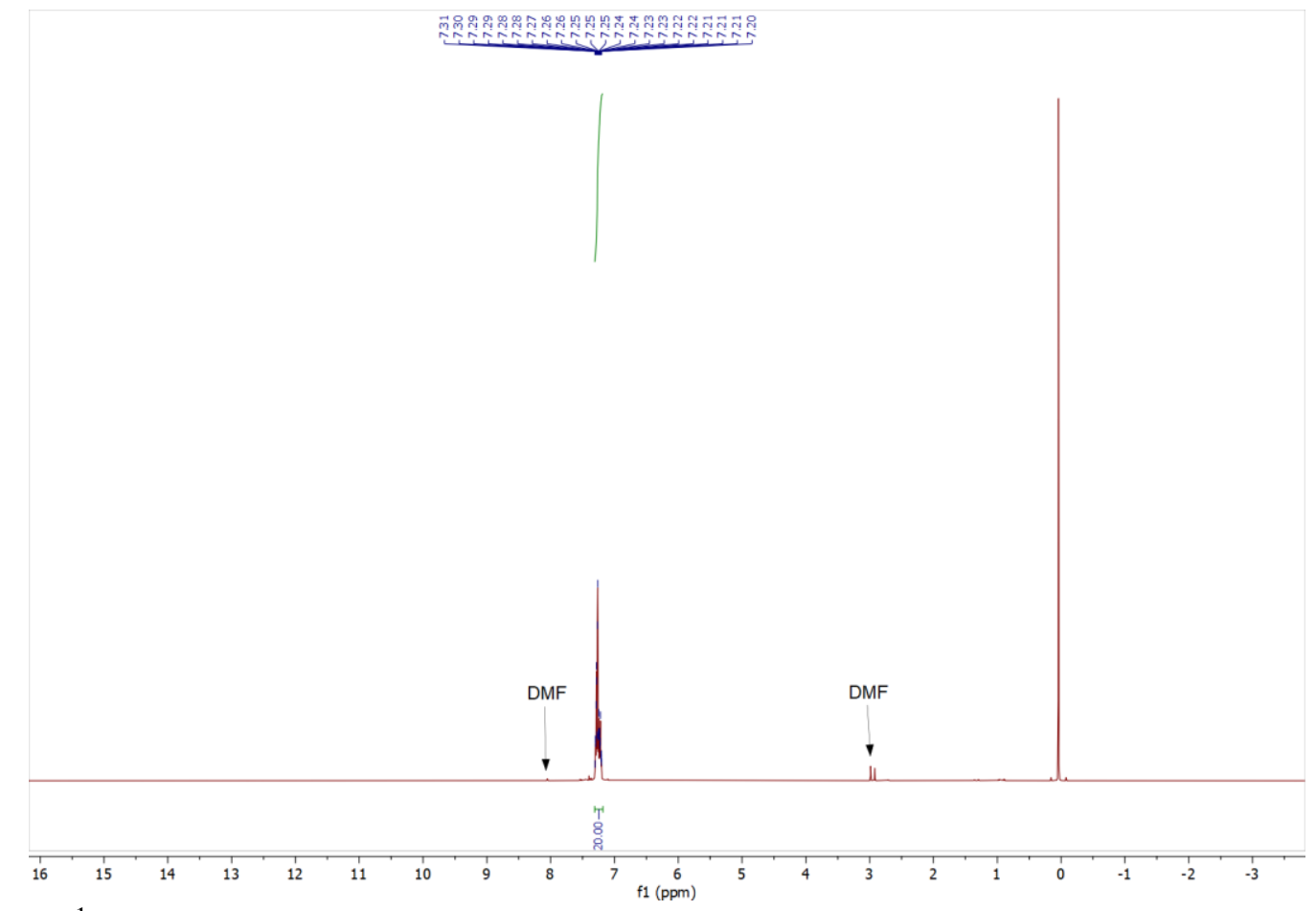

Figure S2. ${ }^{1} \mathrm{H}$ NMR $\left(500 \mathrm{MHz}, \mathrm{CDCl}_{3}\right)$ spectrum of tetraphenylmethane used in this work.

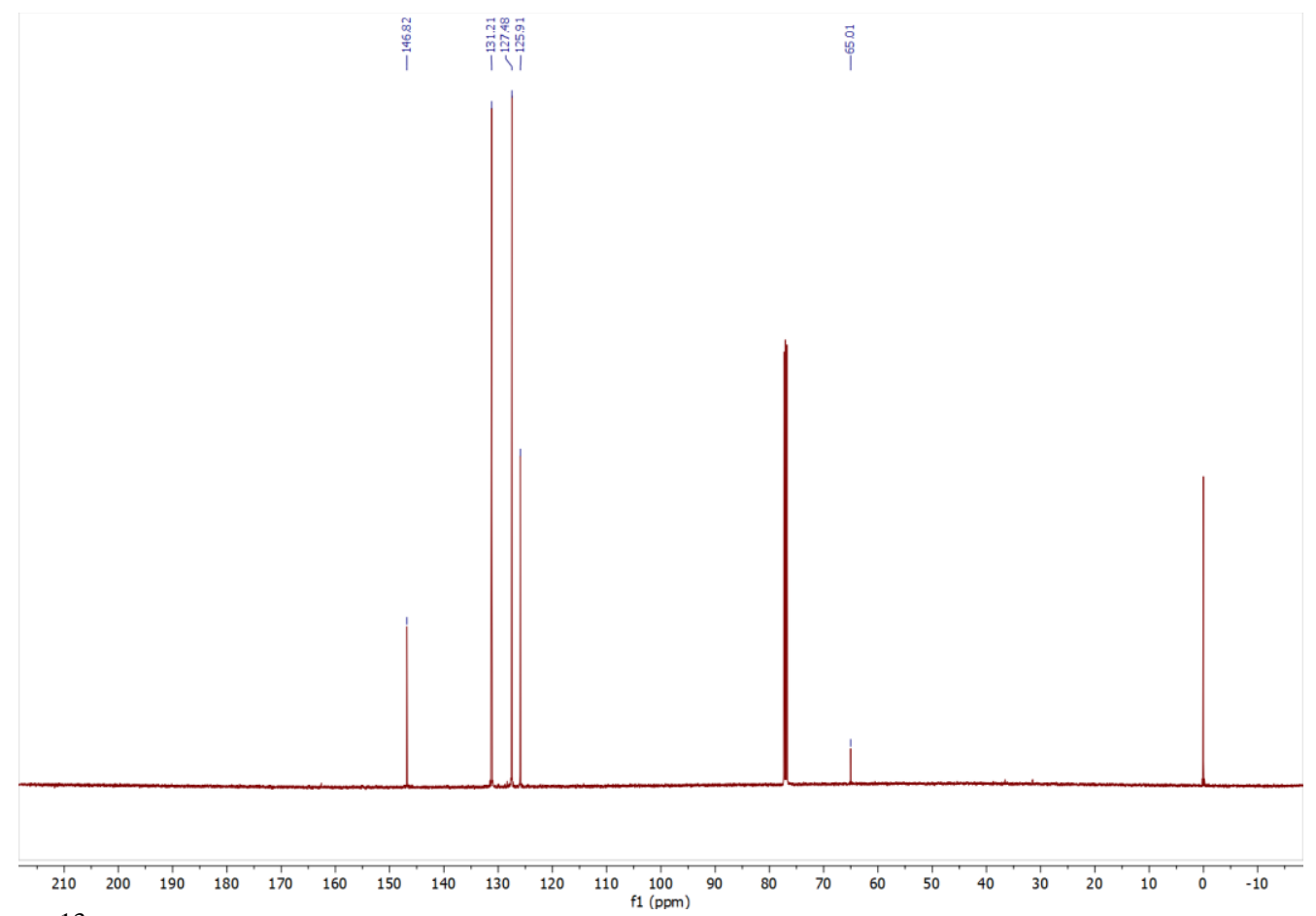

Figure S3. ${ }^{13} \mathrm{C}-\mathrm{NMR}\left(125 \mathrm{MHz}, \mathrm{CDCl}_{3}\right)$ spectrum of tetraphenylmethane used in this work. 


\section{b. Tetrakis(4-acetylphenyl)methane (TAPM).}

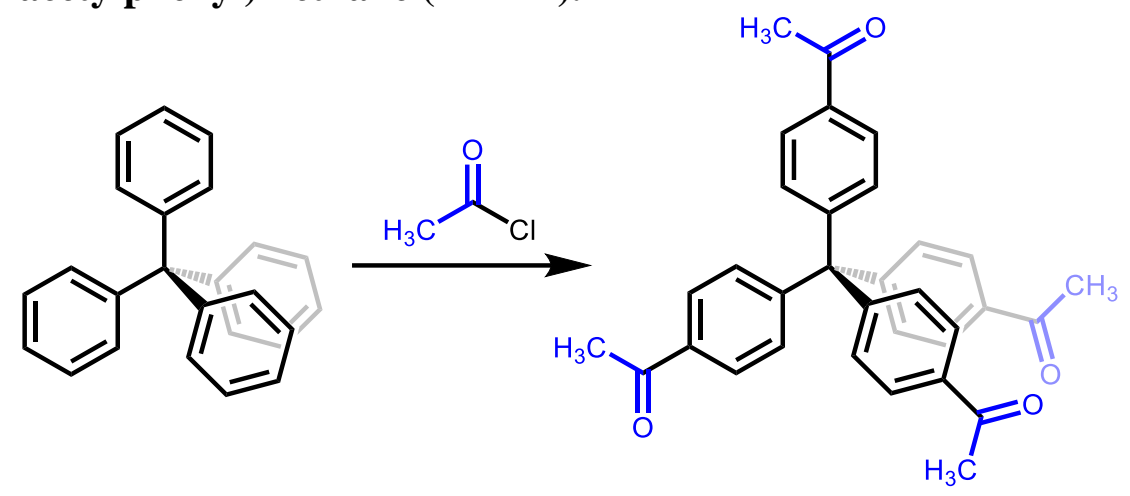

Figure S4. Synthesis of tetrakis(4-acetylphenyl)methane (TAPM).

TAPM was prepared according to the literature procedure. ${ }^{2}$ Solid $\mathrm{AlCl}_{3}(2.2 \mathrm{~g}, 16 \mathrm{mmol}$, 5.2 eq.) was added portion-wise to a stirred solution of tetraphenylmethane $(1.0 \mathrm{~g}, 3.1 \mathrm{mmol}, 1.0$ eq.) and acetyl chloride $\left(1.5 \mathrm{~g}, 19 \mathrm{mmol}, 6.1\right.$ eq.) in $\mathrm{CS}_{2}(16 \mathrm{~mL})$. The reddish-brown mixture was heated to reflux for $36 \mathrm{~h}$. The reaction mixture was cooled to room temperature, and the remaining $\mathrm{CS}_{2}$ was decanted from the dark brown, odorous precipitate. Ice, concentrated $\mathrm{HCl}(12 \mathrm{M}, 5 \mathrm{~mL})$, and $\mathrm{CH}_{2} \mathrm{Cl}_{2}(20 \mathrm{~mL})$ were added until the precipitate dissolved. The layers were separated, and the aqueous layer was further extracted with $\mathrm{CH}_{2} \mathrm{Cl}_{2}(3 \times 20 \mathrm{~mL})$. The combined organic extracts were dried over $\mathrm{Na}_{2} \mathrm{SO}_{4}$ and filtered. The solvent was removed under reduced pressure and the resulting dark brown oily residue was purified by column chromatography $\left(\mathrm{SiO}_{2}\right.$, gradient of $0 \% \rightarrow 10 \%$ $\rightarrow 30 \% \rightarrow 50 \% \rightarrow 70 \% \rightarrow 100 \%$ acetone/hexanes) to afford the final product ( $0.84 \mathrm{~g}, 63 \%$ yield) as a fluffy, pale yellow solid.

${ }^{1} \mathrm{H}$ NMR $\left(500 \mathrm{MHz}, \mathrm{CDCl}_{3}\right): \delta 7.89(\mathrm{~d}, \mathrm{~J}=8.3 \mathrm{~Hz}, 8 \mathrm{H}), 7.35(\mathrm{~d}, \mathrm{~J}=8.6 \mathrm{~Hz}, 8 \mathrm{H}), 2.59(\mathrm{~s}$, $12 \mathrm{H})$ ppm. ${ }^{13} \mathrm{C}$ NMR $\left(125 \mathrm{MHz}, \mathrm{CDCl}_{3}\right) \delta 197.4,150.1,135.5,130.9,128.2$, 65.6, $26.6 \mathrm{ppm}$. These spectra are consistent with those reported in the literature. ${ }^{2}$ 

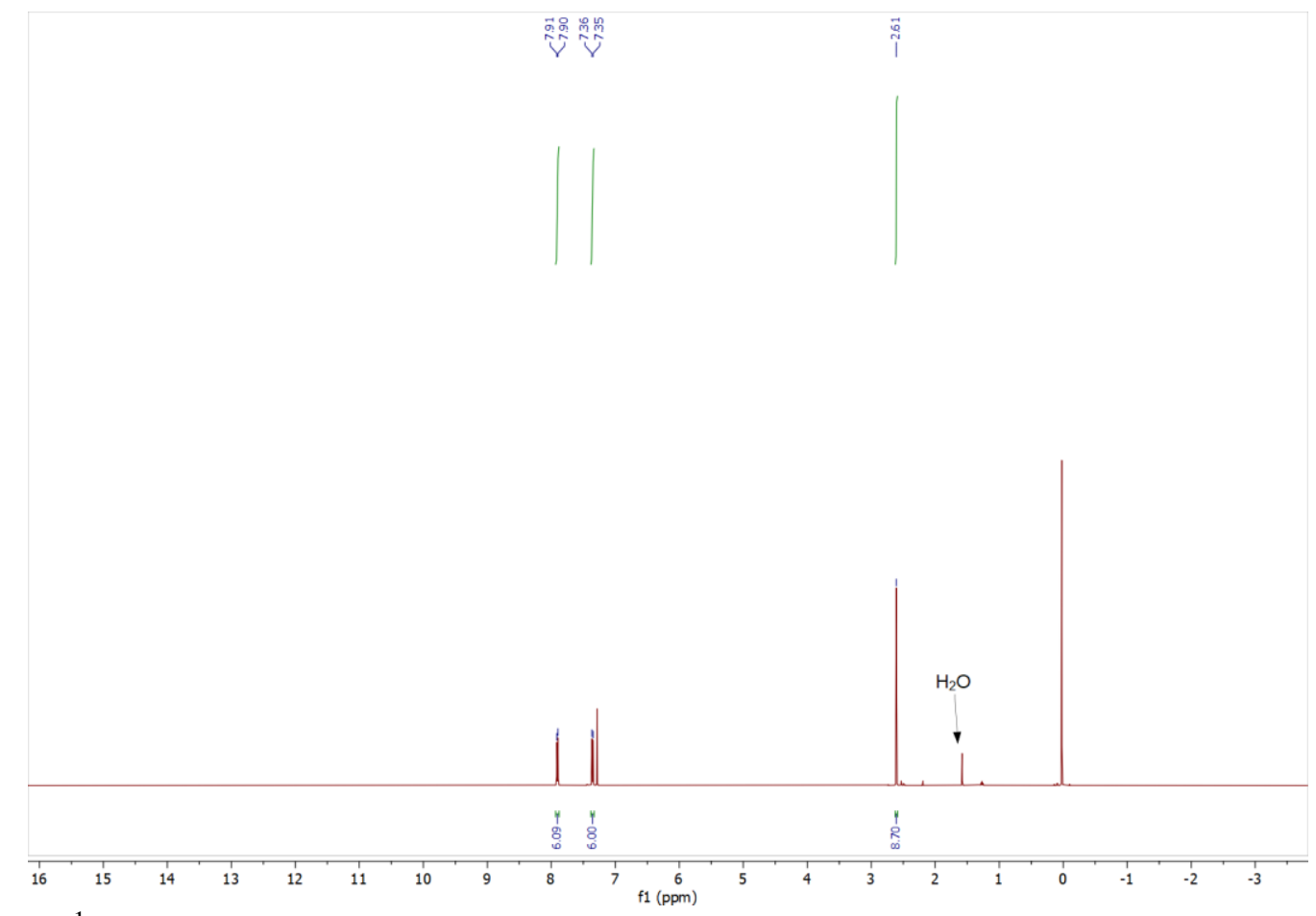

Figure S5. ${ }^{1} \mathrm{H}-\mathrm{NMR}\left(500 \mathrm{MHz}, \mathrm{CDCl}_{3}\right.$ ) spectrum of tetrakis(4-acetylphenylmethane) used in this work.

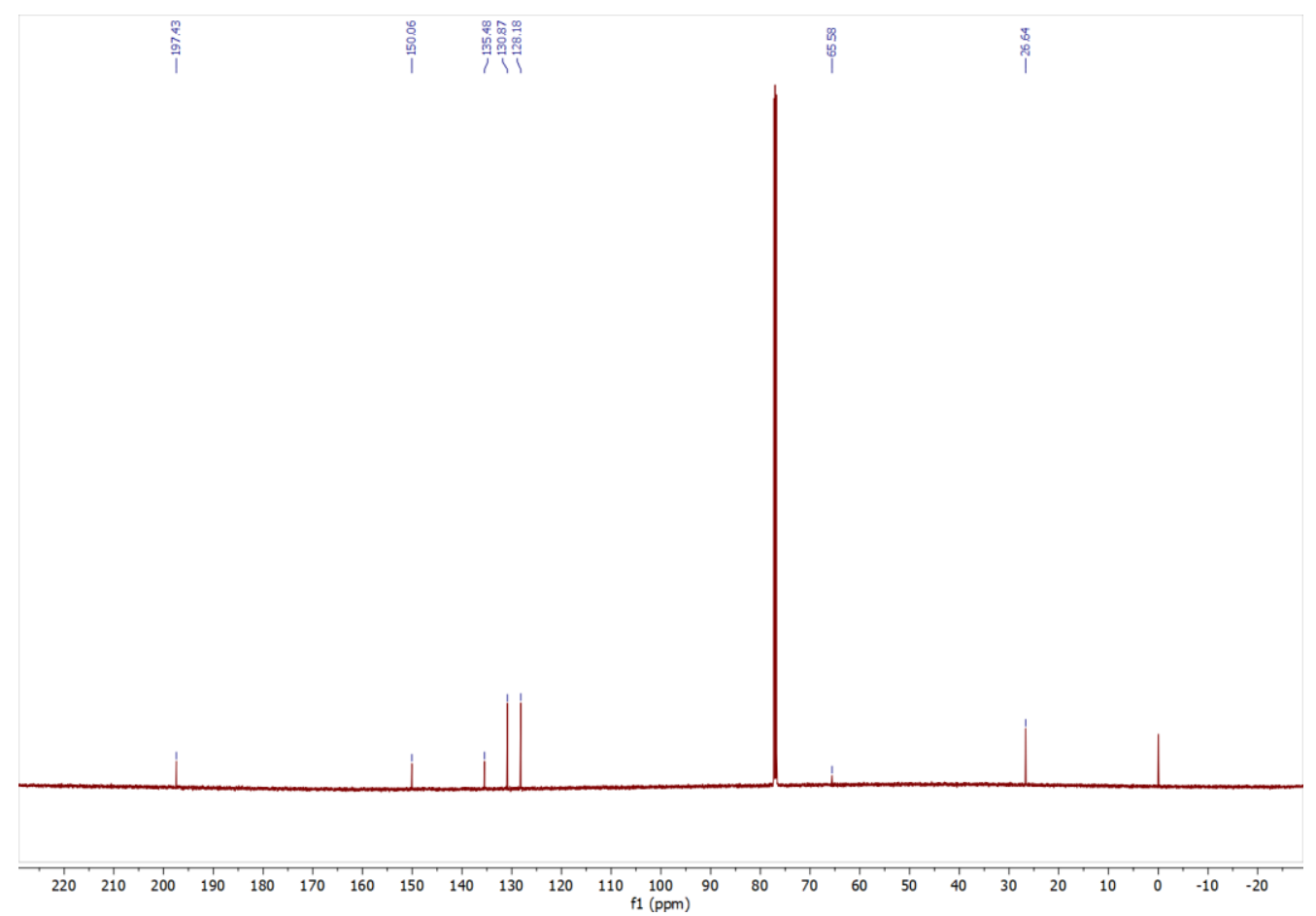

Figure S6. ${ }^{13} \mathrm{C}$ NMR (125 MHz, $\mathrm{CDCl}_{3}$ ) spectrum of tetrakis(4-acetylphenylmethane) used in this work. 


\section{c. 1,3,5-tris(4-acetylphenyl)benzene (TAPB).}

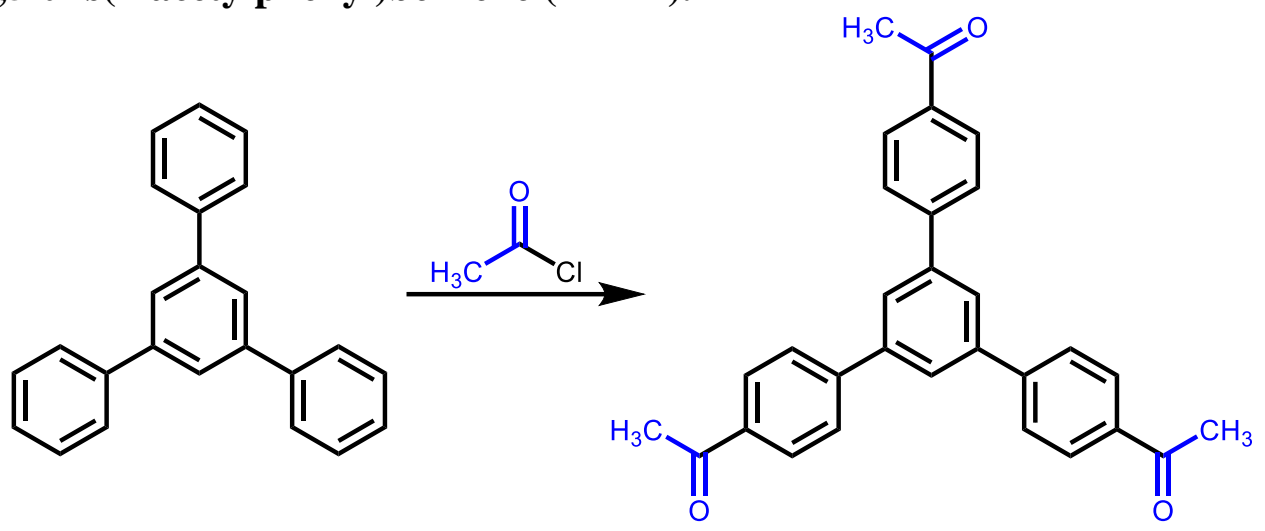

Figure S7. Synthesis of 1,3,5-tris(4-acetylphenyl)benzene (TAPB).

The following procedure was adapted from the procedure used to make tetrakis(4acetylphenyl)methane (TAPM) ${ }^{2}$ Solid $\mathrm{AlCl}_{3}(2.0 \mathrm{~g}, 15 \mathrm{mmol})$ was added portion-wise to a stirred solution of 1,3,5-triphenylbenzene $(1.1 \mathrm{~g}, 3.5 \mathrm{mmol})$ and acetyl chloride $(1.2 \mathrm{~g}, 16 \mathrm{mmol})$ in $\mathrm{CS}_{2}$ $(15 \mathrm{~mL})$ at $0{ }^{\circ} \mathrm{C}$ under an $\mathrm{N}_{2}$ atmosphere. The reddish-brown reaction mixture was stirred for 15 min at $0{ }^{\circ} \mathrm{C}$, at which time it was heated to reflux and allowed to stir at reflux for $18 \mathrm{~h}$ under an $\mathrm{N}_{2}$ atmosphere. The reaction mixture was cooled to room temperature followed by addition of ice, concentrated $\mathrm{HCl}(5 \mathrm{ml})$, and $\mathrm{CH}_{2} \mathrm{Cl}_{2}(50 \mathrm{ml})$. The aqueous layer was extracted with $\mathrm{CH}_{2} \mathrm{Cl}_{2}(3 \times$ $100 \mathrm{~mL}$ ). The combined organic extracts were dried over $\mathrm{Na}_{2} \mathrm{SO}_{4}$ and filtered. The solvent was removed under reduced pressure and the resulting solid was purified by column chromatography $\left(\mathrm{SiO}_{2}, 1 \% \mathrm{CH}_{3} \mathrm{OH}\right.$ in $\left.\mathrm{CH}_{2} \mathrm{Cl}_{2}\right)$ to afford the final compound $(1.1 \mathrm{~g}, 72 \%$ yield) as an off-white solid.

${ }^{1} \mathrm{H}$ NMR (500 MHz, $\left.\mathrm{CDCl}_{3}\right): \delta 8.10(\mathrm{~d}, \mathrm{~J}=8 \mathrm{~Hz}, 6 \mathrm{H}), 7.87(\mathrm{~s}, 3 \mathrm{H}), 7.80(\mathrm{~d}, \mathrm{~J}=8 \mathrm{~Hz}, 6 \mathrm{H})$, 2.67 (s, 9H) ppm. ${ }^{13} \mathrm{C}$ NMR $\left(125 \mathrm{MHz}, \mathrm{CDCl}_{3}\right): \delta 197.6,145.0,141.6,136.4,129.1,127.5,126.1$, $27.1 \mathrm{ppm}$. These spectra are consistent with those reported in the literature. ${ }^{3}$ 


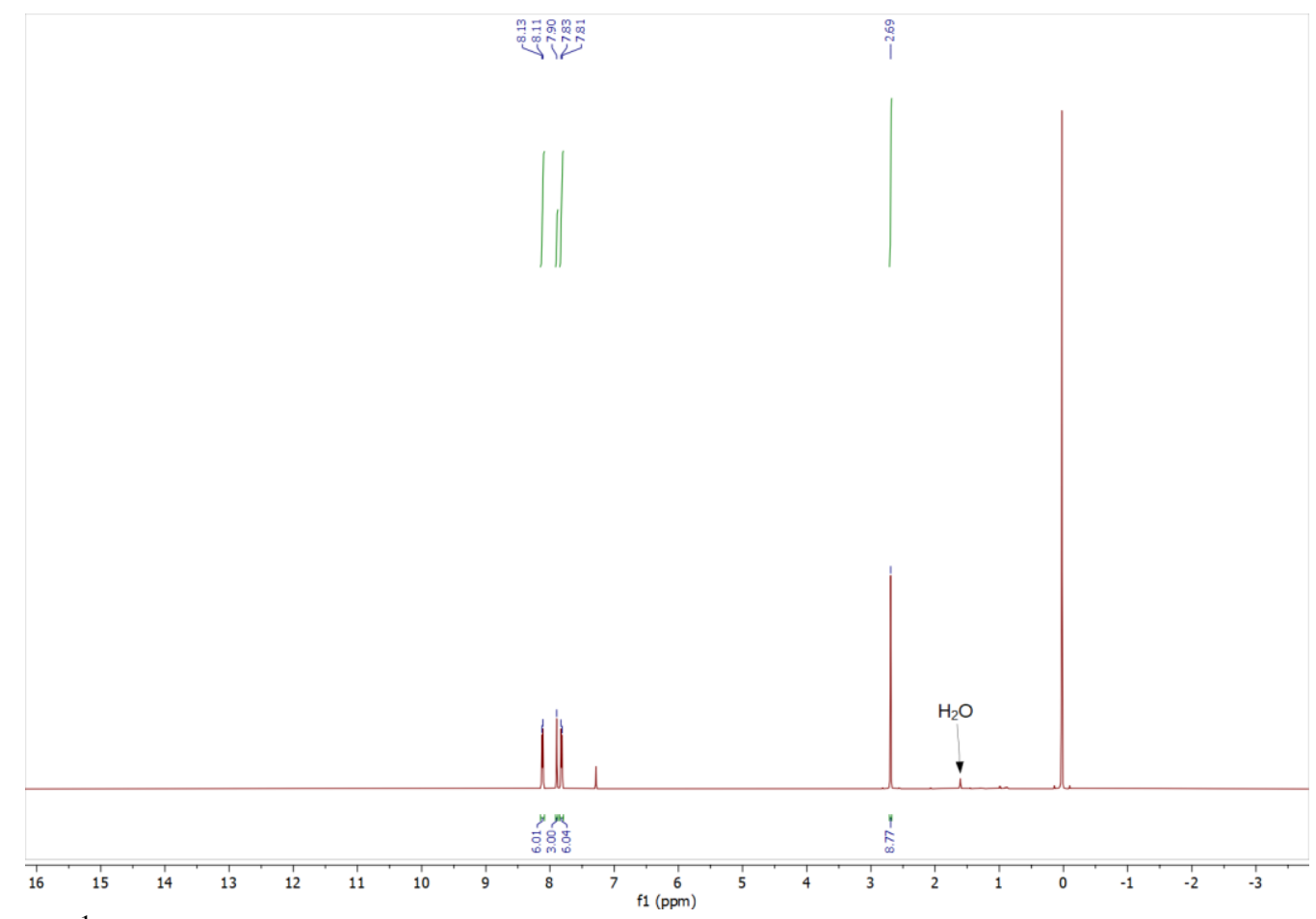

Figure S8. ${ }^{1} \mathrm{H}-\mathrm{NMR}\left(500 \mathrm{MHz}, \mathrm{CDCl}_{3}\right)$ spectrum of 1,3,5-tris(4-acetylphenyl)benzene used in this work.

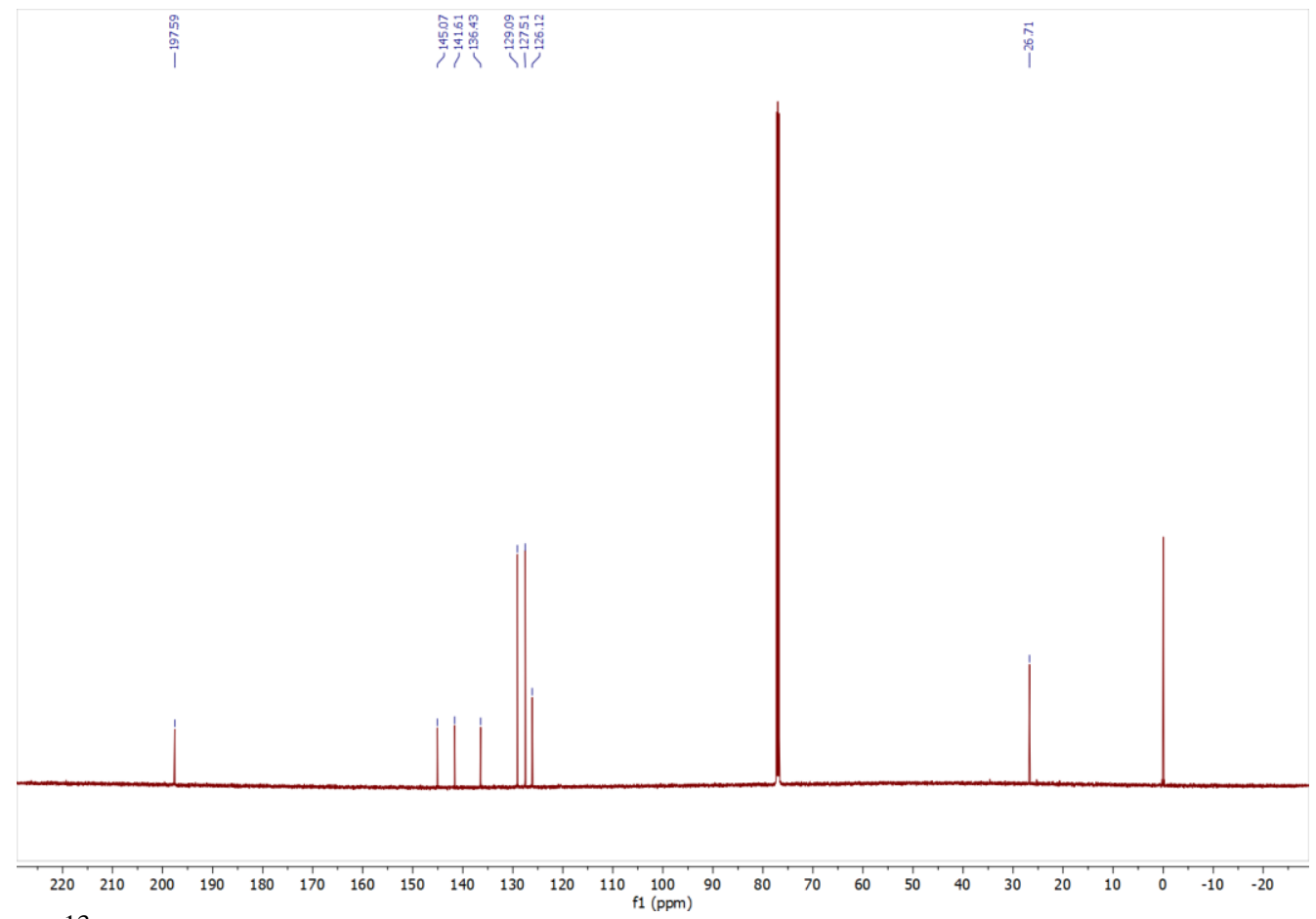

Figure S9. ${ }^{13} \mathrm{C}-\mathrm{NMR}\left(125 \mathrm{MHz} \mathrm{CDCl}_{3}\right)$ spectrum of 1,3,5-tris(4-acetylphenyl)benzene used in this work. 


\section{d. 1,3,5-tris(4-acetylphenyl)triazine (TAPT).}

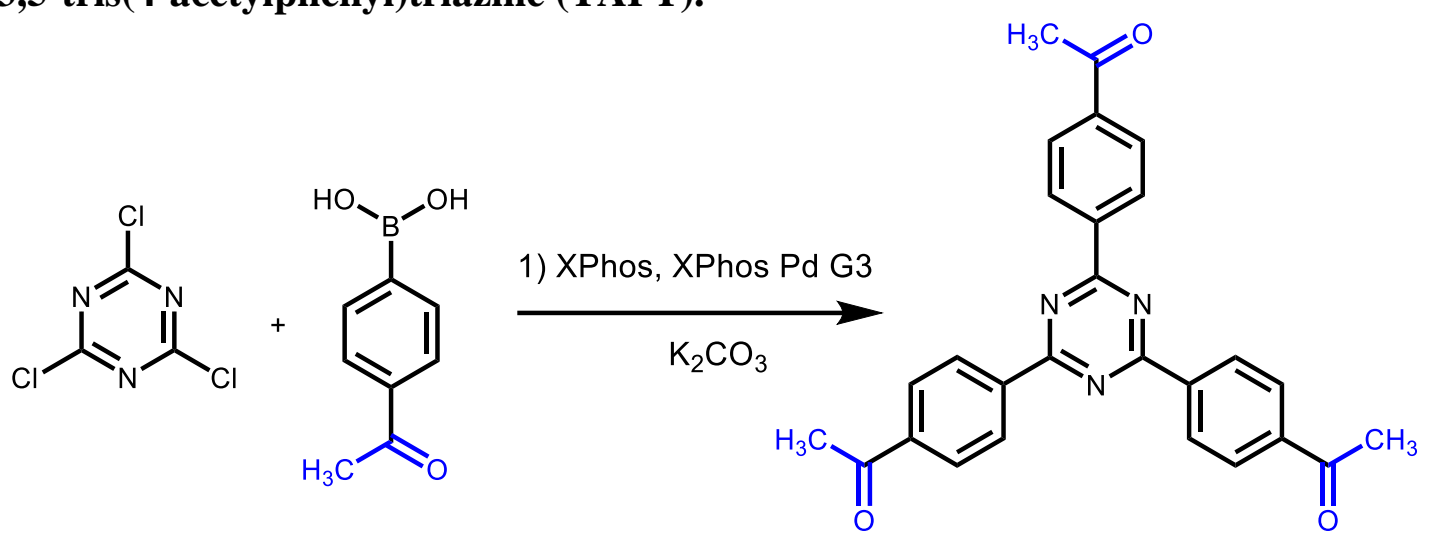

Figure S10. Synthesis of 1,3,5-tris(4-acetylphenyl)triazine (TAPT).

To a $250 \mathrm{~mL}$ 3-neck flask, cyanuric chloride (1.8 g, $10 \mathrm{mmol})$, 4-acetylphenylboronic acid (7.379 g, $45 \mathrm{mmol}$ ), XPhos (215 mg, $0.45 \mathrm{mmol}$ ), XPhos Pd G3 (380.9 mg, $0.45 \mathrm{mmol}$ ), and $\mathrm{K}_{2} \mathrm{CO}_{3}(8.292 \mathrm{~g}, 60 \mathrm{mmol})$ were added. The flask was evacuated ( $\left.<100 \mathrm{mTorr}\right)$ and backfilled with $\mathrm{N}_{2}$. Under a positive pressure of $\mathrm{N}_{2}$, freshly degassed 1,4-dioxane $(100 \mathrm{~mL})$ was added. The reaction mixture was stirred at reflux for $48 \mathrm{~h}$ under $\mathrm{N}_{2}$. The mixture was cooled to room temperature and poured into water $(100 \mathrm{~mL})$. The light yellow, cloudy mixture was filtered and the resulting light-yellow solid was washed with water $(50 \mathrm{~mL})$. The solid was dissolved in $\mathrm{CHCl}_{3}$ and filtered through celite, eluting with $\mathrm{CHCl}_{3}$. The solvent was removed under reduced pressure. The resulting light-yellow solid was dissolved in a minimal amount of $\mathrm{CH}_{2} \mathrm{Cl}_{2}$ and placed in a freezer $\left(-14{ }^{\circ} \mathrm{C}\right)$ for $24 \mathrm{~h}$. The resulting suspension was filtered. The resulting solid was redissolved in $\mathrm{CHCl}_{3}$ and placed in a freezer $\left(-14{ }^{\circ} \mathrm{C}\right)$ for $24 \mathrm{~h}$. The resulting suspension was filtered to afford the final product ( $442 \mathrm{mg}, 10 \%$ yield) as a faint yellow, flakey solid.

${ }^{1} \mathrm{H}$ NMR (500 MHz, DMSO-d6) $\delta 8.87(\mathrm{~d}, \mathrm{~J}=8.0 \mathrm{~Hz}, 6 \mathrm{H}), 8.19(\mathrm{~d}, \mathrm{~J}=8.0 \mathrm{~Hz}, 6 \mathrm{H}), 2.74$ (s, 9H) ppm. ${ }^{13} \mathrm{C}$ NMR $\left(125 \mathrm{MHz}, \mathrm{CDCl}_{3}\right) \delta 197.7,171.2,140.3,139.7,129.3,128.6,27.0 \mathrm{ppm}$. IR (powder, $\mathrm{cm}^{-1}$ ): 3342 (w), 3069 (v.w), 3052 (v.w), 2989(v.w), 2358 (v.w), 2333(v.w, br) 1842 (v.w, br), 1690 (s), 1678 (s), 1579 (s), 1510 (s), 1426 (m), 1403 (m), 1349 (s), 1298 (w), 1256 (s), 1177 (w), 1110 (m), 1073 (w), 1011 (m), 993 (w), 955 (m), 871 (m), 846 (m), 810 (s), 757 (w), 722 (s). Melting point: Decomposed at $230{ }^{\circ} \mathrm{C}$. Observed $[\mathrm{M}+\mathrm{H}]^{+}=435.9$, Predicted $[\mathrm{M}+\mathrm{H}]^{+}=$ 436.2 . 


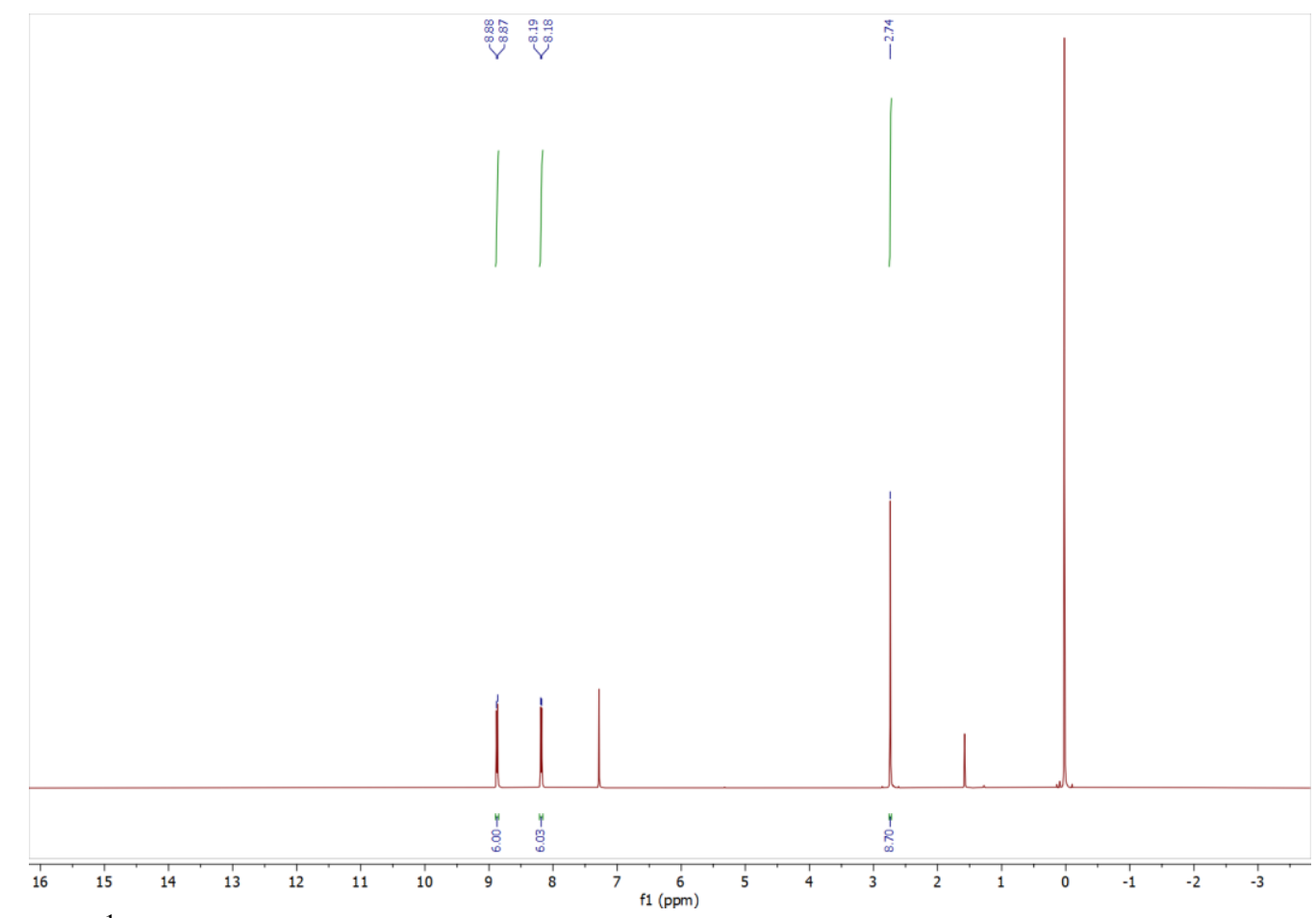

Figure S11. ${ }^{1} \mathrm{H}-\mathrm{NMR}\left(500 \mathrm{MHz}, \mathrm{CDCl}_{3}\right)$ spectrum of 1,3,5-tris(4-acetylphenyl)triazine used in this work.

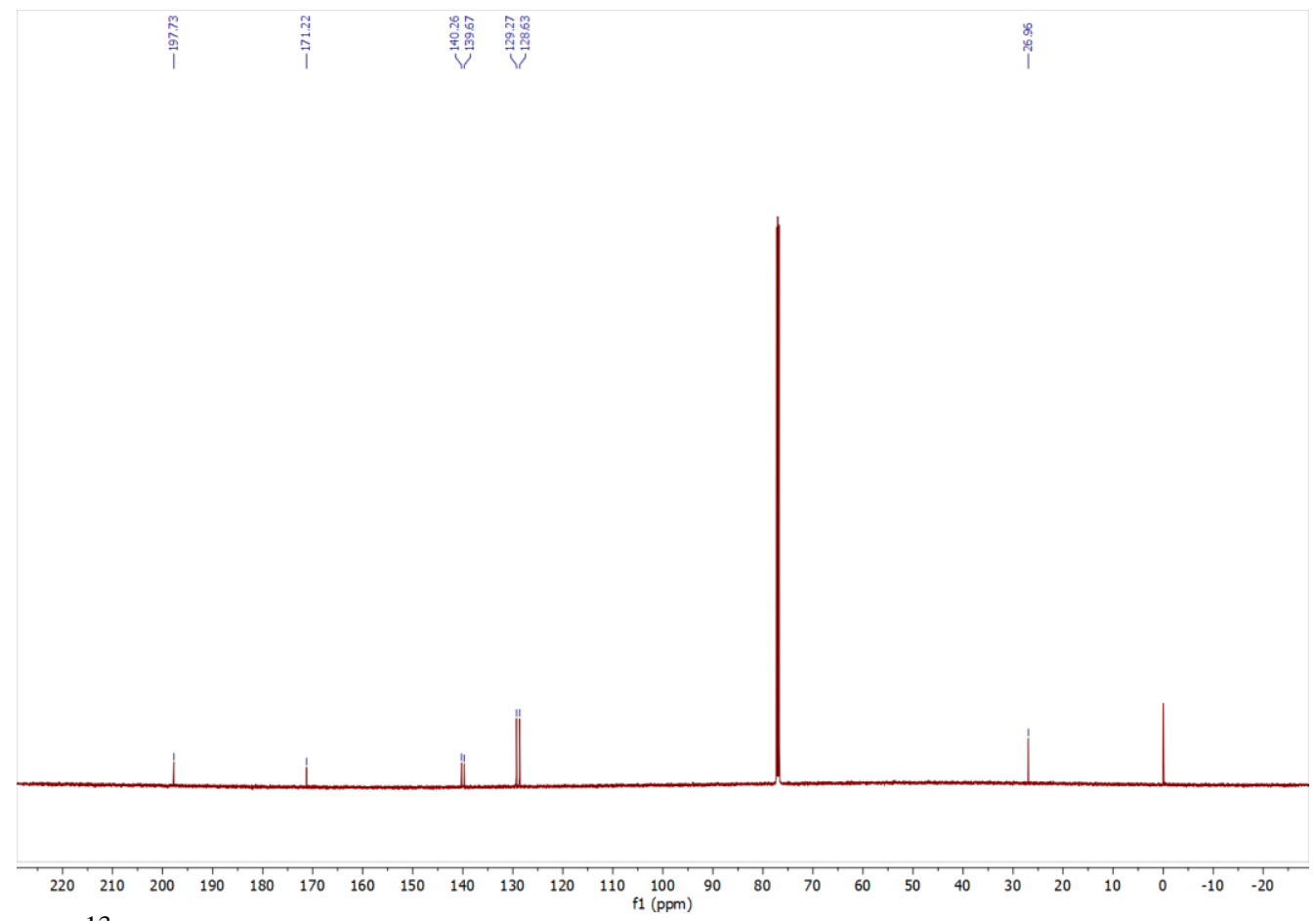

Figure S12. ${ }^{13} \mathrm{C}-\mathrm{NMR}\left(125 \mathrm{MHz}, \mathrm{CDCl}_{3}\right)$ spectrum of 1,3,5-tris(4-acetylphenyl)triazine used in this work. 


\section{General procedure for the synthesis of polymeric materials.}

Three $8 \mathrm{~mm}$ diameter borosilicate glass tubes were each charged with monomer $(40.0 \mathrm{mg})$ and anhydrous zinc chloride (1-10 molar eq.) that was freshly removed from a desiccator. The tubes were evacuated ( $<100 \mathrm{mTorr}$ ), and then flame-sealed under high vacuum using a natural gas torch and a custom-built apparatus (Figure S13). The tubes were placed in an oven and heated at 400 ${ }^{\circ} \mathrm{C}$, unless specified otherwise, for $72 \mathrm{~h}$ (temperature sequence: ramp up to $400{ }^{\circ} \mathrm{C}$ over $6 \mathrm{~h}$ from room temperature, hold at $400{ }^{\circ} \mathrm{C}$ for $72 \mathrm{~h}$, cool down to $23^{\circ} \mathrm{C}$ over $6 \mathrm{~h}$ ). The tubes were cooled to room temperature and were snapped into two pieces using a glass tube cutter. The black reaction mixture was scraped out of the tubes with a Hayman Style spatula, using water $(10 \mathrm{~mL})$ to help slide the mixture off the tube walls. The reaction mixtures from all three tubes were combined in a $100 \mathrm{~mL}$ jar and suspended in $3 \mathrm{M} \mathrm{HCl}(28 \mathrm{~mL})$. The suspension was allowed to stir for $24 \mathrm{~h}$. The heterogeneous mixture was filtered, and the resulting shiny black solid was rinsed with water $(3 \times$ $5 \mathrm{~mL})$ and THF $(3 \times 5 \mathrm{~mL})$. The solid was transferred to a $20 \mathrm{~mL}$ scintillation vial filled with THF and allowed to stand for $24 \mathrm{~h}$ at room temperature, after which the THF was decanted off and replaced with fresh THF. This soaking process was repeated two more times for a total of three THF soaks. After the third THF soak, the THF was decanted from the solid and replaced with acetone. The vial was allowed to stand for $24 \mathrm{~h}$ at room temperature, after which the acetone was decanted from the solid and replaced with fresh acetone. This soaking process was repeated two more times for a total of three acetone soaks. The acetone was decanted, and the solid was ovendried at $120{ }^{\circ} \mathrm{C}$ for $6 \mathrm{~h}$ and then allowed to cool to room temperature prior to characterization.

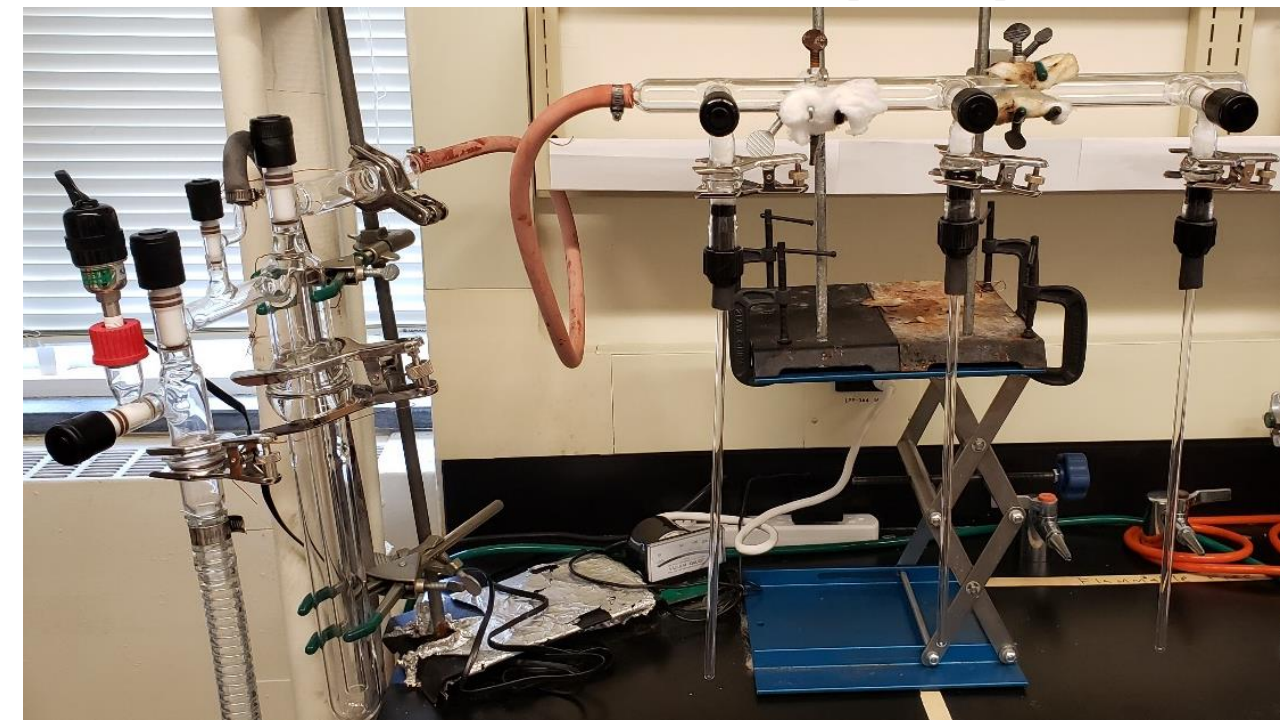

Figure S13. A custom-built apparatus for flame-sealing tubes shown with three empty $8 \mathrm{~mm}$ tubes. 


\section{Synthesis and characterization of trimerized materials.}

a. 1,3,5-triacetylbenzene trimerization.<smiles>CC(=O)c1cc(C(C)=O)cc(C(C)=O)c1</smiles><smiles>CC(C)c1cc(-c2cc(-c3cc(-c4cc(-c5cc(-c6cc(-c7cc(-c8cc(C(C)(C)C)cc(C(C)(C)C)c8)cc(C(C)(C)C)c7)cc(C(C)(C)C)c6)cc(C(C)(C)C)c5)cc(C(C)(C)C)c4)cc(C(C)(C)C)c3)cc(C(C)(C)C)c2)cc(C(C)(C)C)c1</smiles>

Figure S14. Synthesis of TAB-CMP series from 1,3,5-triacetylbenzene (TAB) using varying temperatures and equivalents of $\mathrm{ZnCl}_{2}$.

Following the general procedure, the TAB-CMP series were synthesized using varying amounts of 1,3,5-triacetylbenzene (TAB) and varying equivalents of $\mathrm{ZnCl}_{2}$ (Table S1) to yield shiny black solids from each trial. The combination of 5.00 equivalents of $\mathrm{ZnCl}_{2}$ at $400{ }^{\circ} \mathrm{C}$ was found to yield the highest surface area material and thus was characterized further.

TAB-CMP- $400{ }^{\circ} \mathrm{C}, 5.0$ eq. was also synthesized with one tube charged with $80 \mathrm{mg}$ for 24 $\mathrm{h}$, with $6 \mathrm{~h}$ of ramp-up time and $6 \mathrm{~h}$ of cool-down time to investigate whether trimerization was complete within $24 \mathrm{~h}$. An ATR IR spectrum of the resulting black solid ( $24 \mathrm{mg}$ ) was taken, and it was observed that any residual carbonyl peaks were barely detectable, but to ensure complete trimerization, other reactions were run for $72 \mathrm{~h}$. 
Table S1. List of conditions to synthesize each of the TAB-CMPs with yields. The condition that yielded the most porous solid is highlighted in yellow.

\begin{tabular}{|c|c|c|c|c|c|c|c|c|}
\hline Name & $\begin{array}{l}\text { Number } \\
\text { of tubes }\end{array}$ & $\begin{array}{l}\text { Mass of } \\
\text { TAB per } \\
\text { tube } \\
(\mathrm{mg})\end{array}$ & $\begin{array}{c}\text { Mass of } \\
\mathrm{ZnCl}_{2} \\
\text { per tube } \\
(\mathrm{mg})\end{array}$ & $\begin{array}{c}\text { Total } \\
\text { mass of } \\
\text { TAB } \\
(\mathrm{mg})\end{array}$ & $\begin{array}{l}\text { Total } \\
\text { mass of } \\
\mathrm{ZnCl}_{2} \\
(\mathrm{mg})\end{array}$ & $\begin{array}{l}\text { Eq. of } \\
\mathrm{ZnCl}_{2}\end{array}$ & $\begin{array}{c}\text { Temperature } \\
\left({ }^{\circ} \mathrm{C}\right)\end{array}$ & $\begin{array}{l}\text { Total } \\
\text { yield } \\
(\mathrm{mg})\end{array}$ \\
\hline $\begin{array}{c}\text { TAB- } \\
\text { CMP-400 } \\
{ }^{\circ} \mathrm{C}, 1.0 \text { eq. }\end{array}$ & 3 & 80 & 53.4 & 240 & 160 & 1 & 400 & 172 \\
\hline $\begin{array}{c}\text { TAB- } \\
\text { CMP-400 } \\
{ }^{\circ} \mathrm{C}, 5.0 \text { eq. }\end{array}$ & 3 & 80 & 267 & 240 & 801 & 5 & 400 & 131 \\
\hline $\begin{array}{c}\text { TAB- } \\
\text { CMP-300 } \\
{ }^{\circ} \mathrm{C}, 10 \text { eq. }\end{array}$ & 3 & 40 & 267 & 120 & 801 & 10 & 300 & 100 \\
\hline $\begin{array}{c}\text { TAB- } \\
\text { CMP-400 } \\
{ }^{\circ} \mathrm{C}, 10 \text { eq. }\end{array}$ & 12 & 40 & 267 & 480 & 3200 & 10 & 400 & 302 \\
\hline $\begin{array}{c}\text { TAB- } \\
\text { CMP-500 } \\
{ }^{\circ} \mathrm{C}, 10 \text { eq. }\end{array}$ & 3 & 40 & 267 & 120 & 801 & 10 & 500 & 85.1 \\
\hline
\end{tabular}




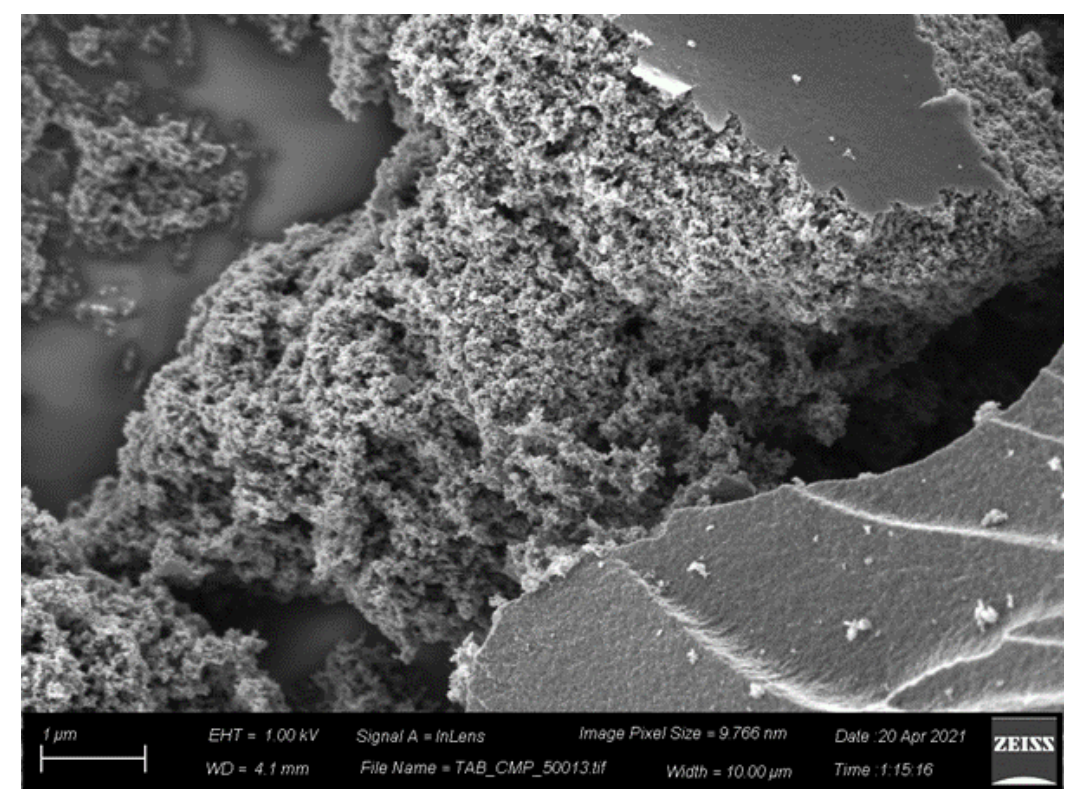

Figure S15. SEM image of TAB-CMP synthesized at $400{ }^{\circ} \mathrm{C}$ with 5.0 equivalents of $\mathrm{ZnCl}_{2}$

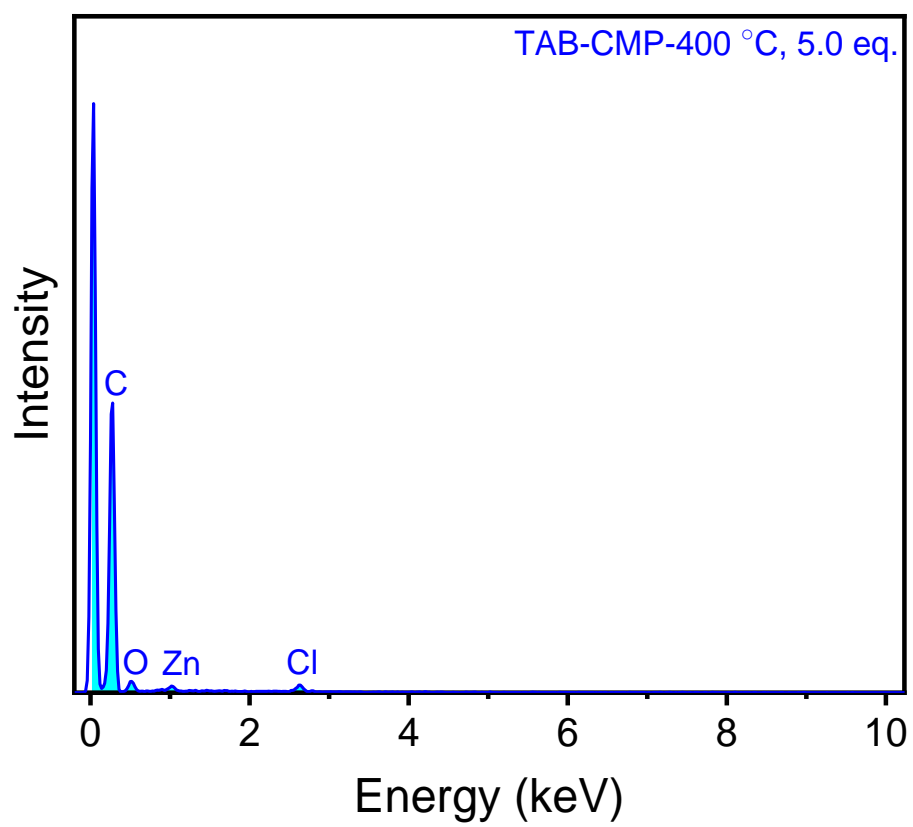

Figure S16. EDS data for TAB-CMP synthesized at $400{ }^{\circ} \mathrm{C}$ with 5 equivalents of $\mathrm{ZnCl}_{2}$.

Table S2. Tabulated EDS data for TAB-CMP synthesized at $400{ }^{\circ} \mathrm{C}$ with 5 equivalents of $\mathrm{ZnCl}_{2}$.

\begin{tabular}{|c|c|c|c|c|}
\hline Element & Line Type & $\mathrm{Wt} \%$ & $\mathrm{Wt} \%$ & Atomic \% \\
\hline $\mathrm{C}$ & K series & 2.95 & 0.06 & 93.64 \\
\hline $\mathrm{O}$ & K series & 0.21 & 0.03 & 4.95 \\
\hline $\mathrm{Cl}$ & K series & 0.10 & 0.01 & 1.12 \\
\hline $\mathrm{Zn}$ & L series & 0.05 & 0.02 & 0.30 \\
\hline Total: & & 3.32 & & 100.00 \\
\hline
\end{tabular}




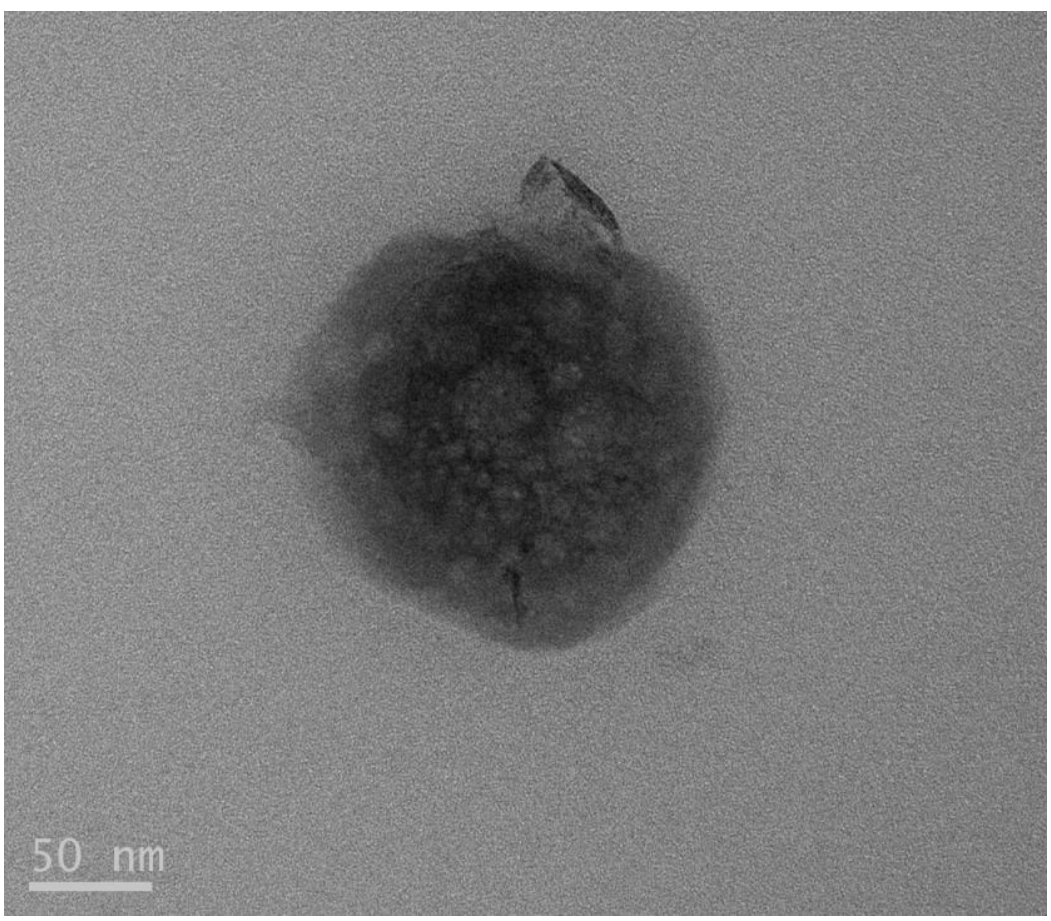

Figure S17. TEM image of TAB-CMP synthesized at $400{ }^{\circ} \mathrm{C}$ with 5.0 equivalents of $\mathrm{ZnCl}_{2}$. 


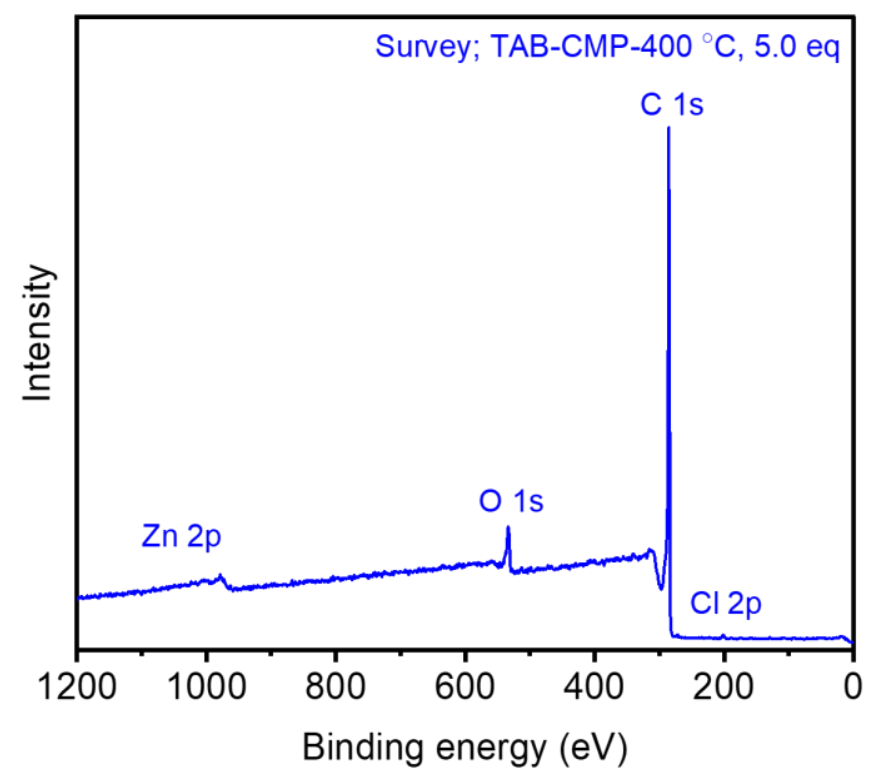

Figure S18. XPS spectrum for TAB-CMP synthesized at $400{ }^{\circ} \mathrm{C}$ with 5.0 equivalents of $\mathrm{ZnCl}_{2}$.

Table S3. Tabulated survey XPS data for TAB-CMP synthesized at $400{ }^{\circ} \mathrm{C}$ with 5.0 equivalents of $\mathrm{ZnCl}_{2}$.

\begin{tabular}{|c|c|c|c|c|}
\hline Element & Peak label & Position & Area & Atomic \% \\
\hline $\mathrm{C}$ & $\mathrm{C} 1 \mathrm{~s}$ & 285.65 & 1174.91 & 95.21 \\
\hline $\mathrm{O}$ & $\mathrm{O} 1 \mathrm{~s}$ & 533.65 & 158.97 & 4.40 \\
\hline $\mathrm{Cl}$ & $\mathrm{Cl} 2 \mathrm{p}$ & 201.65 & 10.77 & 0.38 \\
\hline $\mathrm{Zn}$ & $\mathrm{Zn} 2 \mathrm{p}$ & 1022.50 & 3.11 & 0.01 \\
\hline Total: & & & & 100.00 \\
\hline
\end{tabular}




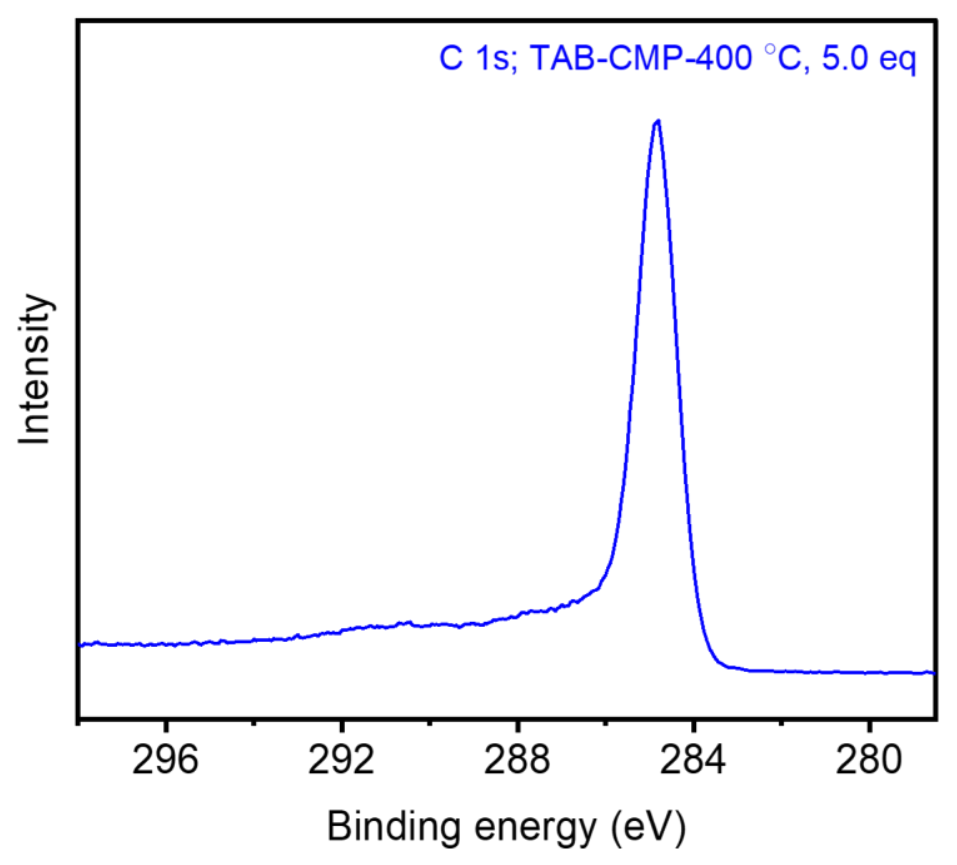

Figure S19. High resolution C 1s XPS spectrum of TAB-CMP synthesized at $400{ }^{\circ} \mathrm{C}$ with 5.0 equivalents of $\mathrm{ZnCl}_{2}$.

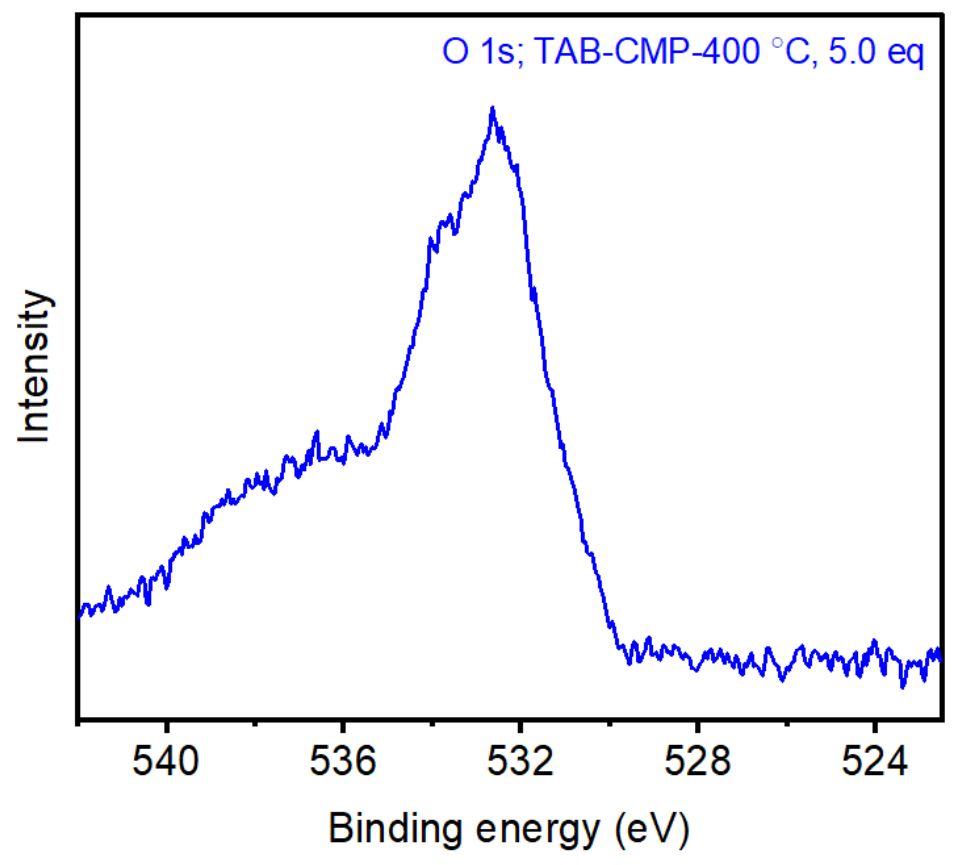

Figure S20. High resolution O 1s XPS spectrum of TAB-CMP synthesized at $400{ }^{\circ} \mathrm{C}$ with 5.0 equivalents of $\mathrm{ZnCl}_{2}$. 


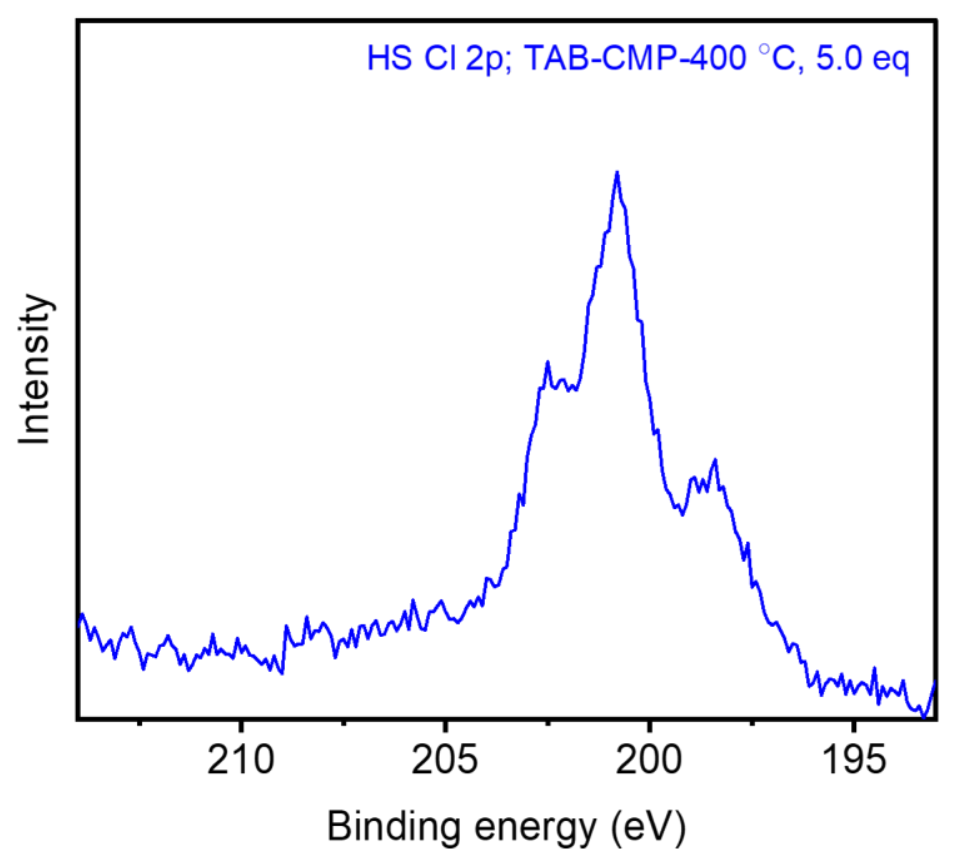

Figure S21. High sensitivity (HS) Cl 2p XPS spectrum of TAB-CMP synthesized at $400{ }^{\circ} \mathrm{C}$ with 5.0 equivalents of $\mathrm{ZnCl}_{2}$.

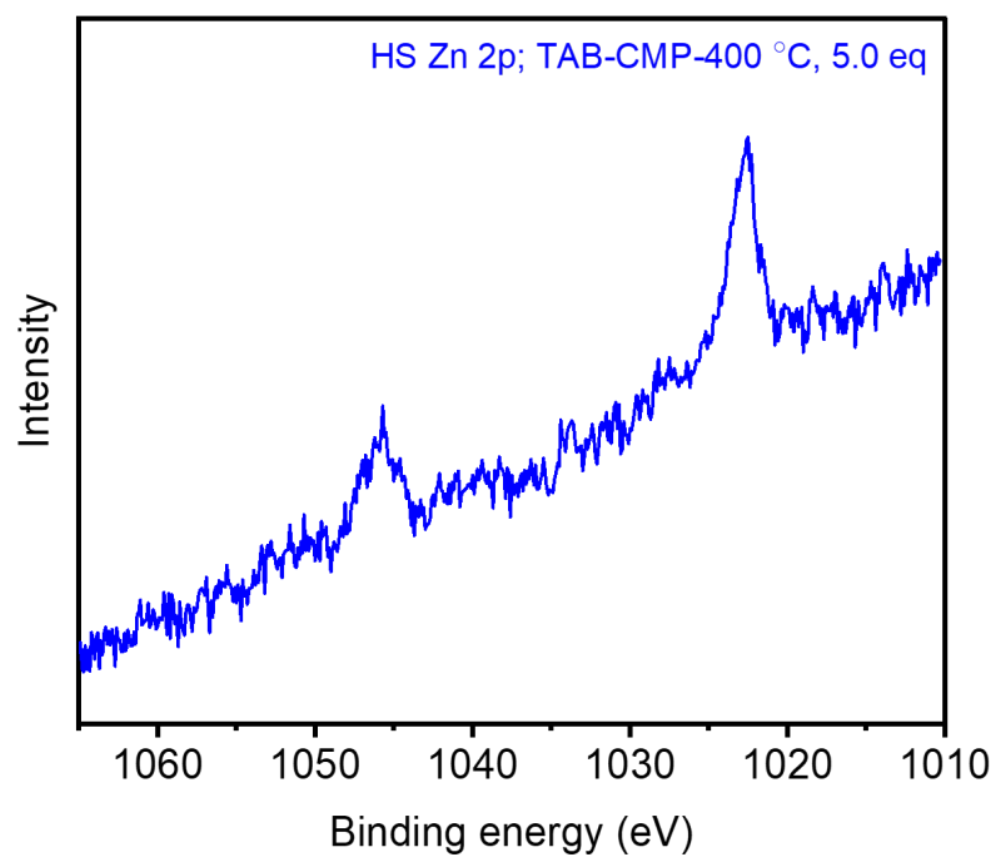

Figure S22. High sensitivity (HS) Zn 2p XPS spectrum of TAB-CMP synthesized at $400{ }^{\circ} \mathrm{C}$ with 5.0 equivalents of $\mathrm{ZnCl}_{2}$. 


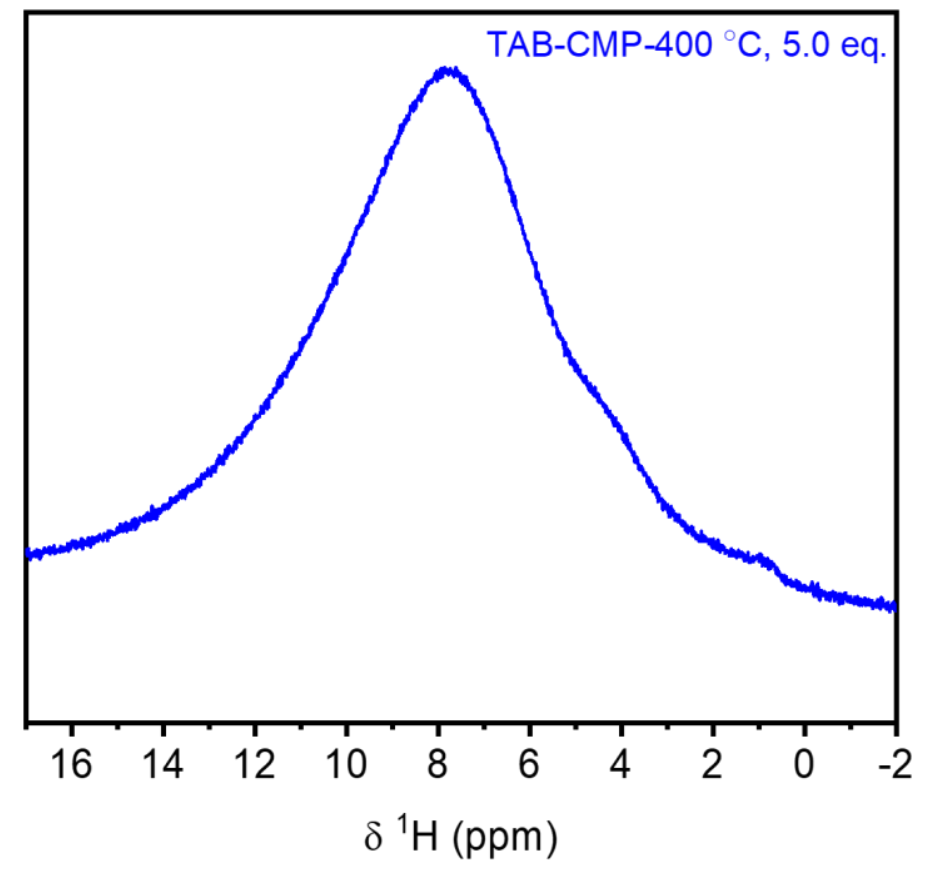

Figure S23. MAS ${ }^{1} \mathrm{H}$ SSNMR (500 MHz) spectrum of an independently prepared TAB-CMP synthesized at $400{ }^{\circ} \mathrm{C}$ with 5.0 equivalents of $\mathrm{ZnCl}_{2}$ collected at a spinning speed of $20 \mathrm{kHz}$.

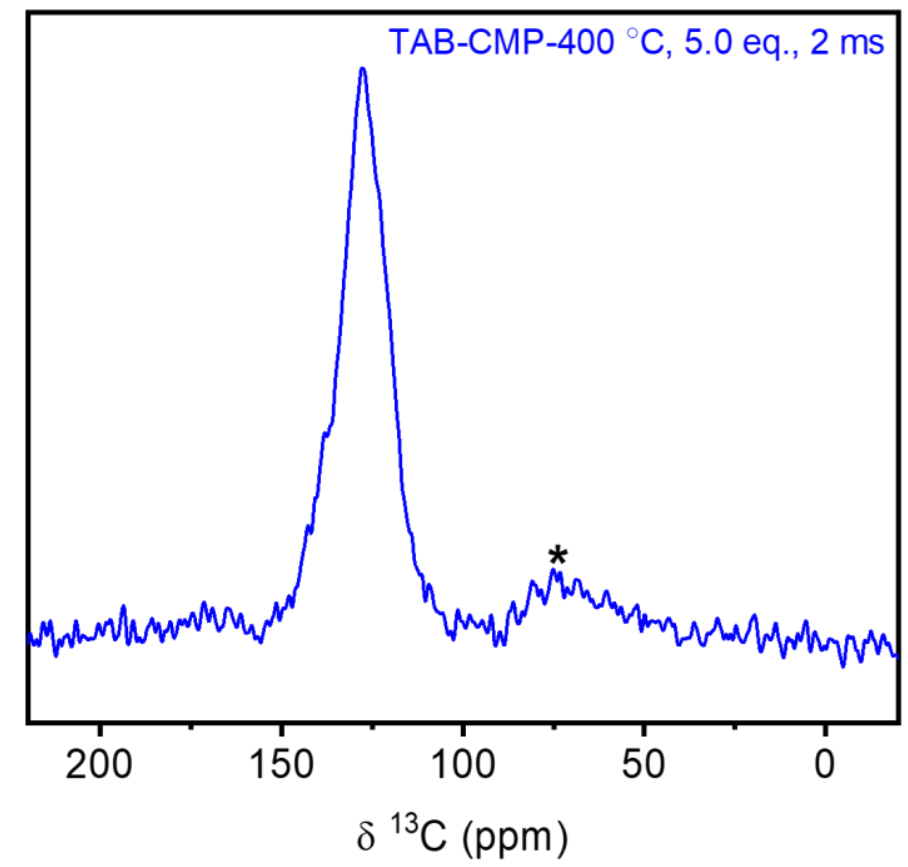

Figure S24. CP MAS ${ }^{13} \mathrm{C}$ SSNMR (125 MHz) spectrum of an independently prepared TAB-CMP synthesized at $400{ }^{\circ} \mathrm{C}$ with 5.0 equivalents of $\mathrm{ZnCl}_{2}$ with a ${ }^{1} \mathrm{H}-{ }^{13} \mathrm{C}$ contact time of $2 \mathrm{~ms}$ collected at a spinning speed of $20 \mathrm{kHz}$. The indicated peak $\left(^{*}\right)$ in the $13 \mathrm{C} \mathrm{NMR}$ spectrum is due to instrument background. 


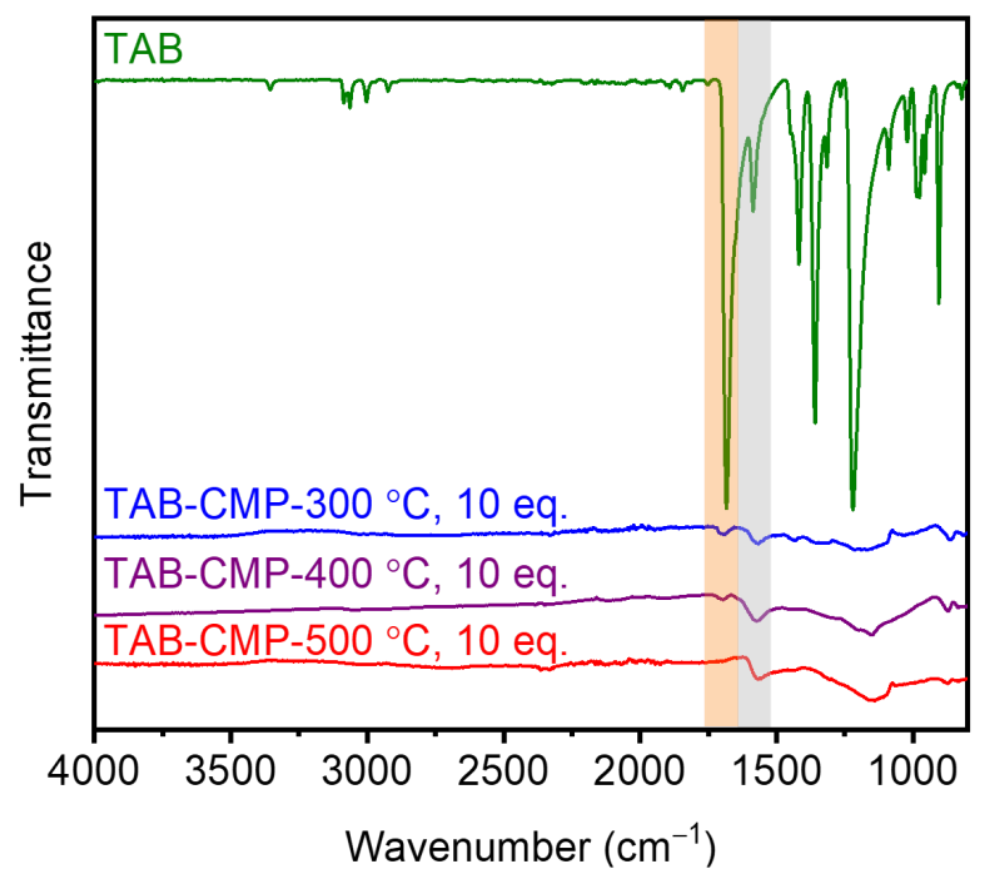

Figure S25. ATR IR spectra of TAB and TAB-CMP synthesized at varying temperatures with 10 equivalents of $\mathrm{ZnCl}_{2}$.

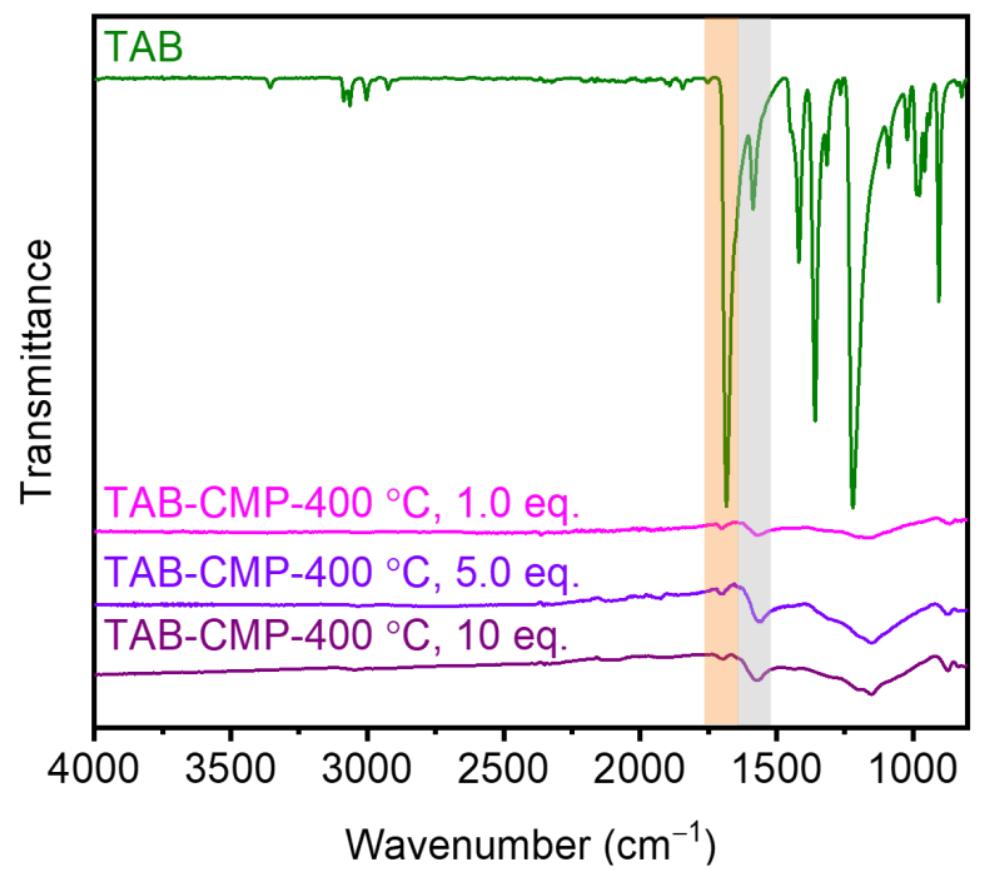

Figure S26. ATR IR spectra of $\mathrm{TAB}$ and $\mathrm{TAB}-\mathrm{CMP}$ synthesized at $400{ }^{\circ} \mathrm{C}$ with varying equivalents of $\mathrm{ZnCl}_{2}$. 


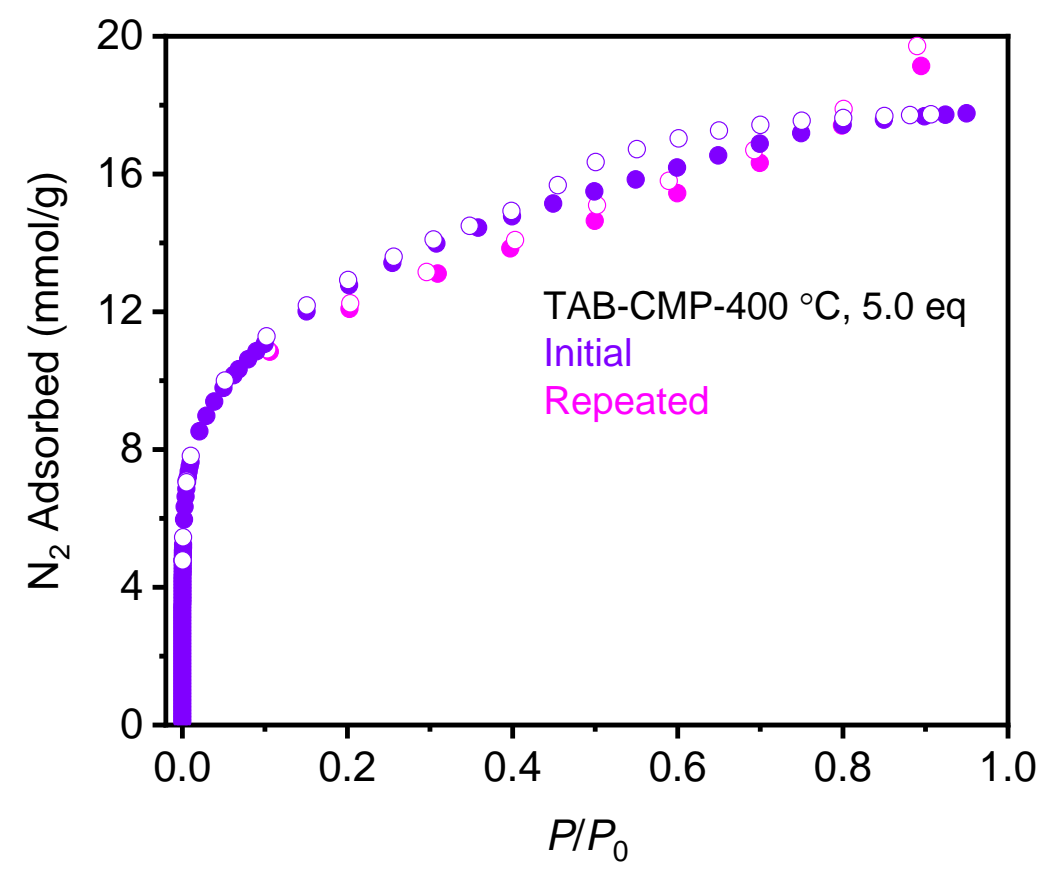

Figure S27. $77 \mathrm{~K} \mathrm{~N}_{2}$ adsorption (filled circles) and desorption (open circles) isotherms for two separately prepared samples of TAB-CMP made at $400{ }^{\circ} \mathrm{C}$ with 5.0 equivalents of $\mathrm{ZnCl}_{2}$, confirming the reproducibility of the synthetic procedure. The Brunauer-Emmett-Teller (BET) and Langmuir surface areas for the "initial" sample were determined to be $929 \pm 6 \mathrm{~m}^{2} / \mathrm{g}$ and $1990 \pm 22$ $\mathrm{m}^{2} / \mathrm{g}$, respectively. The Langmuir surface area of the "repeated" sample was determined to be 1974 $\mathrm{m}^{2} / \mathrm{g}$.

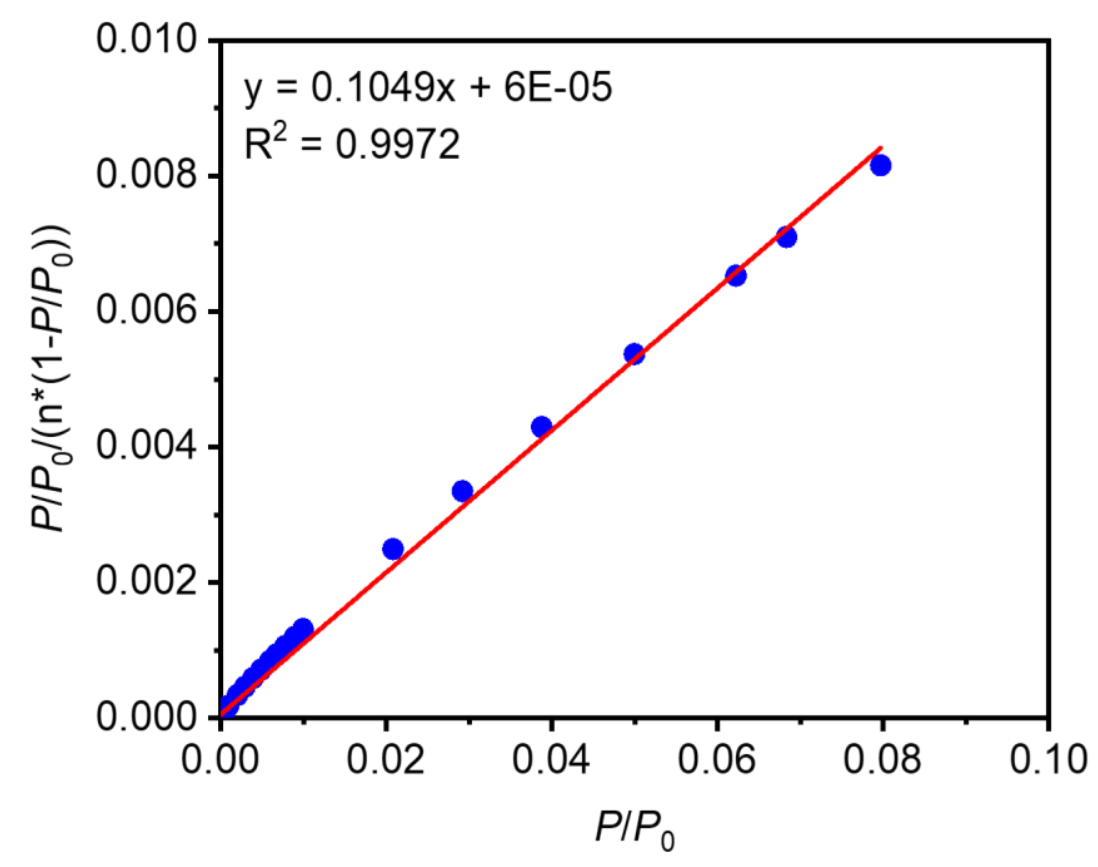

Figure S28. Linearized BET plot of TAB-CMP made at $400{ }^{\circ} \mathrm{C}$ with 5.0 equivalents of $\mathrm{ZnCl}_{2}$. 


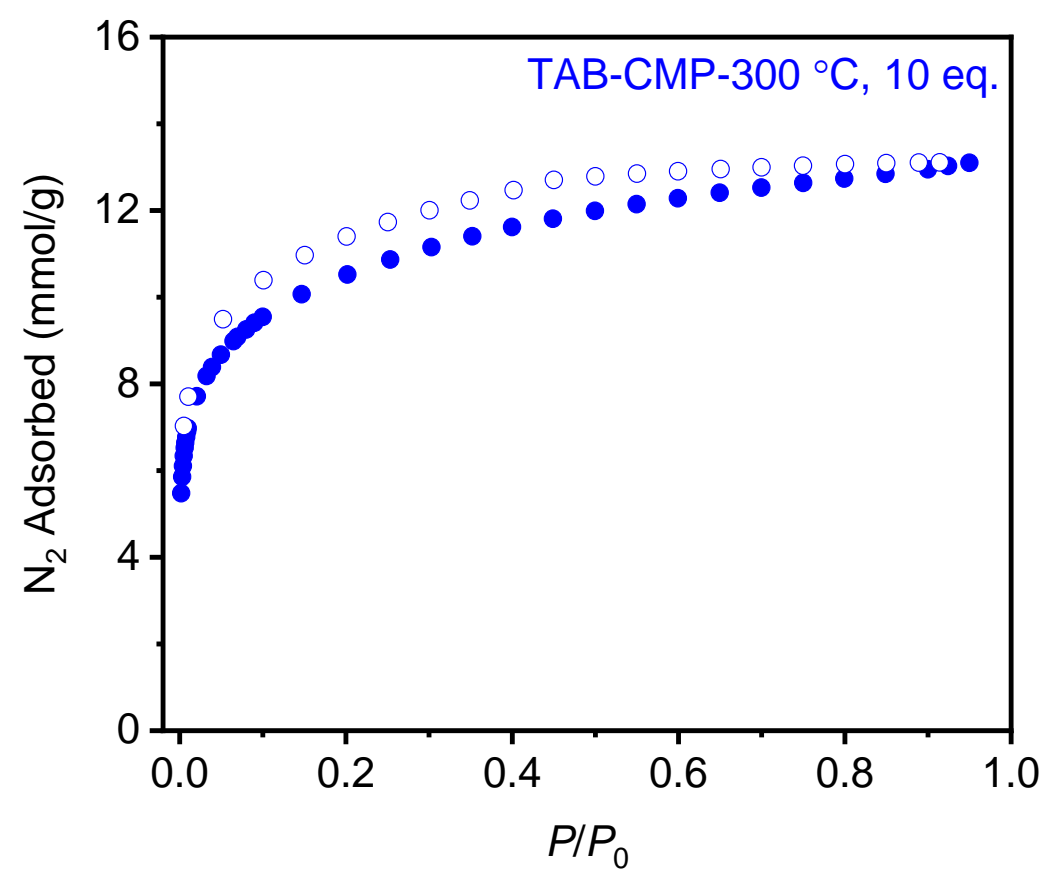

Figure S29. $77 \mathrm{~K} \mathrm{~N}_{2}$ adsorption (filled circles) and desorption (open circles) isotherms for TAB$\mathrm{CMP}$ made at $300{ }^{\circ} \mathrm{C}$ with 10 equivalents of $\mathrm{ZnCl}_{2}$. The Brunauer-Emmett-Teller (BET) and Langmuir surface areas were determined to be $849 \pm 4 \mathrm{~m}^{2} / \mathrm{g}$ and $1344 \pm 8 \mathrm{~m}^{2} / \mathrm{g}$, respectively.

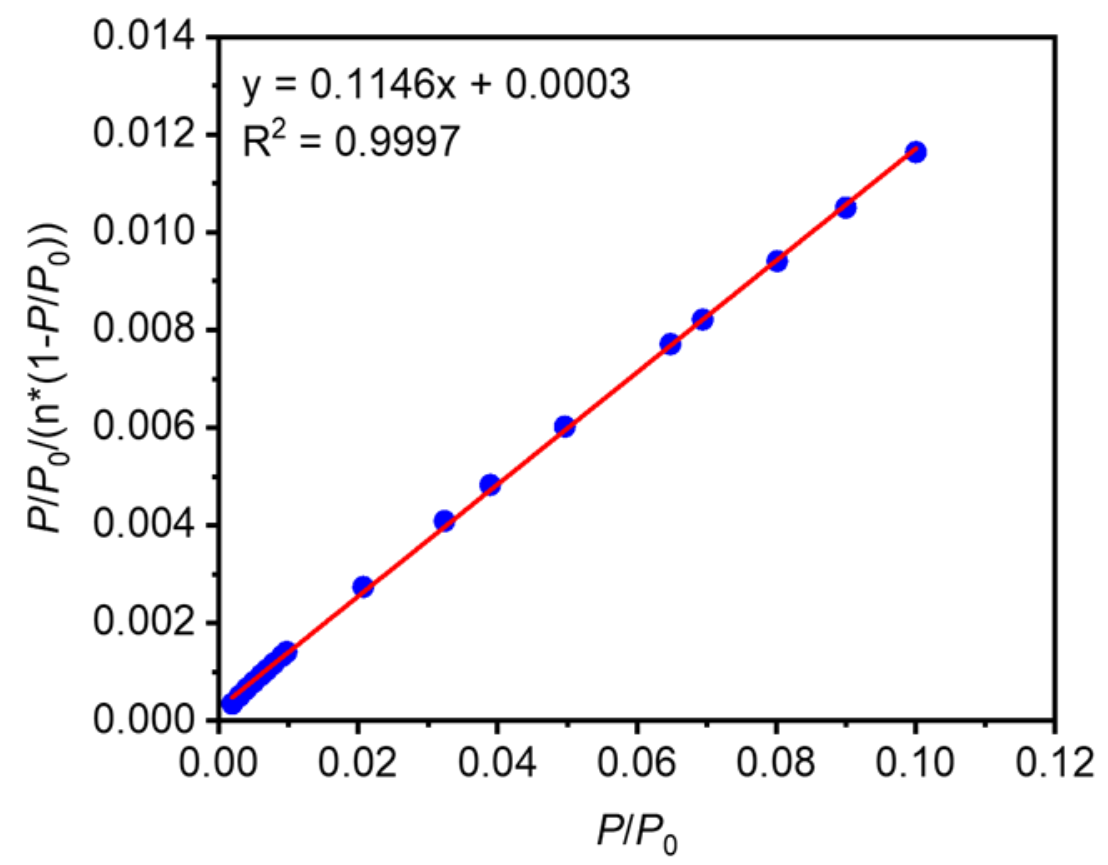

Figure S30. Linearized BET plot of TAB-CMP made at $300{ }^{\circ} \mathrm{C}$ with 10 equivalents of $\mathrm{ZnCl}_{2}$. 


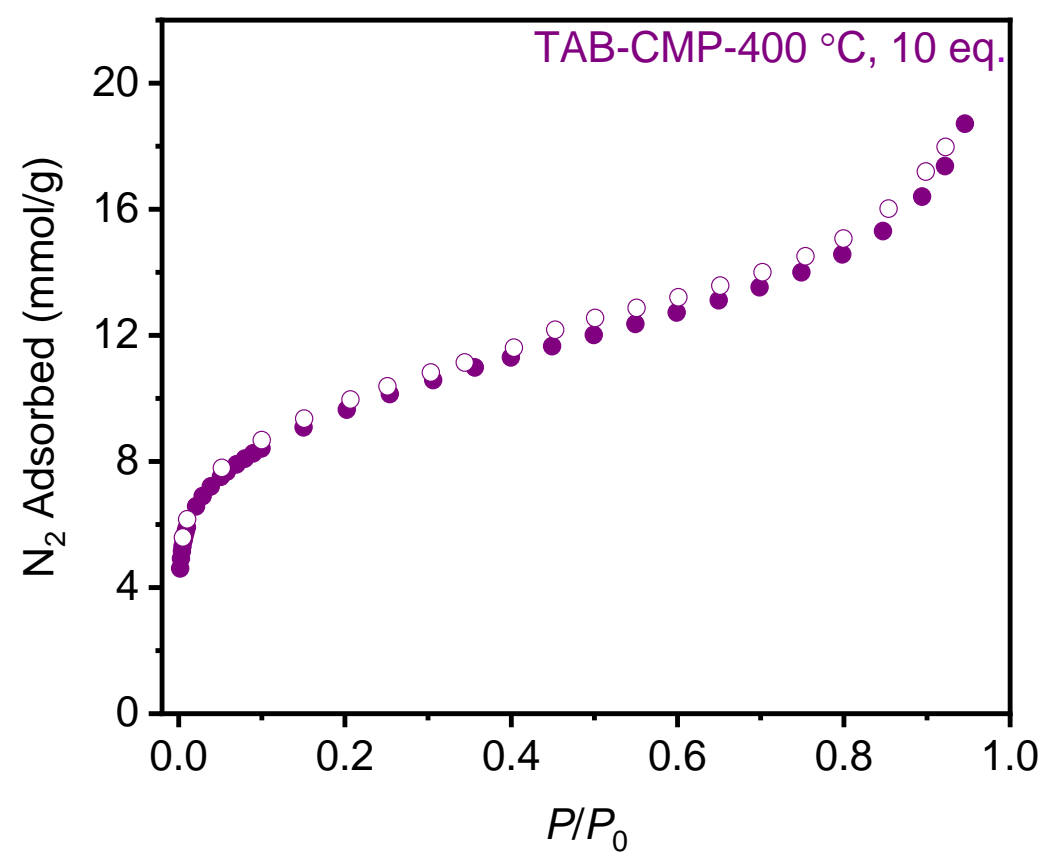

Figure S31. $77 \mathrm{~K} \mathrm{~N}_{2}$ adsorption (filled circles) and desorption (open circles) isotherms for TAB$\mathrm{CMP}$ made at $400{ }^{\circ} \mathrm{C}$ with 10 equivalents of $\mathrm{ZnCl}_{2}$. The Brunauer-Emmett-Teller (BET) and Langmuir surface areas were determined to be $756 \pm 5 \mathrm{~m}^{2} / \mathrm{g}$ and $1576 \pm 44 \mathrm{~m}^{2} / \mathrm{g}$ respectively.

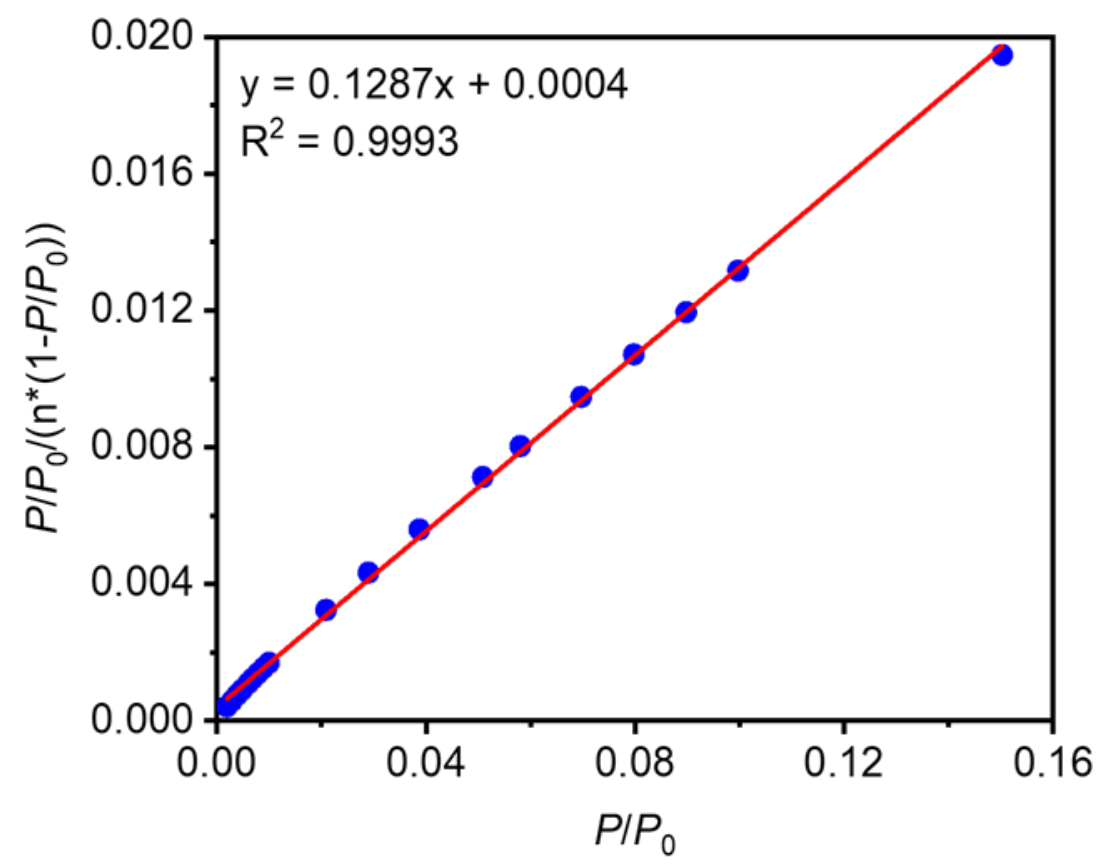

Figure S32. Linearized BET plot of TAB-CMP made at $400{ }^{\circ} \mathrm{C}$ with 10 equivalents of $\mathrm{ZnCl}_{2}$. 


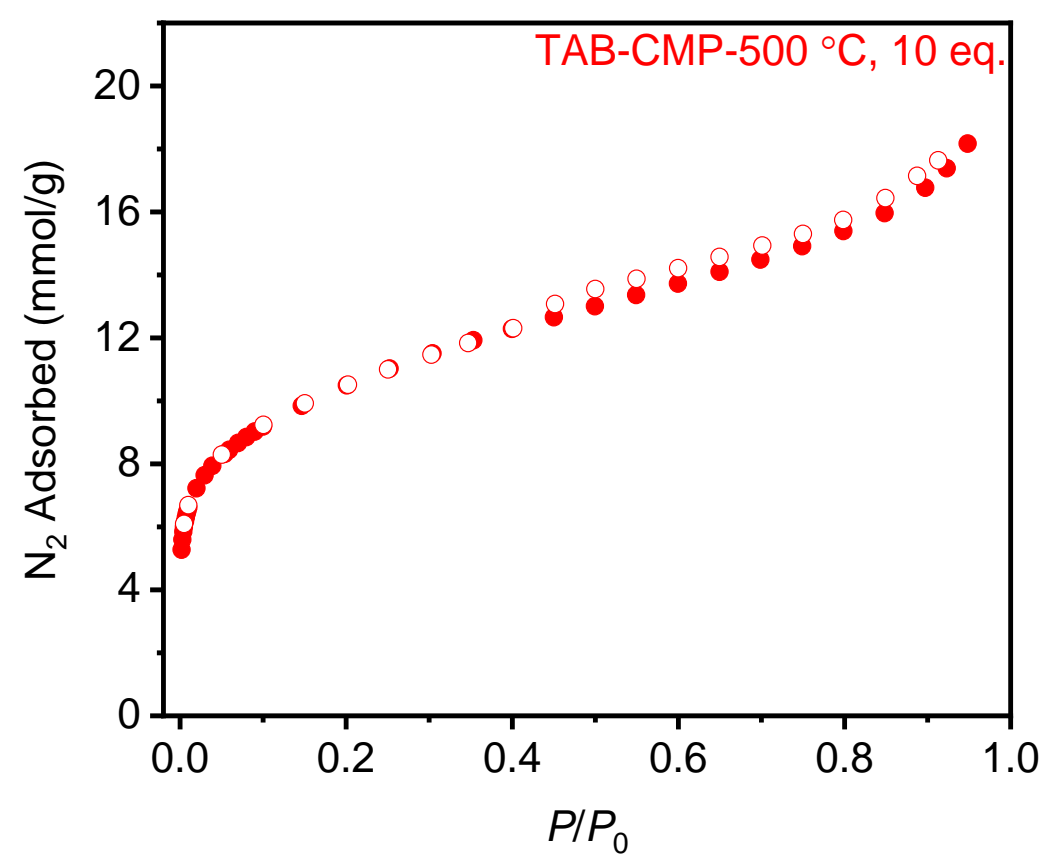

Figure S33. $77 \mathrm{~K} \mathrm{~N}_{2}$ adsorption (filled circles) and desorption (open circles) isotherms for TAB$\mathrm{CMP}$ made at $500{ }^{\circ} \mathrm{C}$ with 10 equivalents of $\mathrm{ZnCl}_{2}$. The Brunauer-Emmett-Teller (BET) and Langmuir surface areas were determined to be $823 \pm 5 \mathrm{~m}^{2} / \mathrm{g}$ and $1588 \pm 32 \mathrm{~m}^{2} / \mathrm{g}$ respectively.

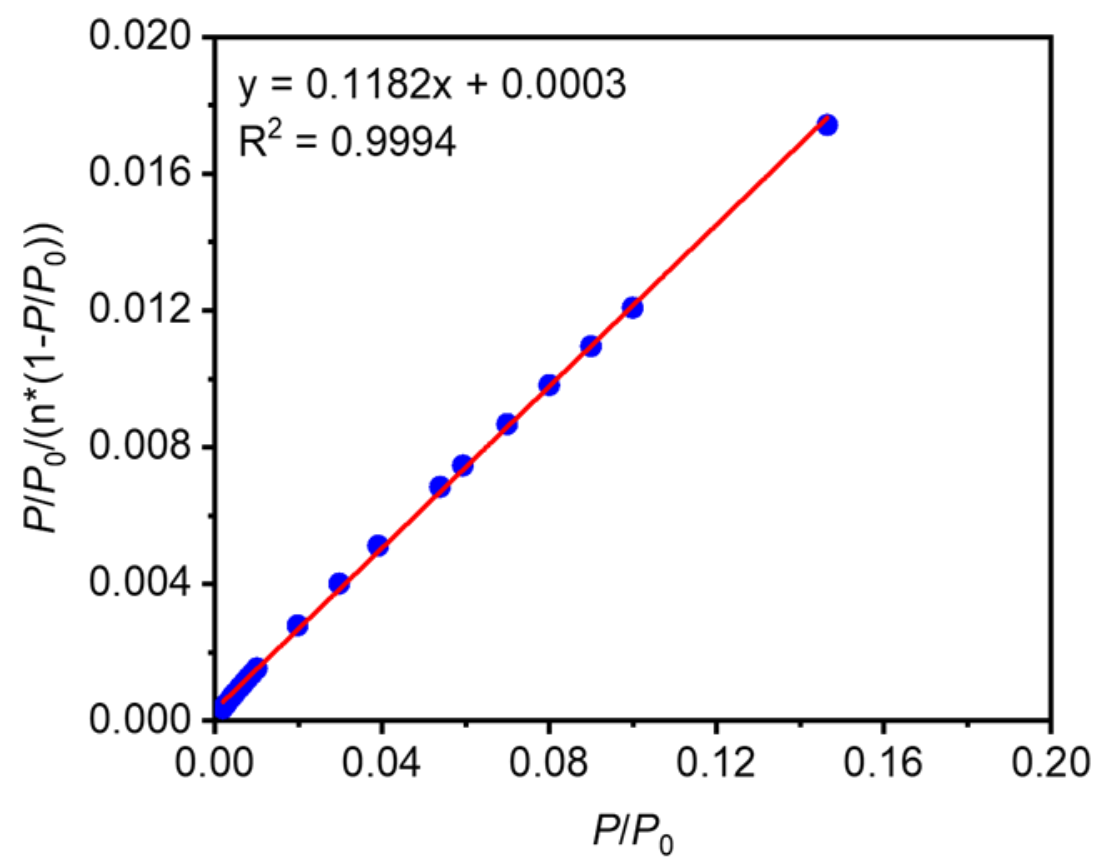

Figure S34. Linearized BET plot of TAB-CMP made at $500{ }^{\circ} \mathrm{C}$ with 10 equivalents of $\mathrm{ZnCl}_{2}$. 


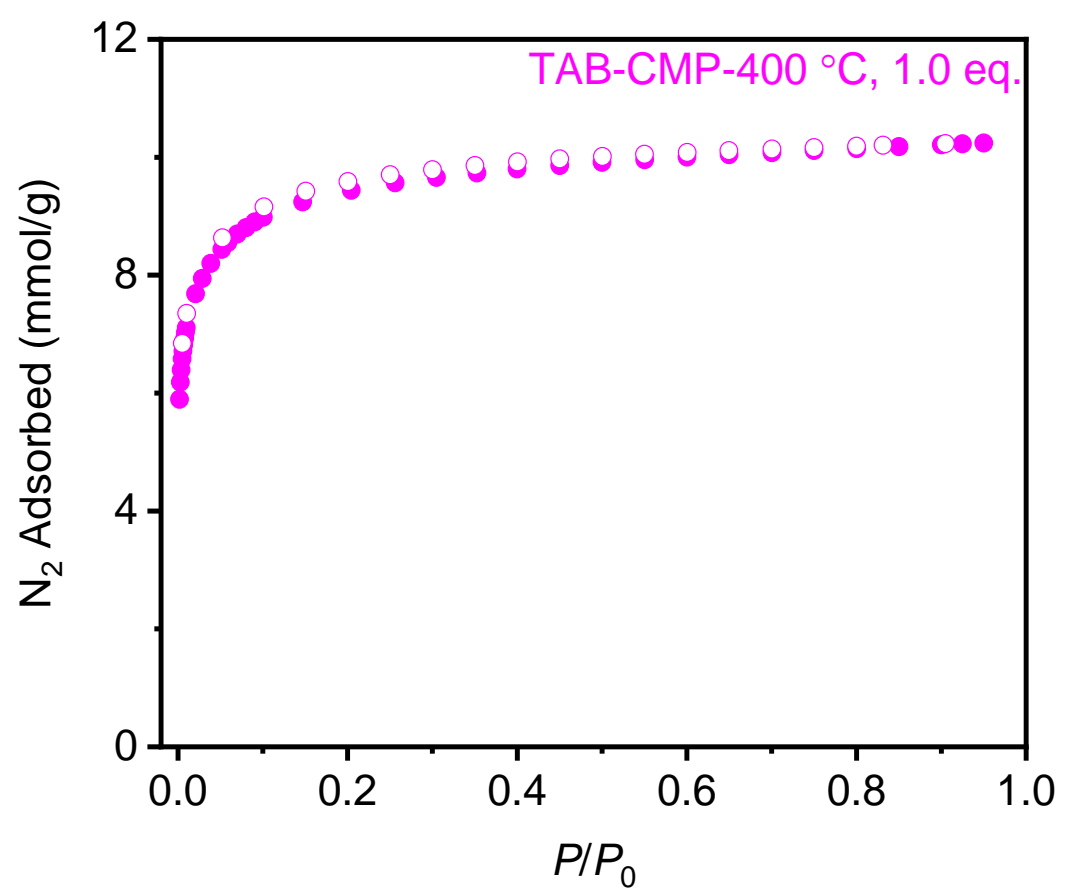

Figure S35. $77 \mathrm{~K} \mathrm{~N}_{2}$ adsorption (filled circles) and desorption (open circles) isotherm for TAB$\mathrm{CMP}$ made at $400{ }^{\circ} \mathrm{C}$ with 1.0 equivalent of $\mathrm{ZnCl}_{2}$. The Brunauer-Emmett-Teller (BET) and Langmuir surface areas were determined to be $801 \pm 3 \mathrm{~m}^{2} / \mathrm{g}$ and $1027 \pm 2 \mathrm{~m}^{2} / \mathrm{g}$ respectively.

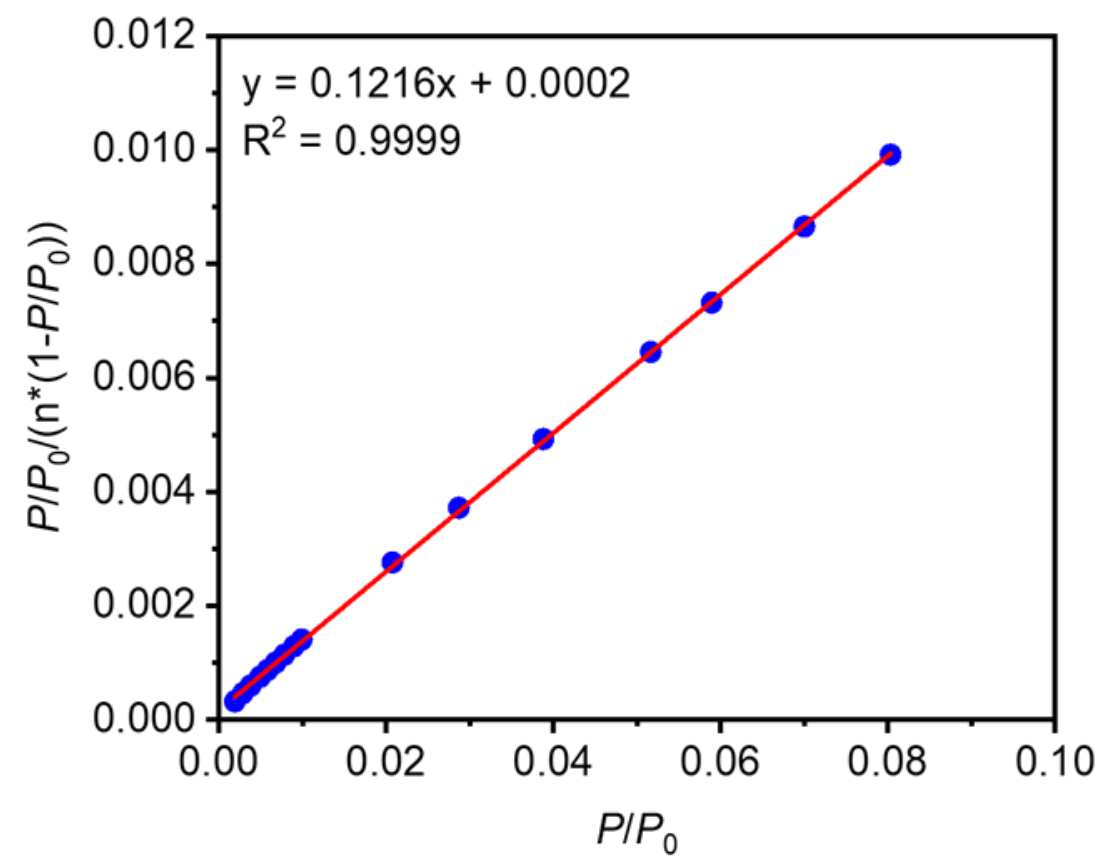

Figure S36. Linearized BET plot of TAB-CMP made at $400{ }^{\circ} \mathrm{C}$ with 1.0 equivalent of $\mathrm{ZnCl}_{2}$. 


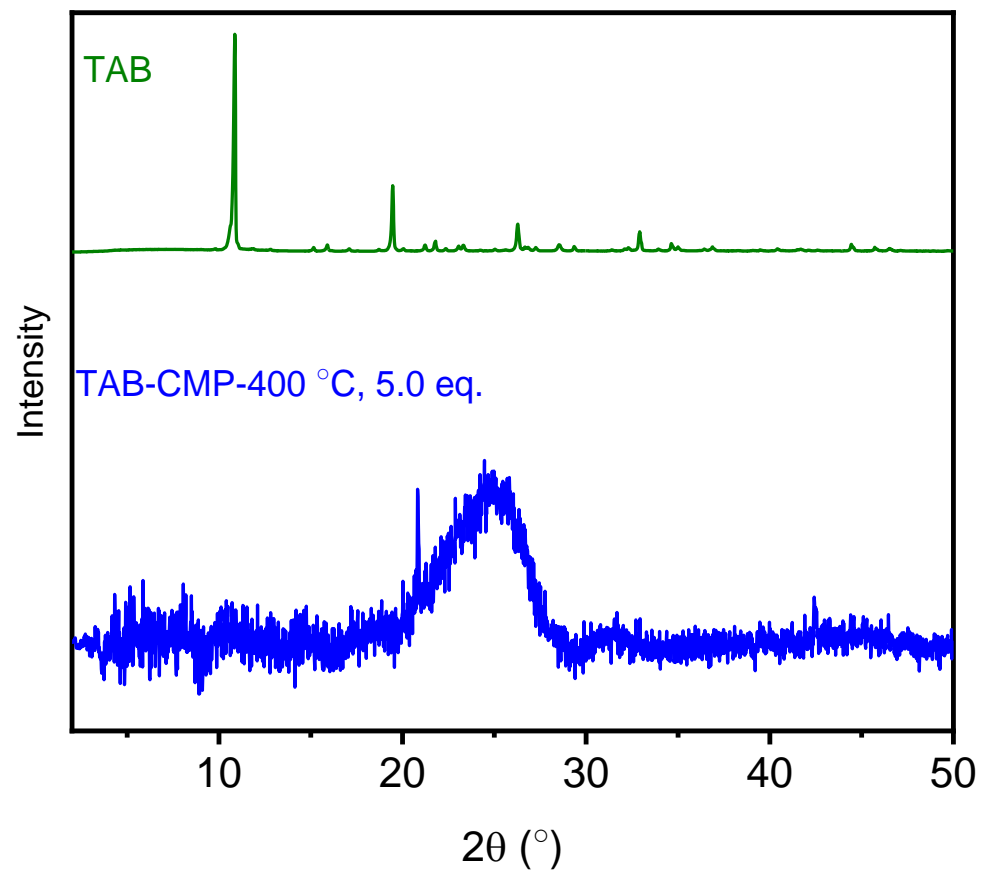

Figure S37. PXRD patterns of TAB and TAB-CMP synthesized at $400{ }^{\circ} \mathrm{C}$ with 5.0 equivalents of $\mathrm{ZnCl}_{2}$, indicating that $\mathrm{TAB}-\mathrm{CMP}-400{ }^{\circ} \mathrm{C}, 5.0 \mathrm{eq}$ is an amorphous polymer.

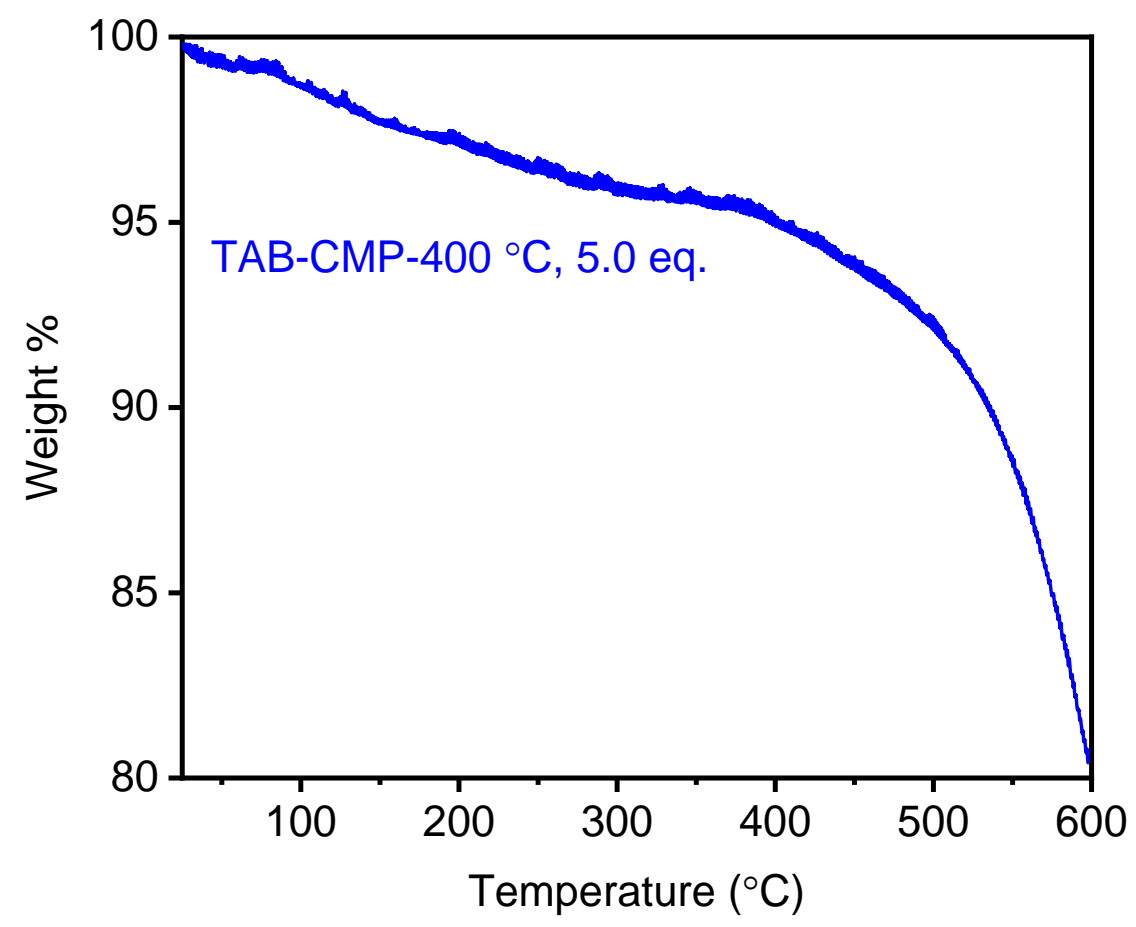

Figure S38. Decomposition profile of TAB-CMP synthesized at $400{ }^{\circ} \mathrm{C}$ with 5.0 equivalents of $\mathrm{ZnCl}_{2}$, indicating that TAB-CMP is stable below $500{ }^{\circ} \mathrm{C}$. 

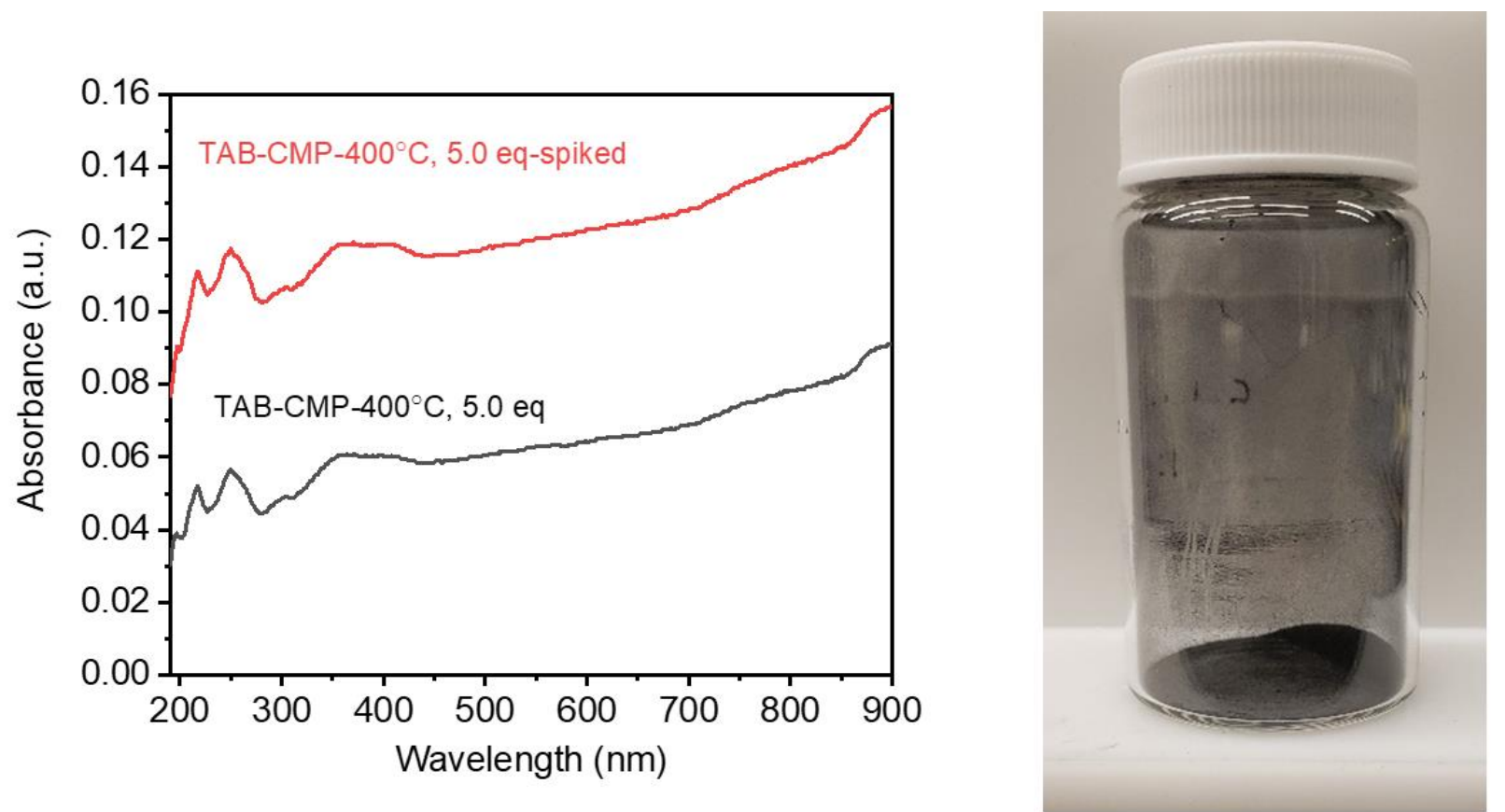

Figure S39. Left: solid-state UV-Vis absorption spectrum of TAB-CMP- $400{ }^{\circ} \mathrm{C}, 5.0$ eq. The sample mixture of CMP in $\mathrm{BaSO}_{4}$ was spiked with additional CMP to ensure the observed absorption spectrum reflected the broadband adsorption of TAB-CMP- $400{ }^{\circ} \mathrm{C}, 5.0$ eq. Right: image of TAB-CMP- $400{ }^{\circ} \mathrm{C}, 5.0$ eq., which is a shiny black solid.

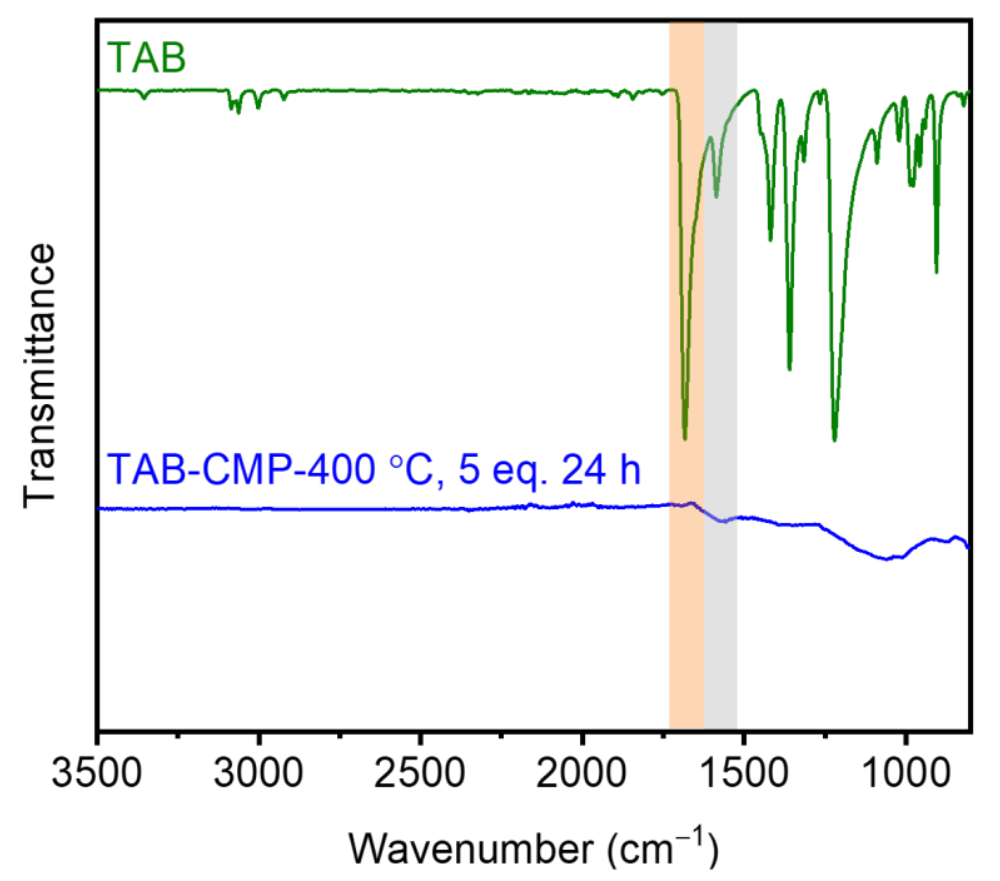

Figure S40. ATR IR spectra of TAB and TAB-CMP synthesized at $400{ }^{\circ} \mathrm{C}$ with 5.0 equivalents of $\mathrm{ZnCl}_{2}$ for $24 \mathrm{~h}$ instead of $72 \mathrm{~h}$. 


\section{b. Tetrakis(4-acetylphenyl)methane trimerization.}
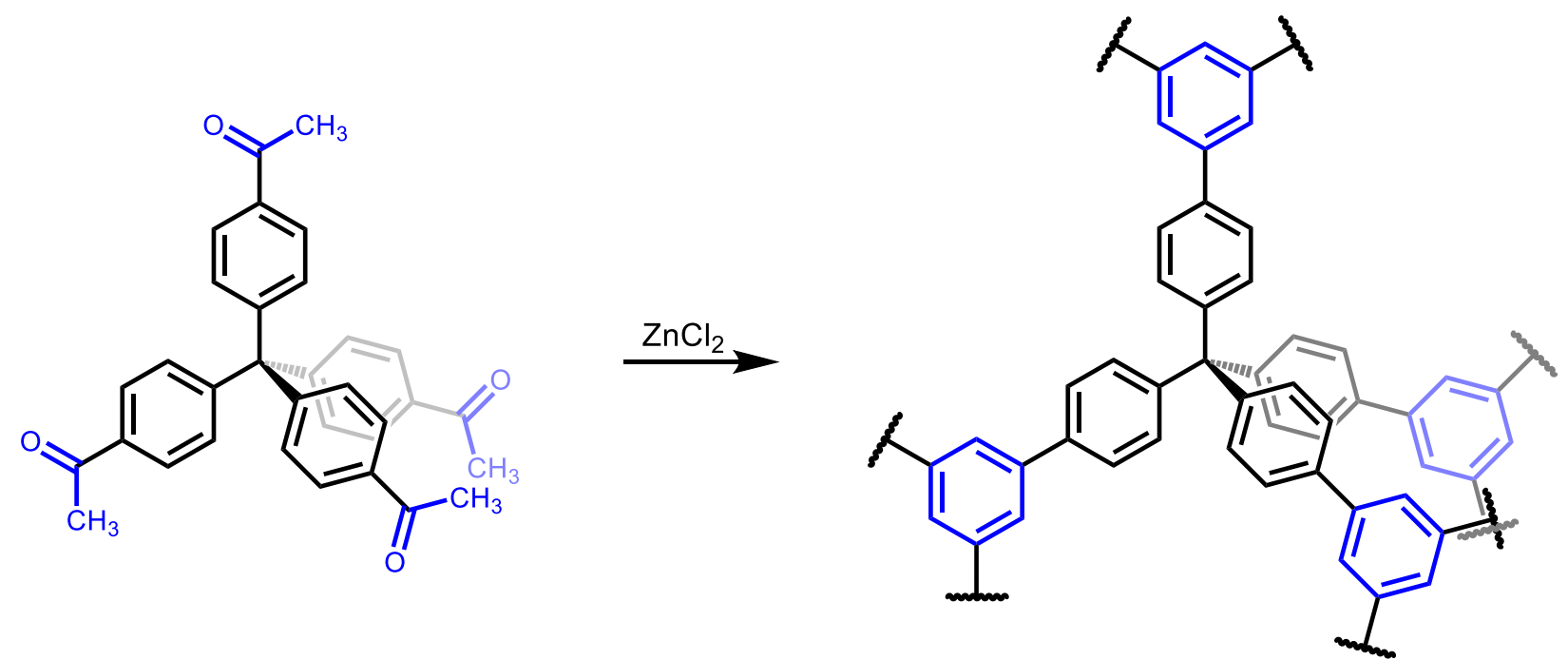

Figure S41. Synthesis of TAPM-PAF series from tetrakis(4-acetylphenyl)methane at various temperatures with 10 equivalents of $\mathrm{ZnCl}_{2}$.

Following the general procedure, three tubes were charged with tetrakis(4acetylphenyl)methane (TAPM) $\left(40 \mathrm{mg}, 0.08 \mathrm{mmol}, 1.00\right.$ eq.) and anhydrous $\mathrm{ZnCl}_{2}(109.2 \mathrm{mg}$, $0.80 \mathrm{mmol}, 10.0$ eq.) and the products were combined to yield shiny black solids. The combination of 10.0 equivalents of $\mathrm{ZnCl}_{2}$ at $300{ }^{\circ} \mathrm{C}$ was found to yield the highest surface area material.

Table S4. List of conditions to synthesize each of the TAPM-PAFs. The condition that yielded the most porous solid is highlighted in yellow.

\begin{tabular}{|c|c|c|c|c|c|c|c|}
\hline Name & $\begin{array}{c}\text { Mass of } \\
\text { TAPM per } \\
\text { tube (mg) }\end{array}$ & $\begin{array}{c}\text { Mass of } \\
\mathrm{ZnCl}_{2} \text { per } \\
\text { tube }(\mathrm{mg})\end{array}$ & $\begin{array}{c}\text { Total mass } \\
\text { of TAPM } \\
(\mathrm{mg})\end{array}$ & $\begin{array}{c}\text { Total mass } \\
\text { of } \mathrm{ZnCl}_{2} \\
(\mathrm{mg})\end{array}$ & $\begin{array}{c}\text { Eq. of } \\
\mathrm{ZnCl}_{2}\end{array}$ & $\begin{array}{c}\text { Temperature } \\
\left({ }^{\circ} \mathrm{C}\right)\end{array}$ & $\begin{array}{c}\text { Yield } \\
(\mathrm{mg})\end{array}$ \\
\hline $\begin{array}{c}\text { TAPM- } \\
\text { PAF-300 } \\
{ }^{\circ} \mathrm{C}, 10 \text { eq. }\end{array}$ & 40 & 267 & 120 & 801 & 10 & 300 & 57 \\
\hline $\begin{array}{c}\text { TAPM- } \\
\text { PAF-400 } \\
{ }^{\circ} \mathrm{C}, 10 \text { eq. }\end{array}$ & 40 & 267 & 120 & 801 & 10 & 400 & 47 \\
\hline $\begin{array}{c}\text { TAPM- } \\
\text { PAF-500 } \\
{ }^{\circ} \mathrm{C}, 10 \text { eq. }\end{array}$ & 40 & 267 & 120 & 801 & 10 & 500 & 44 \\
\hline
\end{tabular}




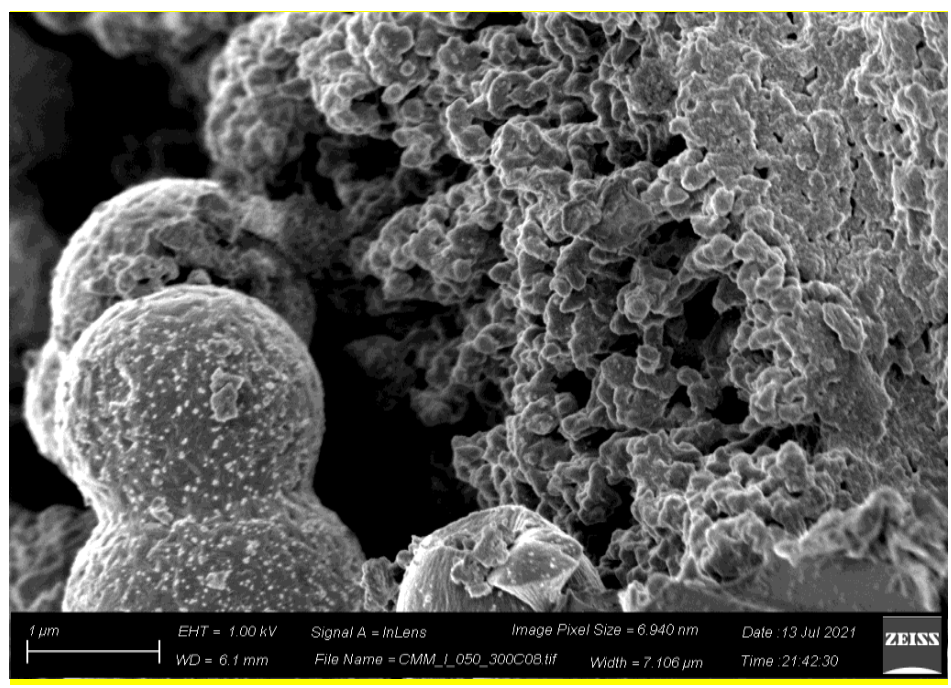

Figure S42. SEM image of TAPM-PAF synthesized at $300{ }^{\circ} \mathrm{C}$ with 10 equivalents of $\mathrm{ZnCl}_{2}$.

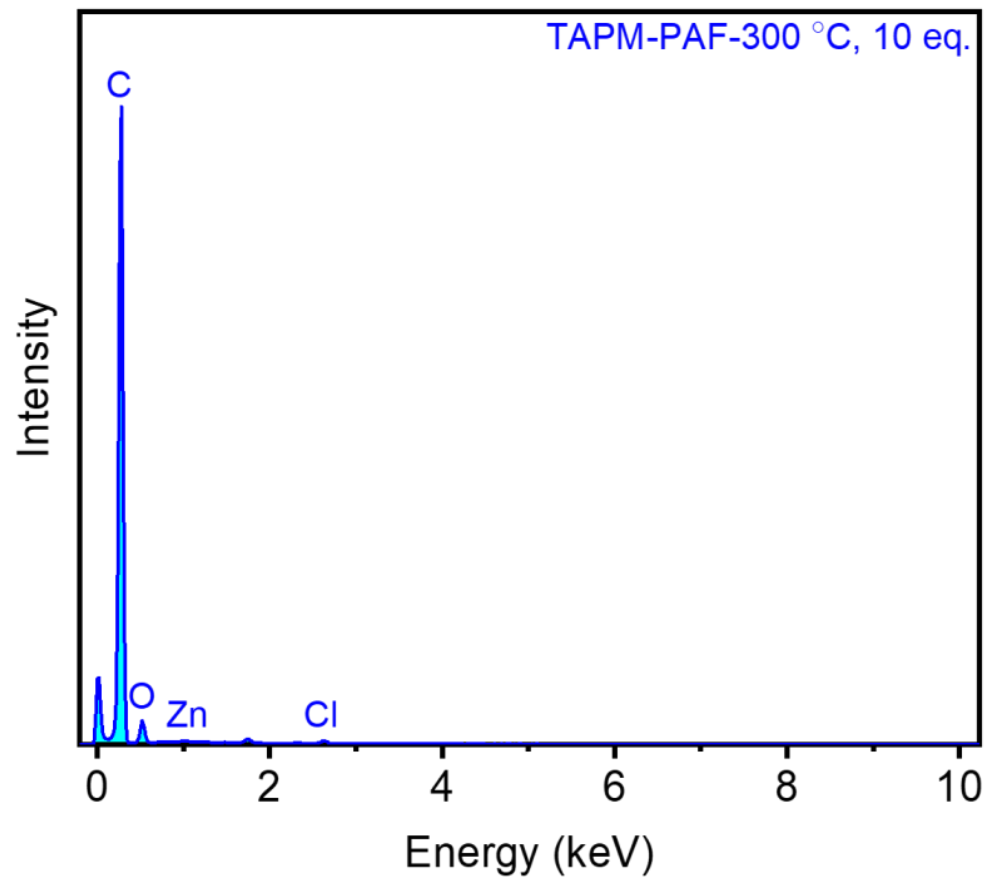

Figure S43. EDS data for TAPM-PAF synthesized at $300{ }^{\circ} \mathrm{C}$ with 10 equivalents of $\mathrm{ZnCl}_{2}$.

Table S5. Tabulated EDS data for TAPM-PAF synthesized at $300{ }^{\circ} \mathrm{C}$ with 10 equivalents of $\mathrm{ZnCl}_{2}$.

\begin{tabular}{|c|c|c|c|c|}
\hline Element & Line Type & $\mathrm{Wt} \%$ & $\mathrm{Wt} \% \sigma$ & Atomic \% \\
\hline $\mathrm{C}$ & K series & 91.56 & 0.22 & 94.03 \\
\hline $\mathrm{O}$ & K series & 7.29 & 0.20 & 5.62 \\
\hline $\mathrm{Cl}$ & K series & 0.85 & 0.06 & 0.30 \\
\hline $\mathrm{Zn}$ & L series & 0.30 & 0.08 & 0.06 \\
\hline Total: & & 100.00 & & 100.00 \\
\hline
\end{tabular}




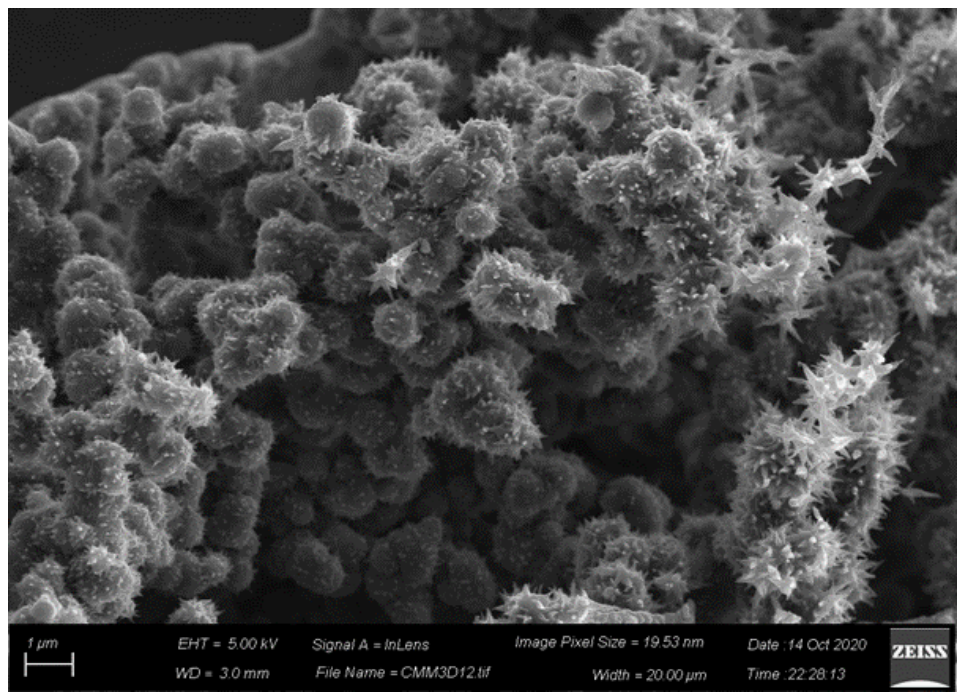

Figure S44. SEM image of TAPM-PAF synthesized at $400{ }^{\circ} \mathrm{C}$ with 10 equivalents of $\mathrm{ZnCl}_{2}$.

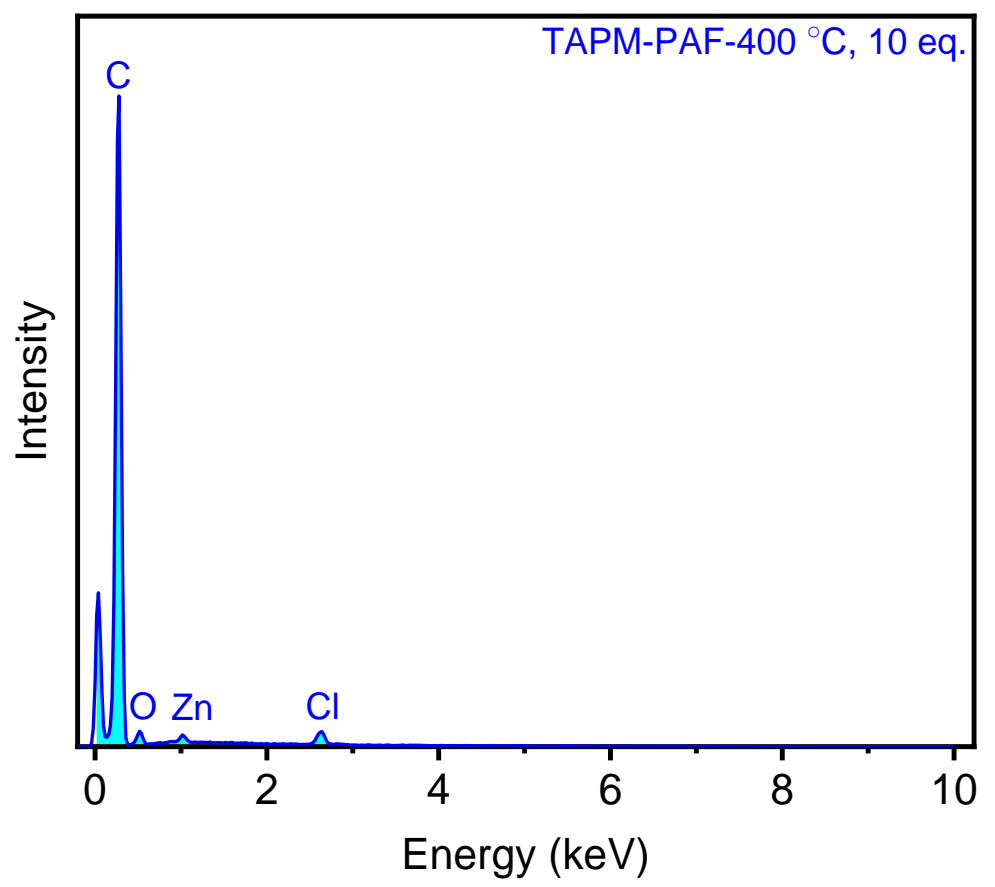

Figure S45. EDS data for TAPM-PAF synthesized at $400{ }^{\circ} \mathrm{C}$ with 10 equivalents of $\mathrm{ZnCl}_{2}$.

Table S6. Tabulated EDS data for TAPM-PAF synthesized at $400{ }^{\circ} \mathrm{C}$ with 10 equivalents of $\mathrm{ZnCl}_{2}$.

\begin{tabular}{|c|c|c|c|c|}
\hline Element & Line Type & Wt\% & Wt\% $\sigma$ & Atomic \% \\
\hline $\mathrm{C}$ & K series & 26.48 & 0.18 & 95.62 \\
\hline $\mathrm{O}$ & K series & 1.14 & 0.06 & 3.09 \\
\hline $\mathrm{Cl}$ & K series & 0.86 & 0.04 & 1.06 \\
\hline $\mathrm{Zn}$ & L series & 0.35 & 0.05 & 0.23 \\
\hline Total: & & 28.83 & & 100.00 \\
\hline
\end{tabular}




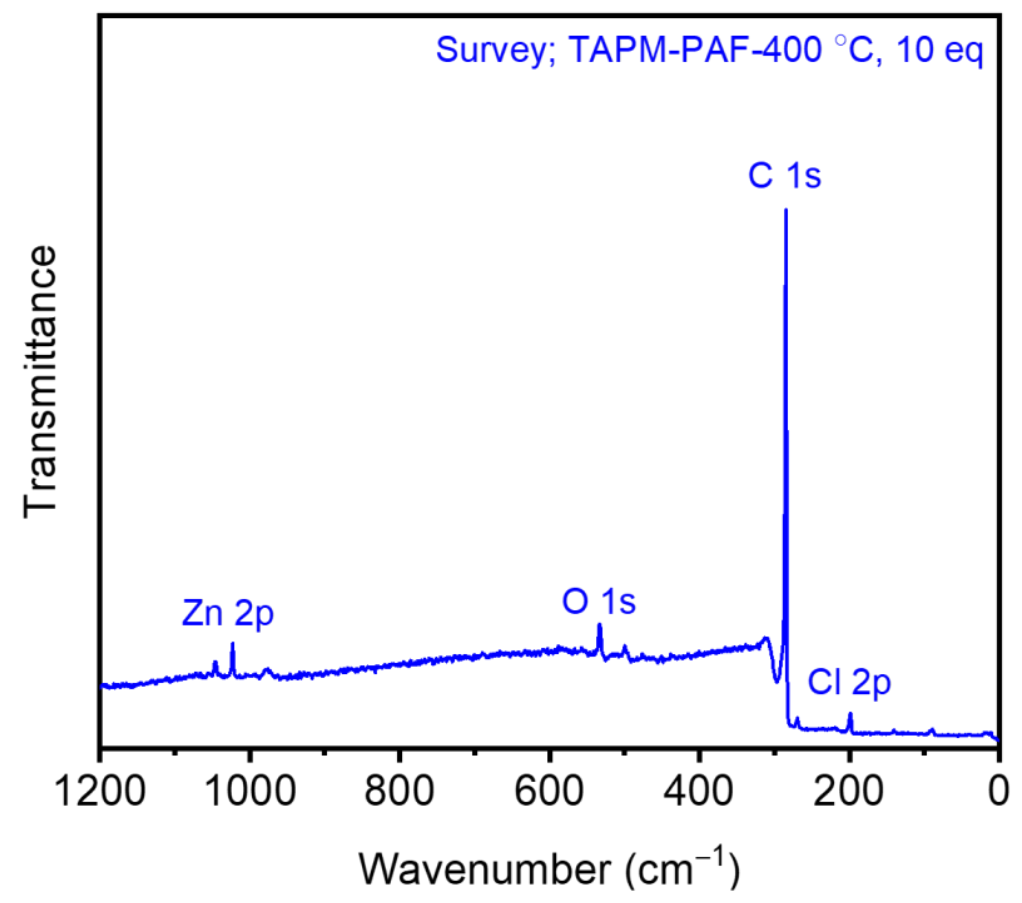

Figure S46. XPS spectrum for TAPM-PAF synthesized at $400{ }^{\circ} \mathrm{C}$ with 10 equivalents of $\mathrm{ZnCl}_{2}$.

Table S7. Tabulated survey XPS data for TAPM-PAF synthesized at $400{ }^{\circ} \mathrm{C}$ with 10 equivalents of $\mathrm{ZnCl}_{2}$.

\begin{tabular}{|c|c|c|c|c|}
\hline Element & Peak label & Position & Area & Atomic \% \\
\hline C & C 1s & 284.70 & 1057.30 & 95.28 \\
\hline O & O 1s & 533.70 & 106.28 & 3.27 \\
\hline Cl & Cl 2p & 198.70 & 30.33 & 1.20 \\
\hline Zn & Zn 2p & 1022.70 & 80.03 & 0.25 \\
\hline Total: & & & & 100.00 \\
\hline
\end{tabular}




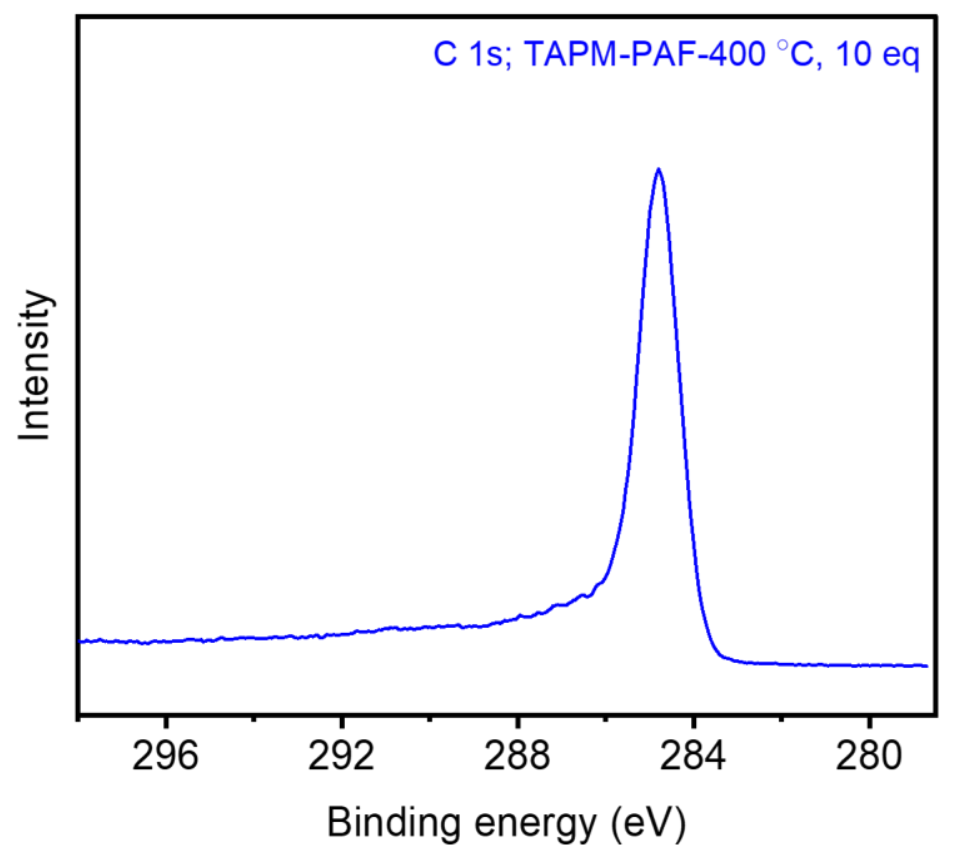

Figure S47. High resolution C 1s XPS spectrum of TAPM-PAF synthesized at $400{ }^{\circ} \mathrm{C}$ with 10 equivalents of $\mathrm{ZnCl}_{2}$.

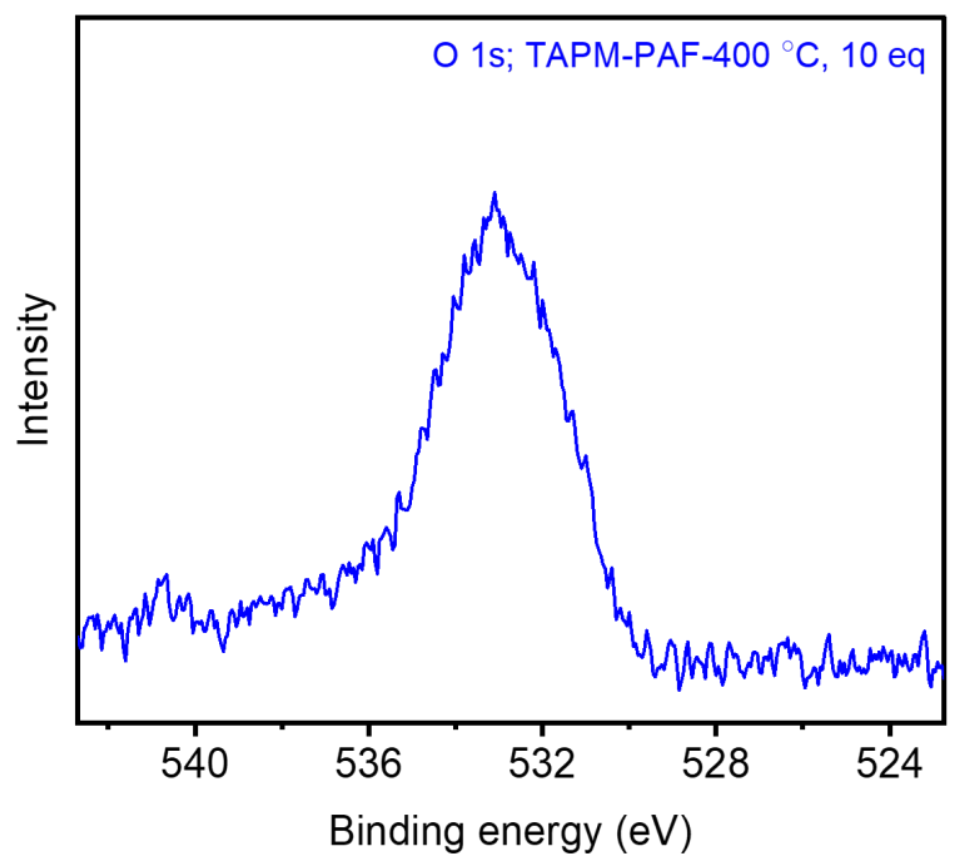

Figure S48. High resolution O 1s XPS spectrum of TAPM-PAF synthesized at $400{ }^{\circ} \mathrm{C}$ with 10 equivalents of $\mathrm{ZnCl}_{2}$. 


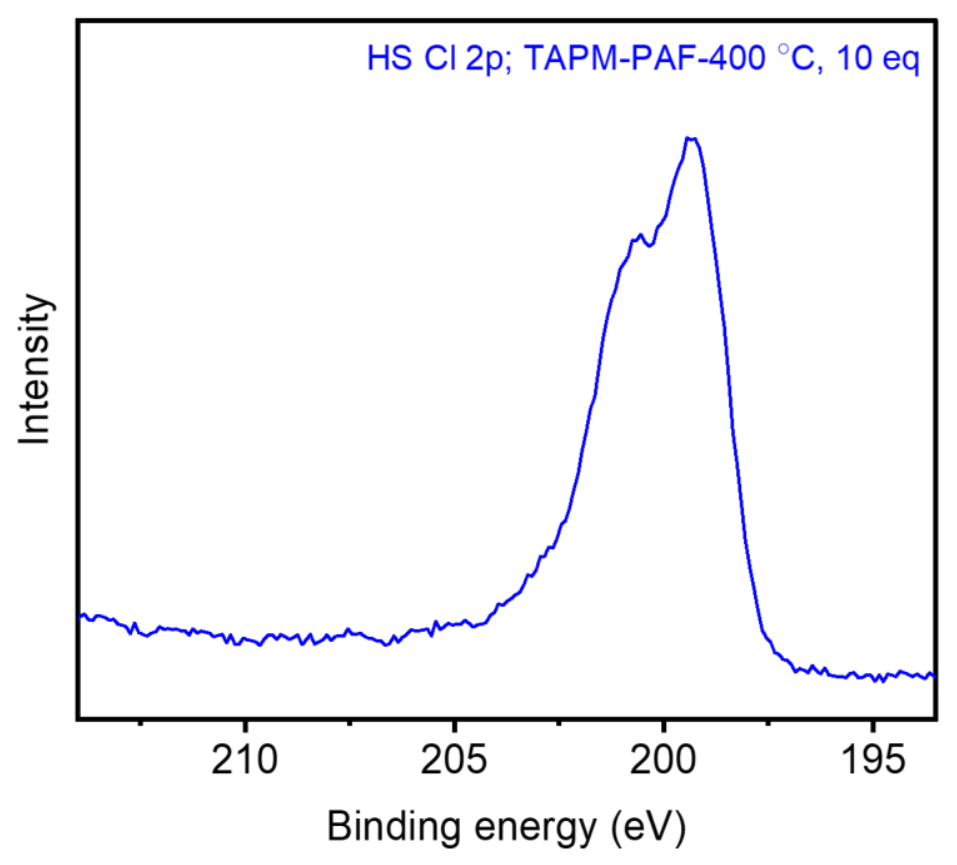

Figure S49. High sensitivity (HS) Cl 2p XPS spectrum of TAPM-PAF synthesized at $400{ }^{\circ} \mathrm{C}$ with 10 equivalents of $\mathrm{ZnCl}_{2}$.

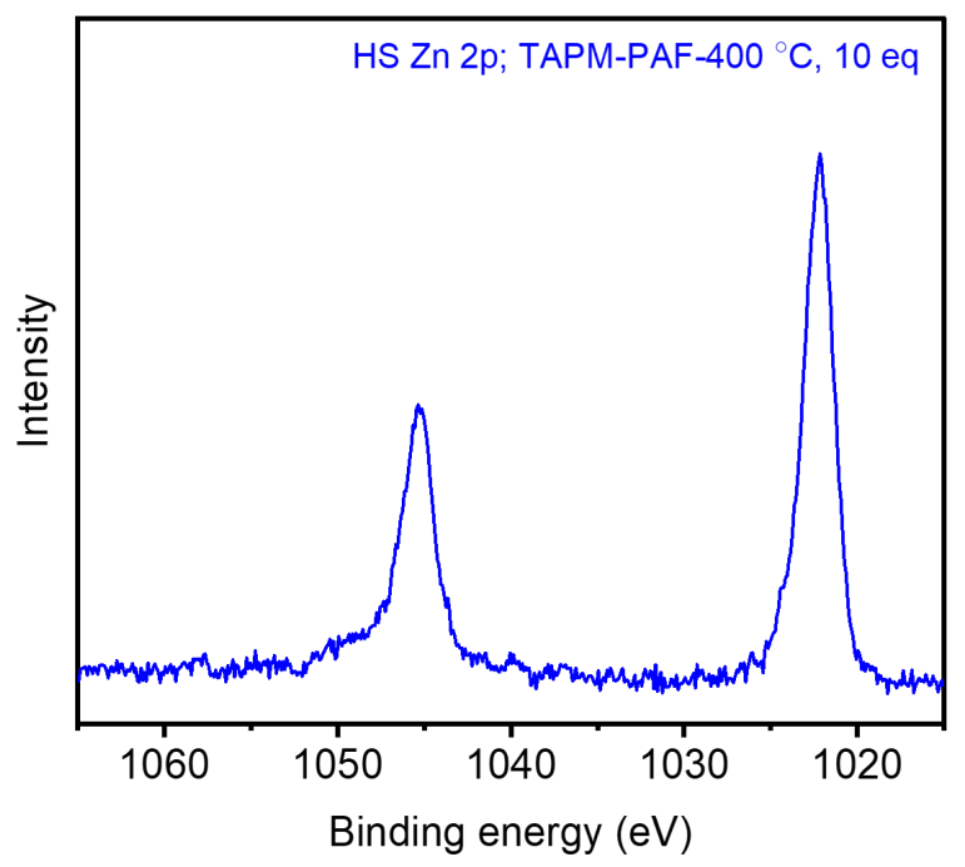

Figure S50. High sensitivity (HS) Zn 2p XPS spectrum of TAPM-PAF synthesized at $400{ }^{\circ} \mathrm{C}$ with 10 equivalents of $\mathrm{ZnCl}_{2}$. 


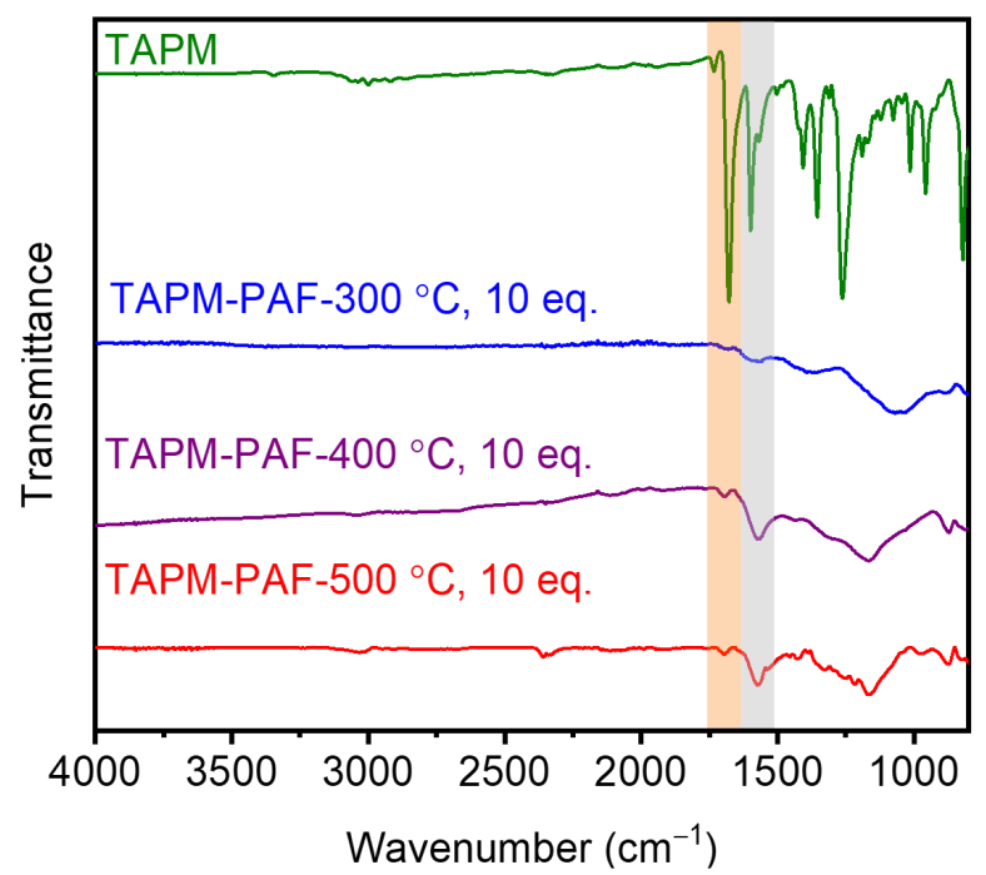

Figure S51. ATR IR spectra of TAPM and TAPM-PAF synthesized at $300{ }^{\circ} \mathrm{C}, 400{ }^{\circ} \mathrm{C}$ and 500 ${ }^{\circ} \mathrm{C}$ with 10 equivalents of $\mathrm{ZnCl}_{2}$.

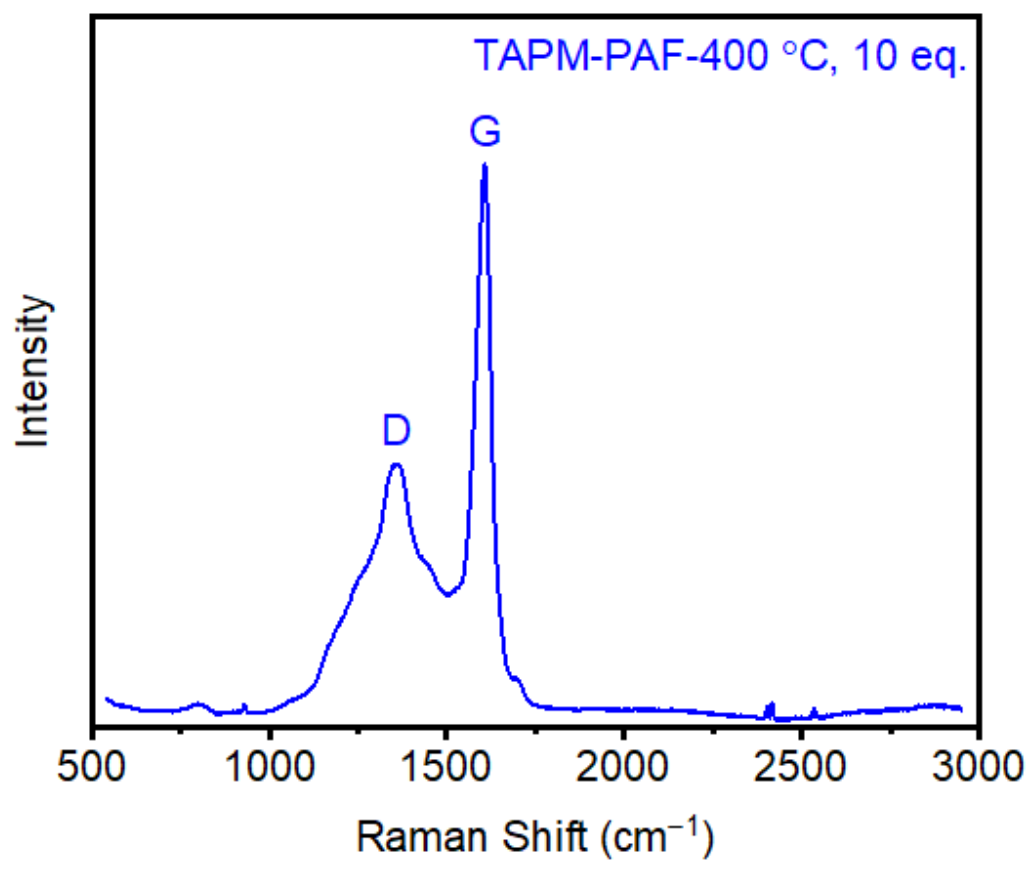

Figure S52. Raman spectrum of TAPM-PAF synthesized at $400{ }^{\circ} \mathrm{C}$ with 10 equivalents of $\mathrm{ZnCl}_{2}$. $\mathrm{D}$ and $\mathrm{G}$ bands resembling those of graphene are labelled. ${ }^{4}$ 


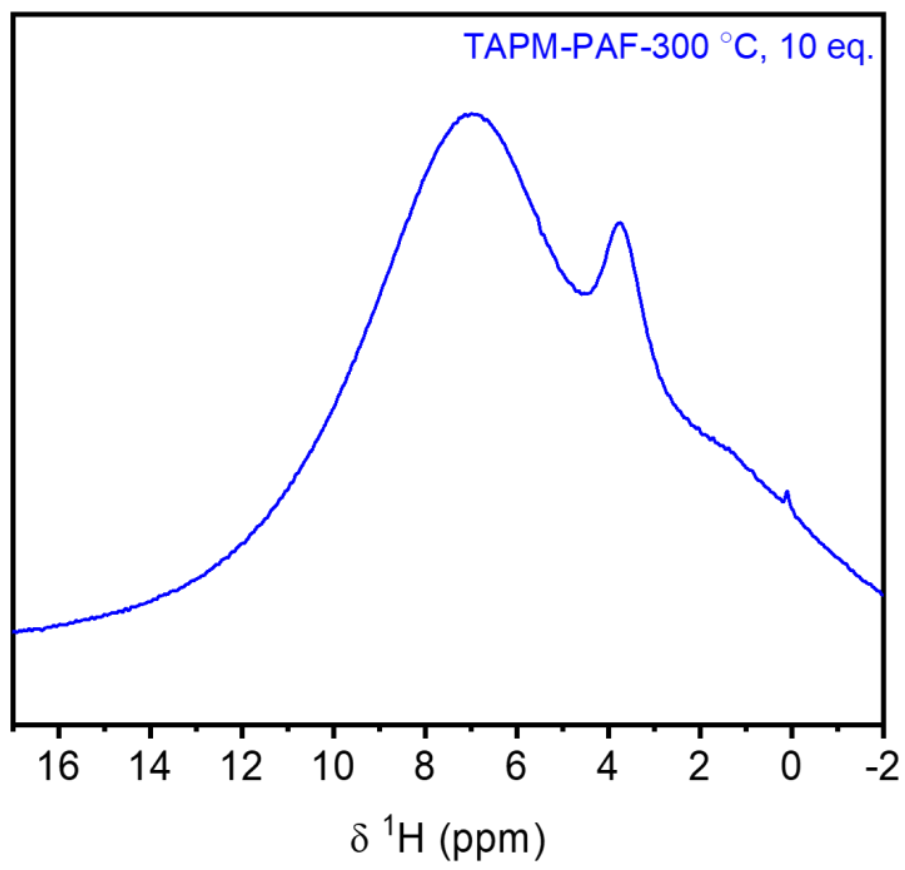

Figure S53. MAS ${ }^{1} \mathrm{H}$ SSNMR (500 MHz) spectrum of TAPM-PAF synthesized at $300{ }^{\circ} \mathrm{C}$ with 10 equivalents of $\mathrm{ZnCl}_{2}$, collected at a spinning speed of $20 \mathrm{kHz}$. 


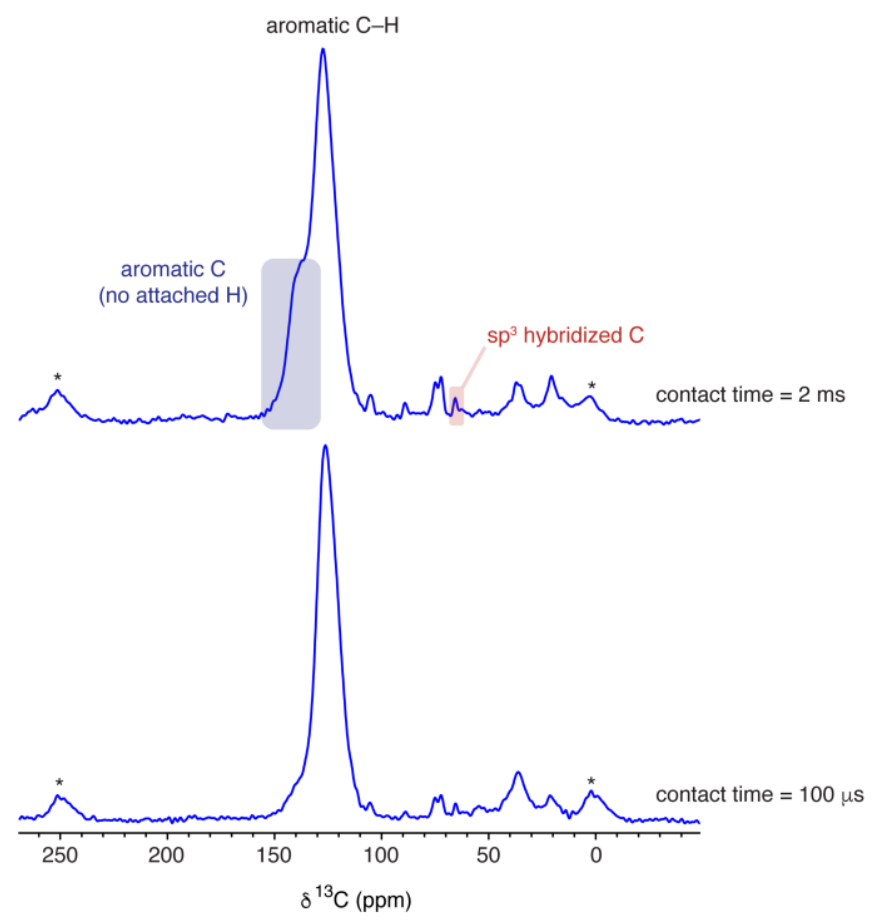

Figure S54. CP MAS ${ }^{13} \mathrm{C}$ SSNMR (100 MHz) spectra of TAPM-PAF-300 ${ }^{\circ} \mathrm{C}$ with two different contact times. A MAS rate of $12.5 \mathrm{kHz}$ was used. Asterisks mark spinning sidebands. Experiments with different contact times allowed the assignment of the main feature at $126.2 \mathrm{ppm}$ to aromatic carbons with attached protons, while the shoulder at $\sim 138 \mathrm{ppm}$ was assigned to quaternary aromatic carbons with no attached protons. A weak resonance was also assignable to the anticipated $\mathrm{sp}^{3}$ hybridized carbon, on the basis of its ${ }^{13} \mathrm{C}$ chemical shift of $66 \mathrm{ppm}$. Additional weak resonances are observed which presumably arise from defects or impurities in the material. 


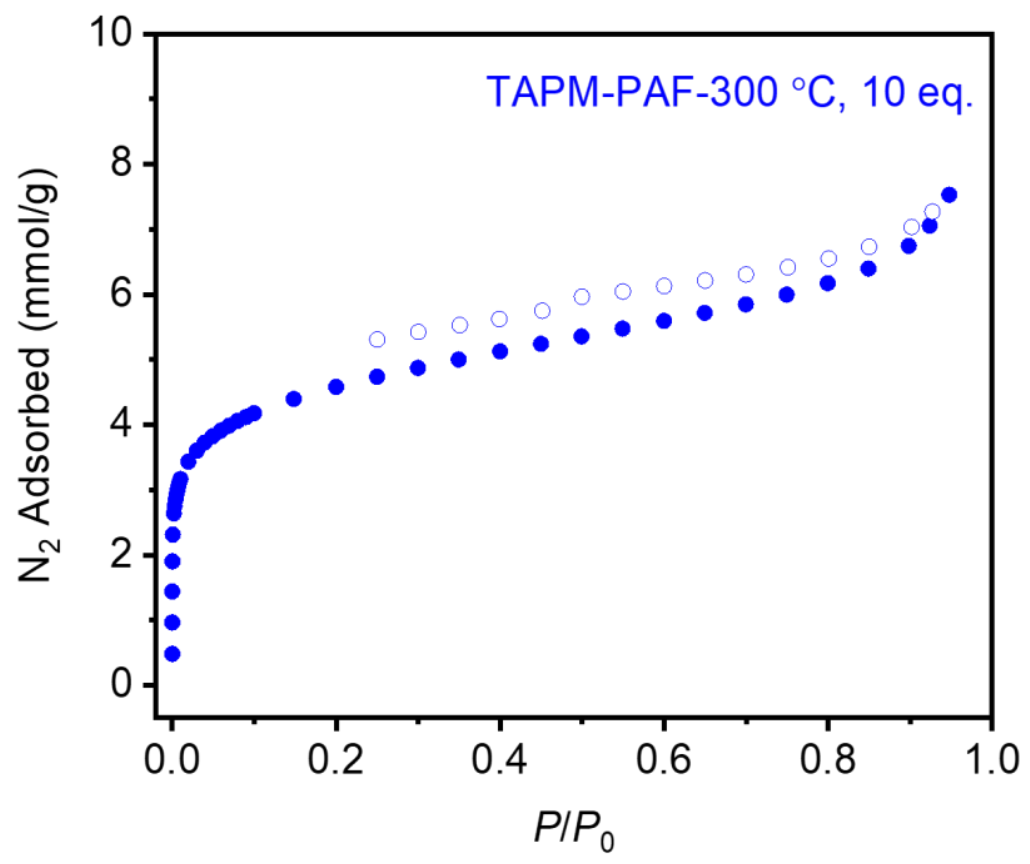

Figure S55. $77 \mathrm{~K} \mathrm{~N}_{2}$ adsorption (filled circles) and desorption (open circles) isotherm for TAPMPAF synthesized at $300{ }^{\circ} \mathrm{C}$ with 10 equivalents of $\mathrm{ZnCl}_{2}$. The Brunauer-Emmett-Teller (BET) and Langmuir surface areas were determined to be $361 \pm 3 \mathrm{~m}^{2} / \mathrm{g}$ and $627 \pm 13 \mathrm{~m}^{2} / \mathrm{g}$, respectively.

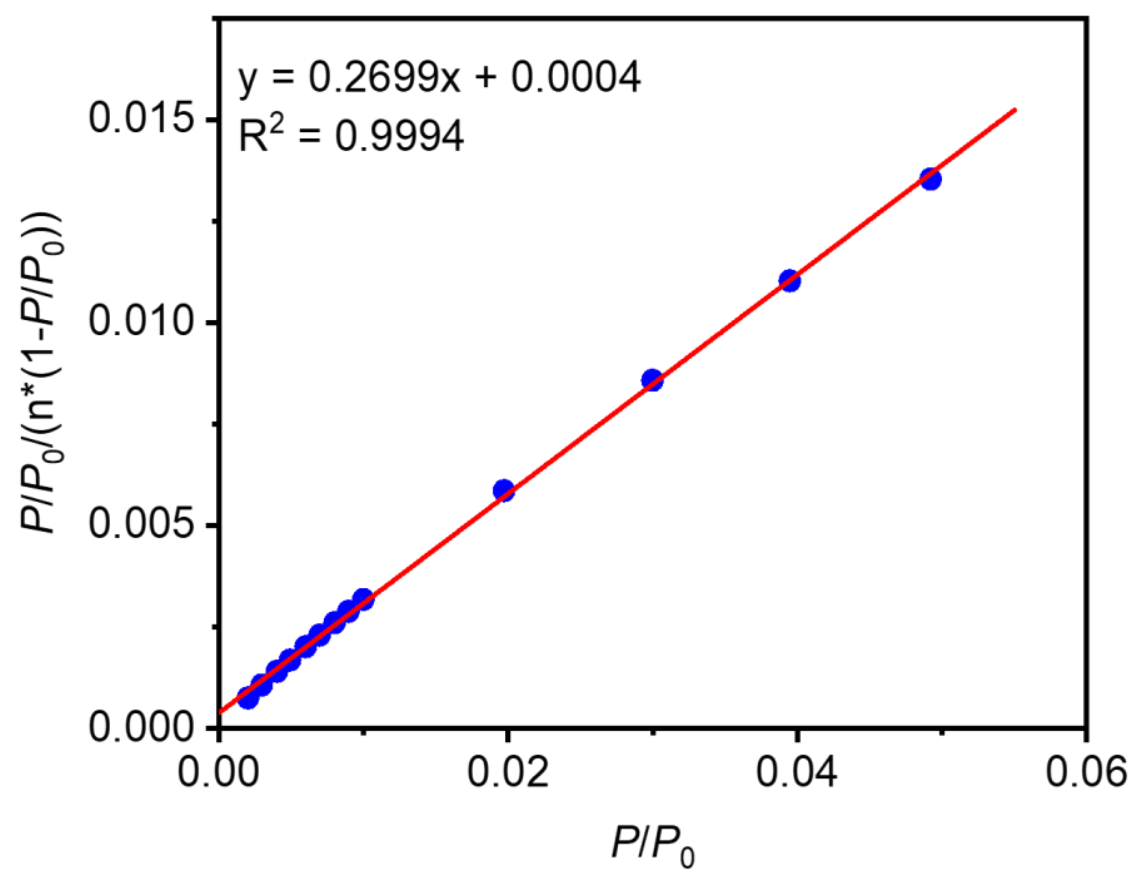

Figure S56. Linearized BET plot of TAPM-PAF made at $300{ }^{\circ} \mathrm{C}$ with 10 equivalents of $\mathrm{ZnCl}_{2}$. 


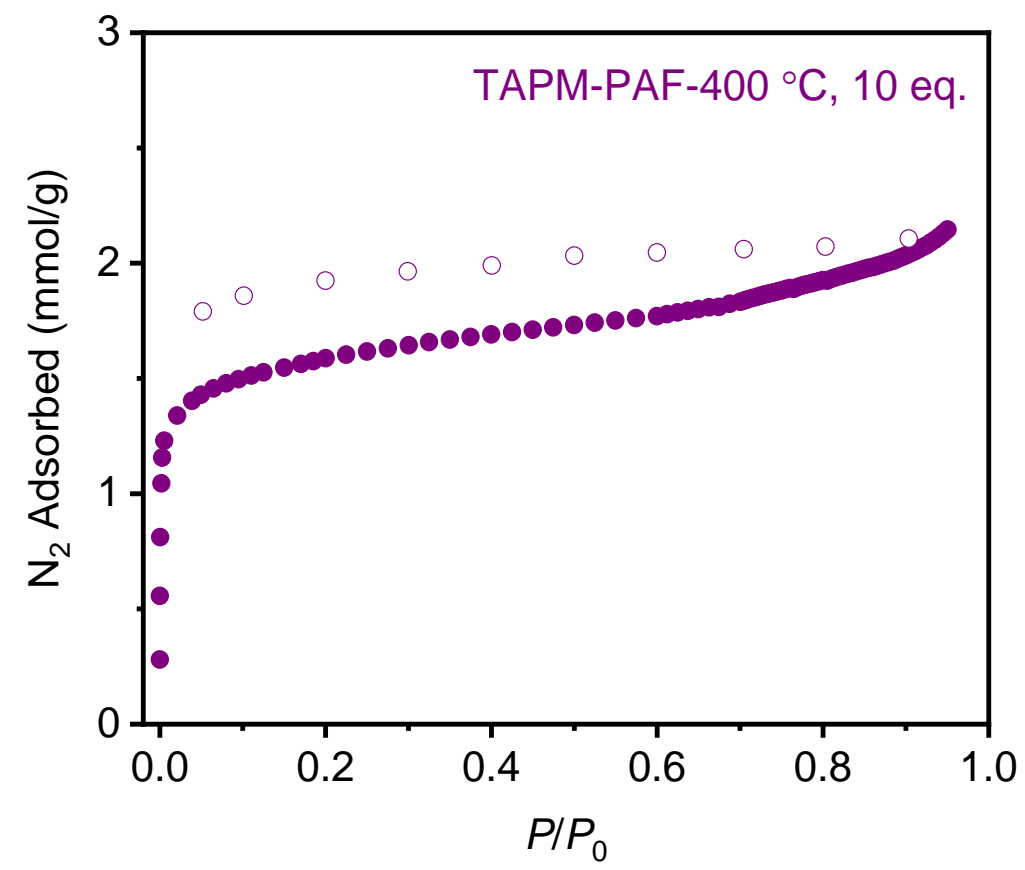

Figure S57. $77 \mathrm{~K} \mathrm{~N}_{2}$ adsorption (filled circles) and desorption (open circles) isotherm for TAPMPAF synthesized at $400{ }^{\circ} \mathrm{C}$ with 10 equivalents of $\mathrm{ZnCl}_{2}$. The Brunauer-Emmett-Teller (BET) and Langmuir surface areas were determined to be $133 \pm 1 \mathrm{~m}^{2} / \mathrm{g}$ and $192 \pm 2 \mathrm{~m}^{2} / \mathrm{g}$, respectively.

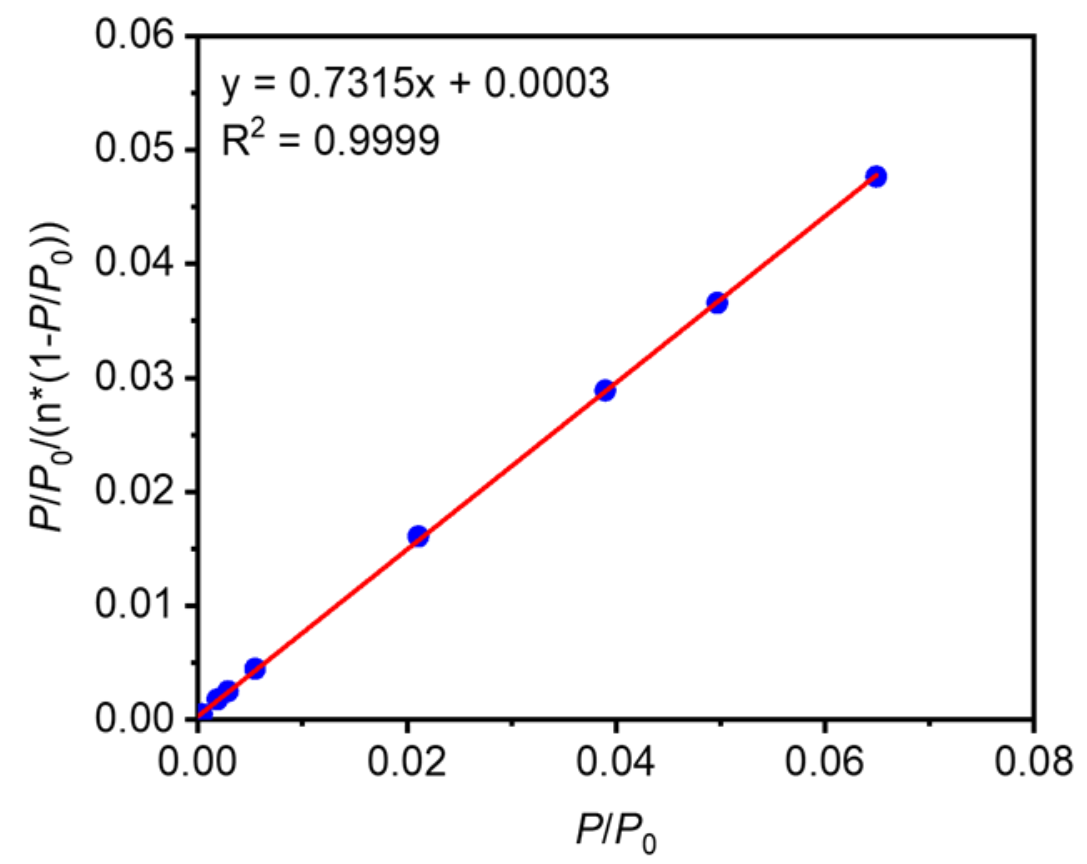

Figure S58. Linearized BET plot of TAPM-PAF made at $400{ }^{\circ} \mathrm{C}$ with 10 equivalents of $\mathrm{ZnCl}_{2}$. 


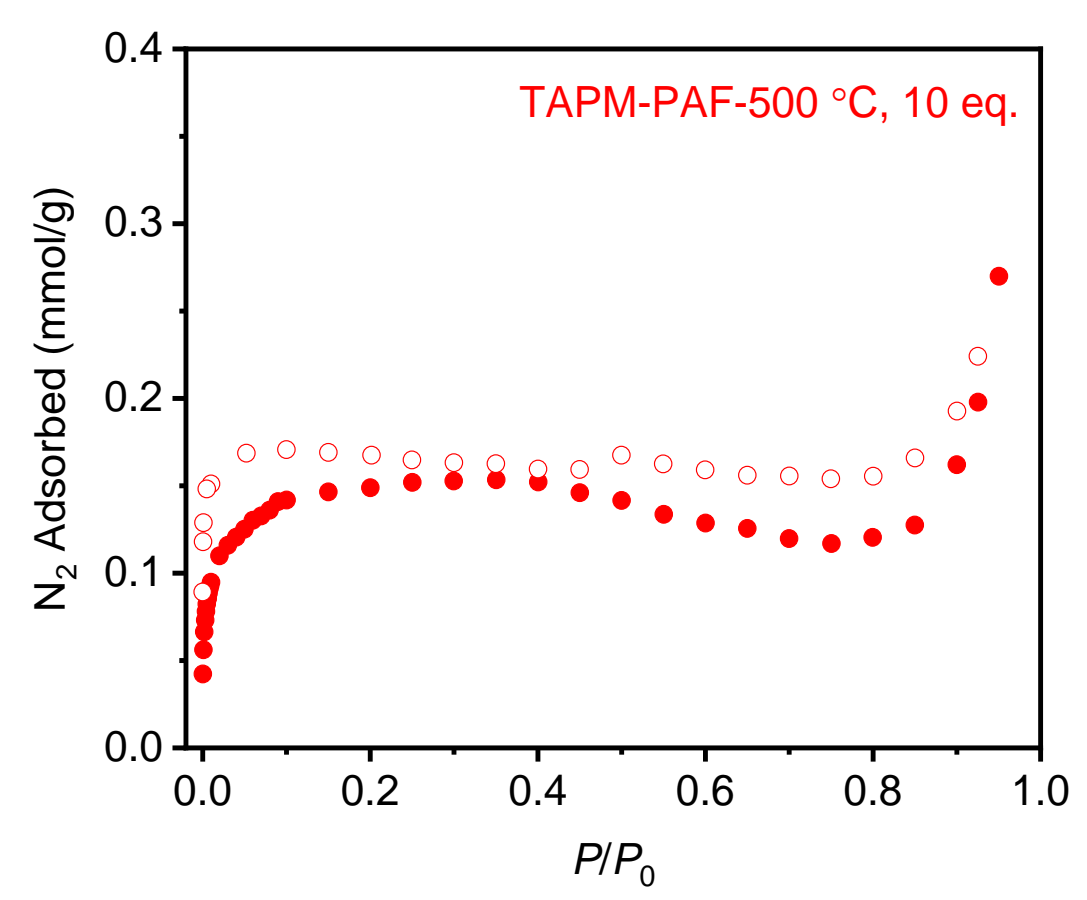

Figure S59. $77 \mathrm{~K} \mathrm{~N}_{2}$ adsorption (filled circles) and desorption (open circles) isotherm for TAPMPAF-500 ${ }^{\circ} \mathrm{C}, 10 \mathrm{eq}$. The Brunauer-Emmett-Teller (BET) and Langmuir surface areas were determined to be $13 \mathrm{~m}^{2} / \mathrm{g}$ and $15 \mathrm{~m}^{2} / \mathrm{g}$, respectively, indicating that this material is effectively nonporous.

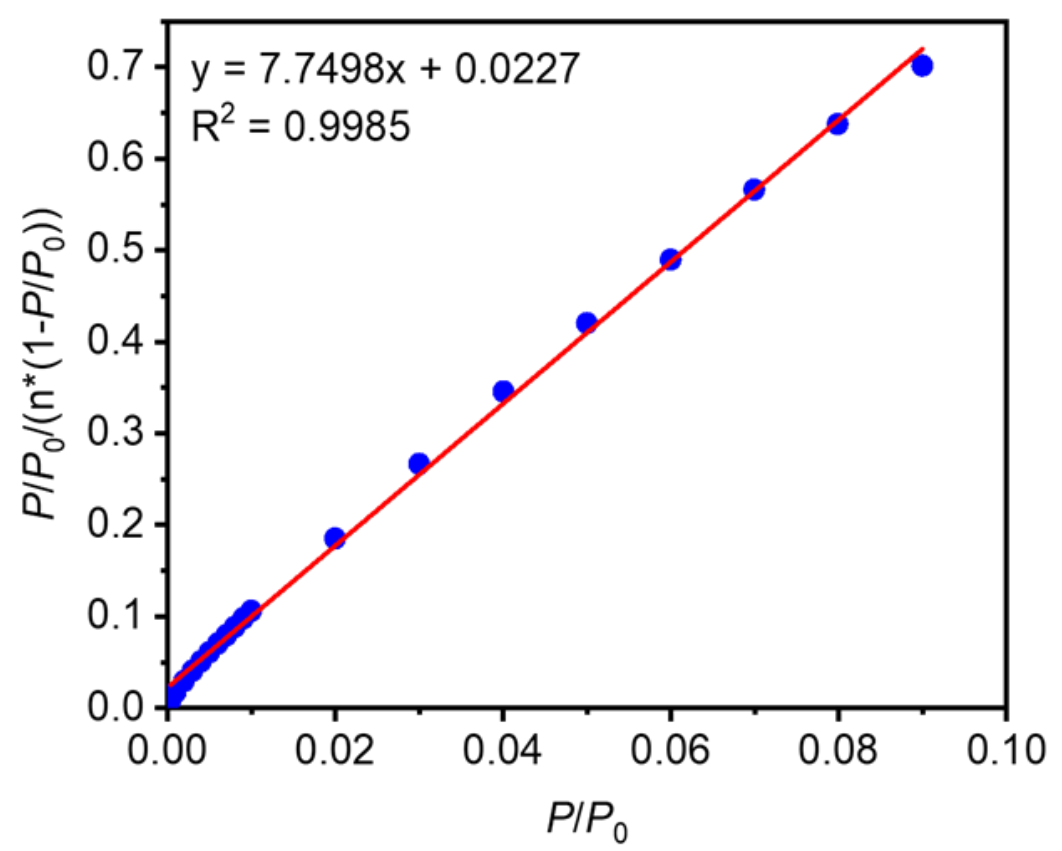

Figure S60. Linearized BET plot of TAPM-PAF made at $500{ }^{\circ} \mathrm{C}$ with 10 equivalents of $\mathrm{ZnCl}_{2}$. 


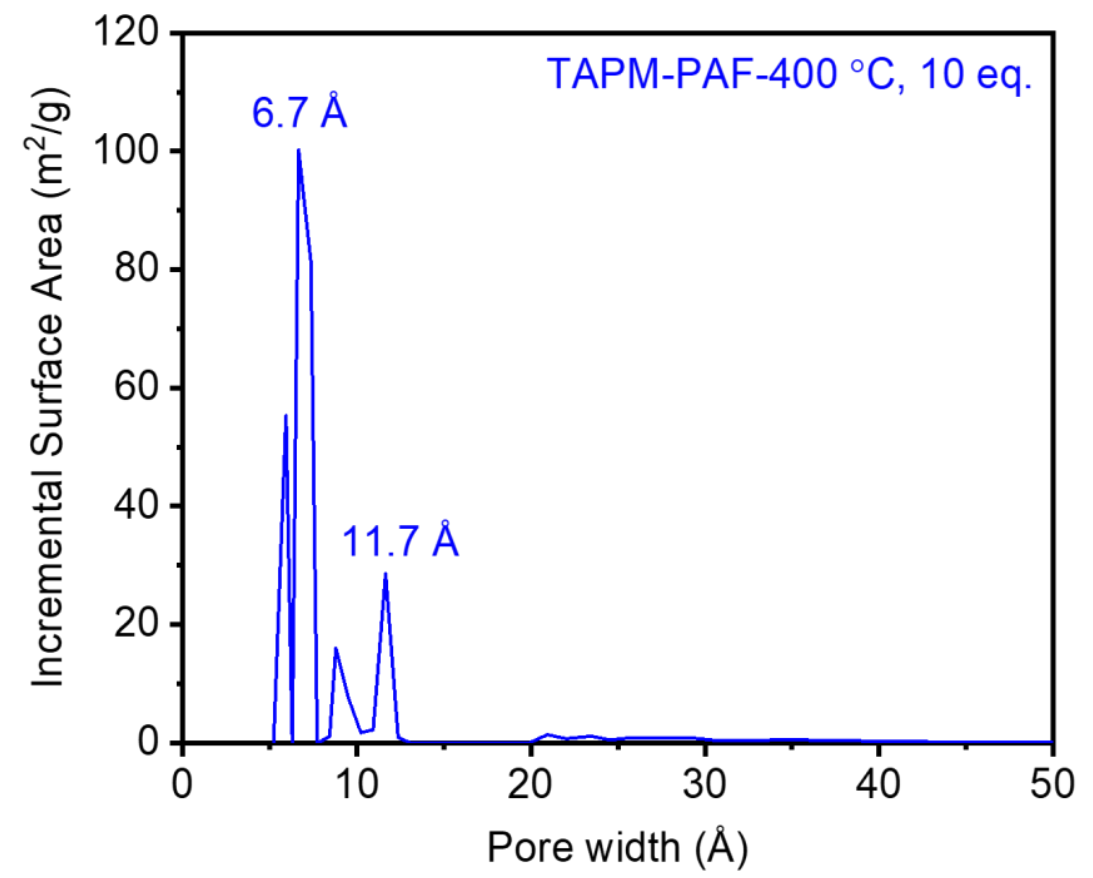

Figure S61. $\mathrm{N}_{2}$-Tarazona NLDFT-calculated pore size distribution for TAPM-PAF synthesized at $400{ }^{\circ} \mathrm{C}$ with 10 equivalents of $\mathrm{ZnCl}_{2}$, assuming a cylindrical pore geometry.

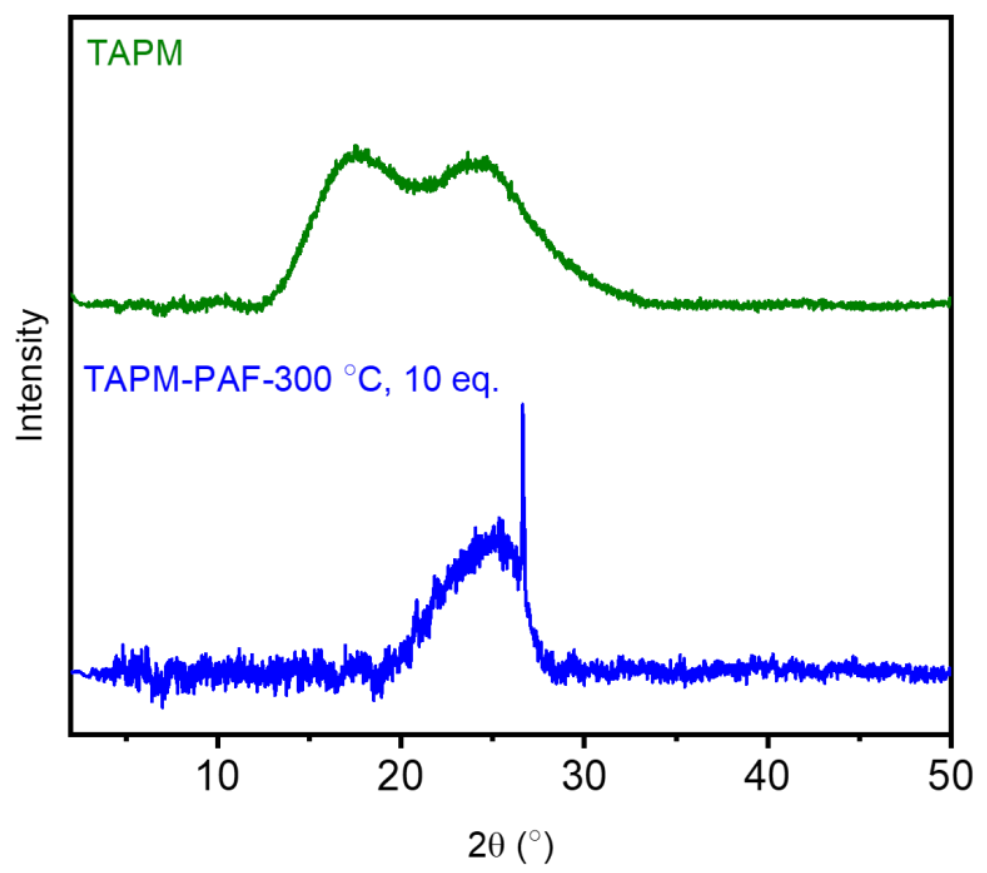

Figure S62. PXRD patterns of TAPM and TAPM-PAF synthesized at $300{ }^{\circ} \mathrm{C}$ with 10 equivalents of $\mathrm{ZnCl}_{2}$, indicating that TAPM-PAF- $300{ }^{\circ} \mathrm{C}, 10$ eq. is an amorphous polymer. 


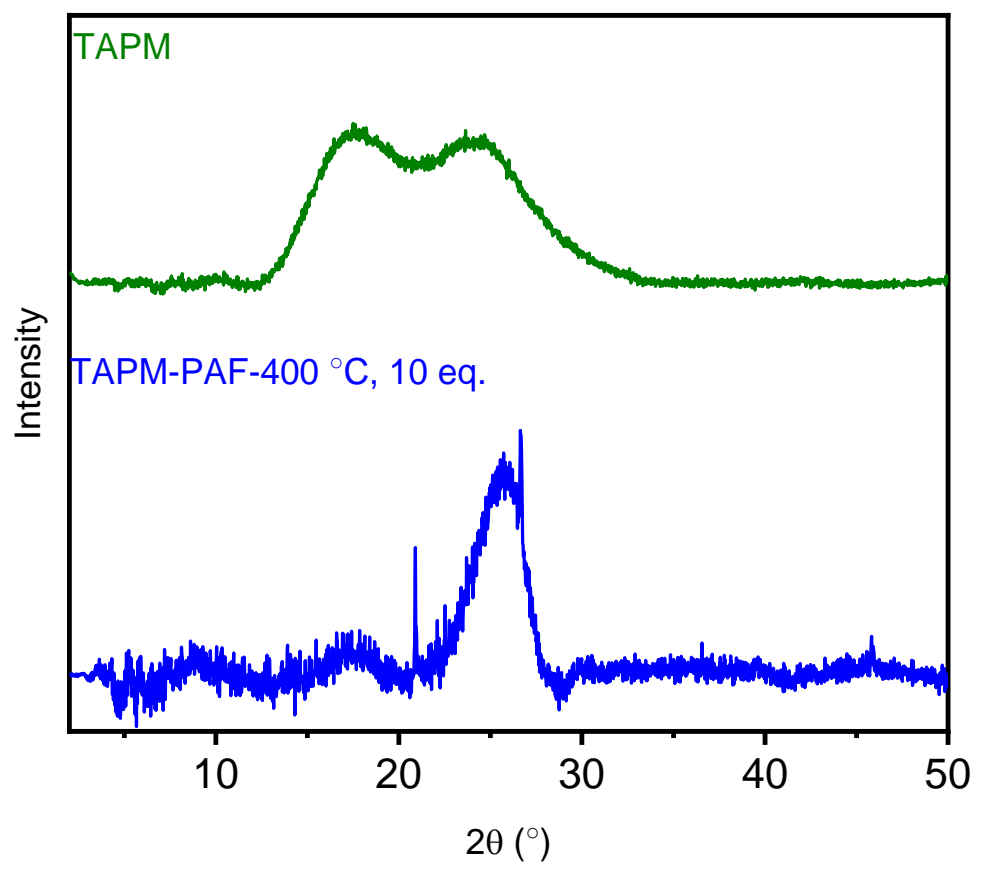

Figure S63. PXRD patterns of TAPM and TAPM-PAF synthesized at $400{ }^{\circ} \mathrm{C}$ with 10 equivalents of $\mathrm{ZnCl}_{2}$, indicating that TAPM-PAF- $400{ }^{\circ} \mathrm{C}, 10$ eq. is an amorphous polymer.

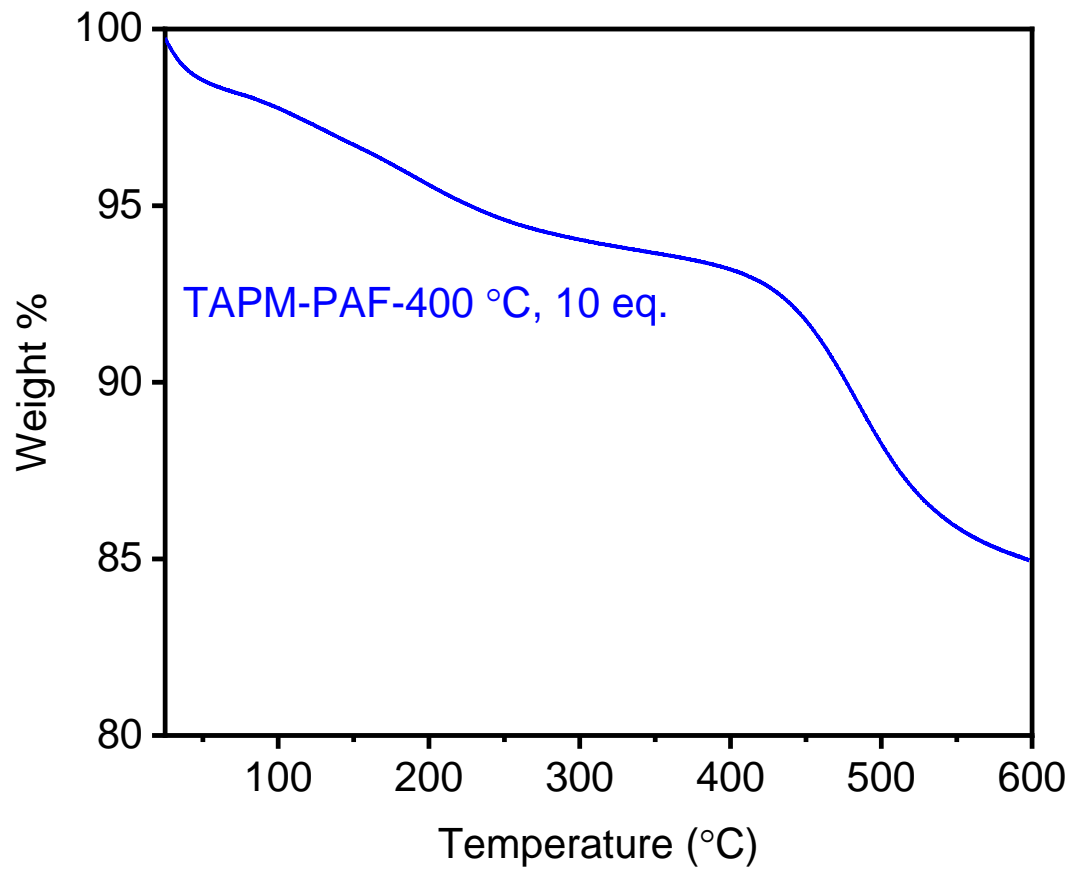

Figure S64. Decomposition profile of TAPM-PAF synthesized at $400{ }^{\circ} \mathrm{C}$ with 10 equivalents of $\mathrm{ZnCl}_{2}$. 


\section{c. 1,4-diacetylbenzene trimerization.}<smiles>CC(=O)c1ccc(C(C)=O)cc1</smiles>

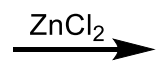

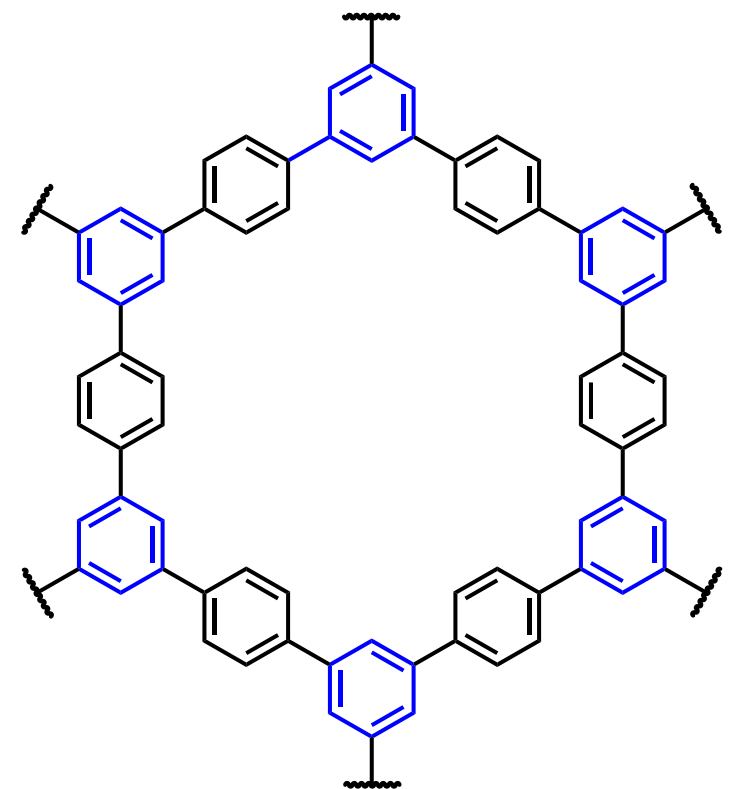

Figure S65. Synthesis of poly(DAB) from 1,4-diacetylbenzene (DAB).

Following the general procedure, three tubes were charged with 1,4-diacetylbenzene (DAB) (40 mg, $0.247 \mathrm{mmol}, 1.00$ eq.) and $\mathrm{ZnCl}_{2}$ (336 mg, $2.47 \mathrm{mmol}, 10.0$ eq.) and the products were combined to yield poly(DAB) as a shiny black solid $(56.4 \mathrm{mg})$.

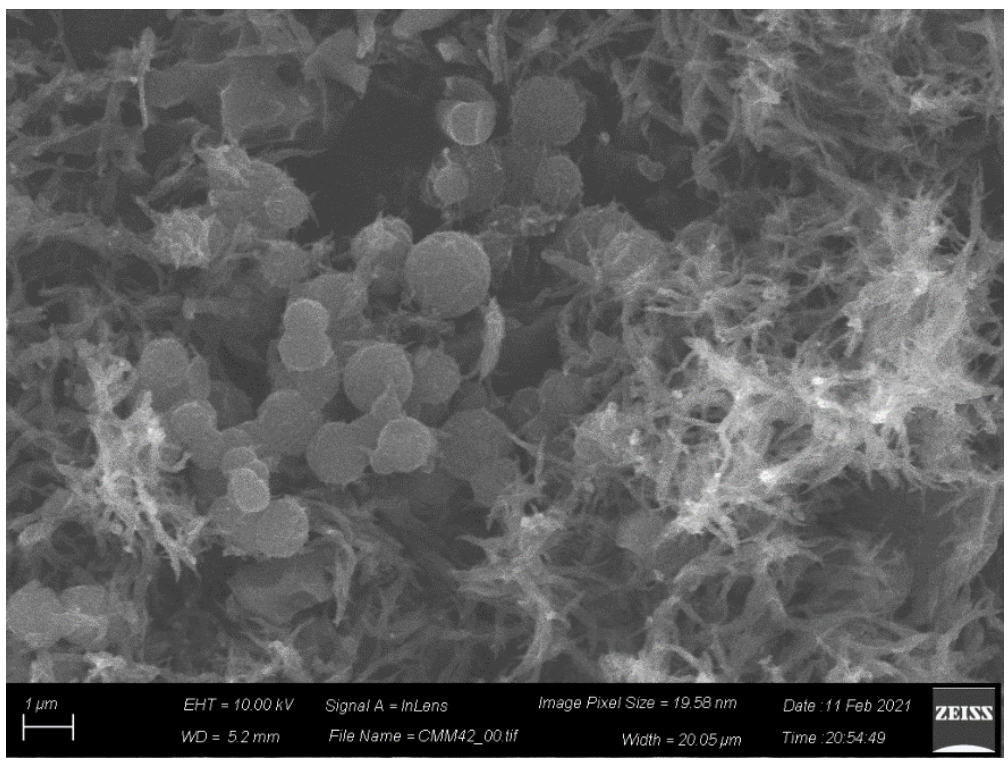

Figure S66. SEM image of poly(DAB) synthesized at $400{ }^{\circ} \mathrm{C}$ with 10 equivalents of $\mathrm{ZnCl}_{2}$. 


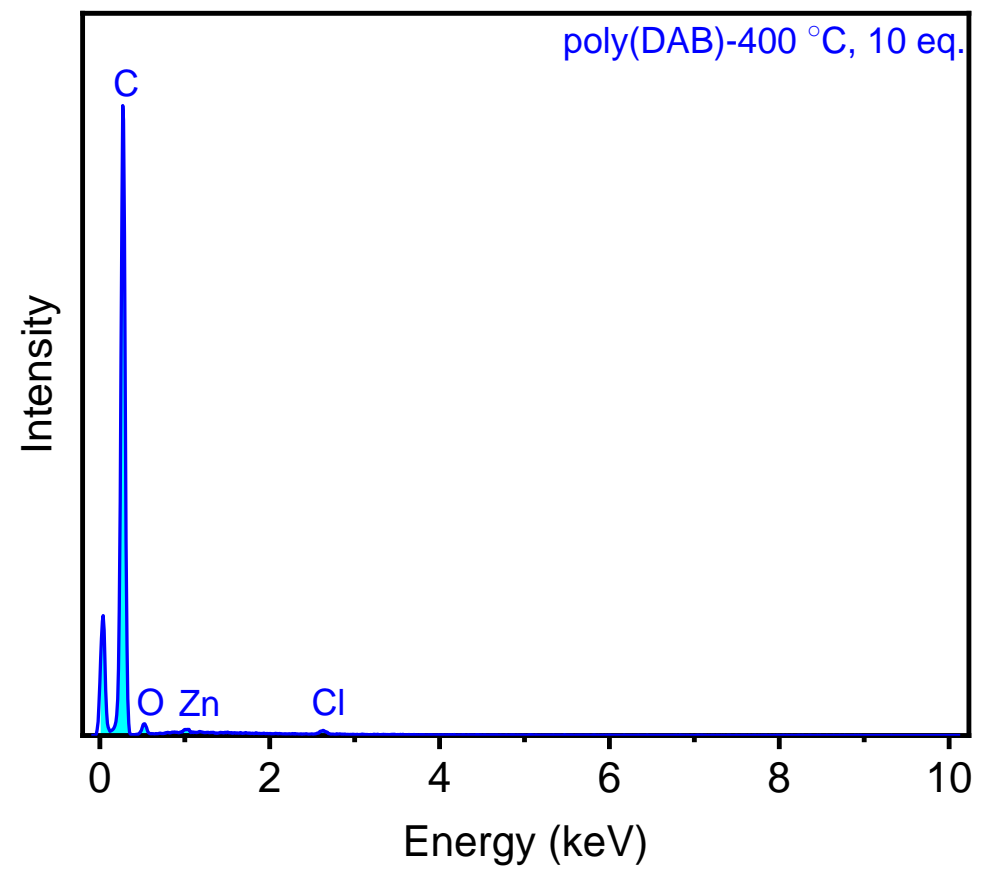

Figure S67. EDS data for poly(DAB) synthesized at $400{ }^{\circ} \mathrm{C}$ with 10 equivalents of $\mathrm{ZnCl}_{2}$.

Table S8. Tabulated EDS data for poly(DAB) synthesized at $400{ }^{\circ} \mathrm{C}$ with 10 equivalents of $\mathrm{ZnCl}_{2}$.

\begin{tabular}{|c|c|c|c|c|c|}
\hline Element & Line Type & k Ratio & Wt\% & Wt\% $\sigma$ & Atomic \% \\
\hline $\mathrm{C}$ & K series & 0.21965 & 25.45 & 0.15 & 96.47 \\
\hline $\mathrm{O}$ & K series & 0.00283 & 1.03 & 0.06 & 2.94 \\
\hline $\mathrm{Cl}$ & K series & 0.00256 & 0.32 & 0.03 & 0.41 \\
\hline $\mathrm{Zn}$ & L series & 0.00159 & 0.26 & 0.02 & 0.18 \\
\hline Total: & & & 32.36 & & 100.00 \\
\hline
\end{tabular}




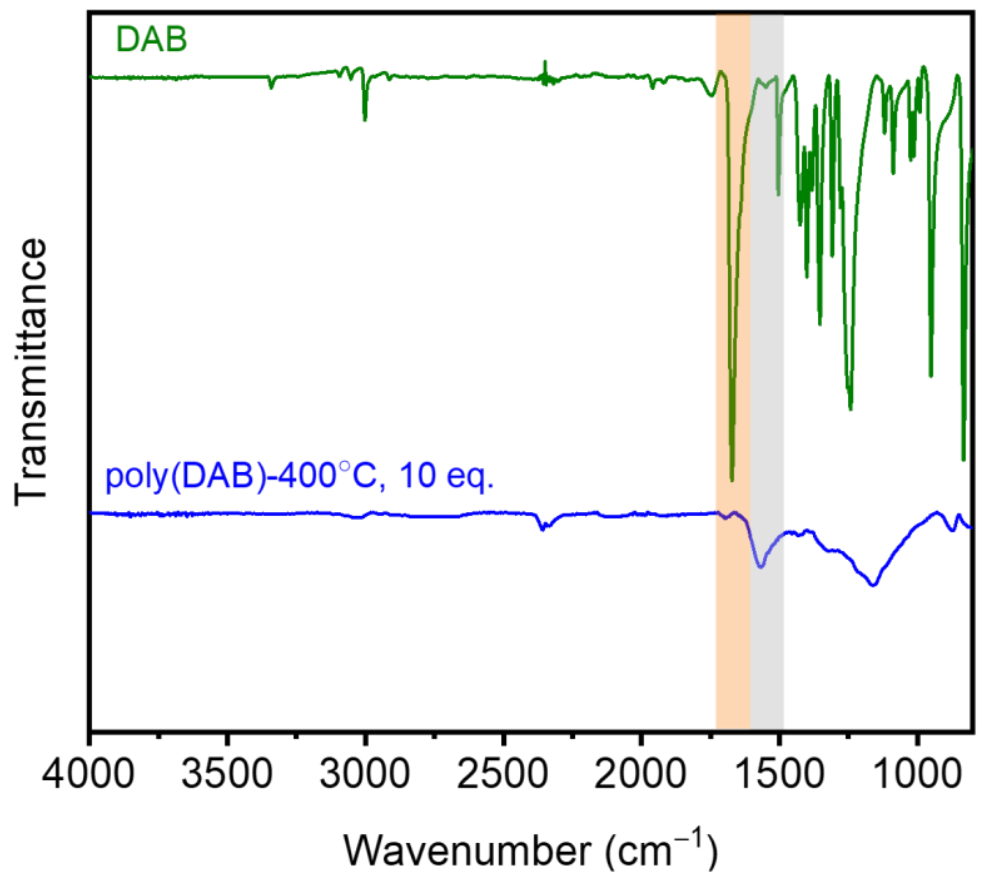

Figure S68. ATR IR spectra of DAB and poly(DAB) synthesized at $400{ }^{\circ} \mathrm{C}$ with 10 equivalents of $\mathrm{ZnCl}_{2}$.

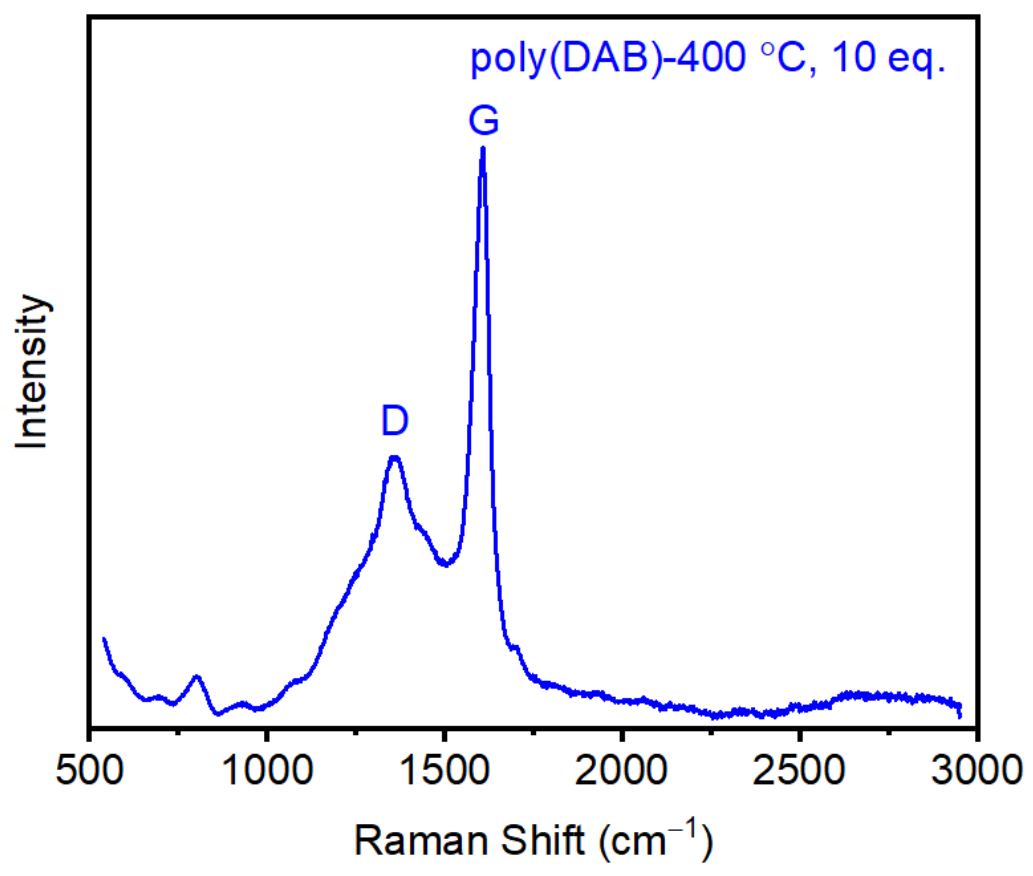

Figure S69. Raman spectrum of poly(DAB) synthesized at $400{ }^{\circ} \mathrm{C}$ with 10 equivalents of $\mathrm{ZnCl}_{2}$. $\mathrm{D}$ and $\mathrm{G}$ bands resembling those of graphene are labelled. ${ }^{4}$ 


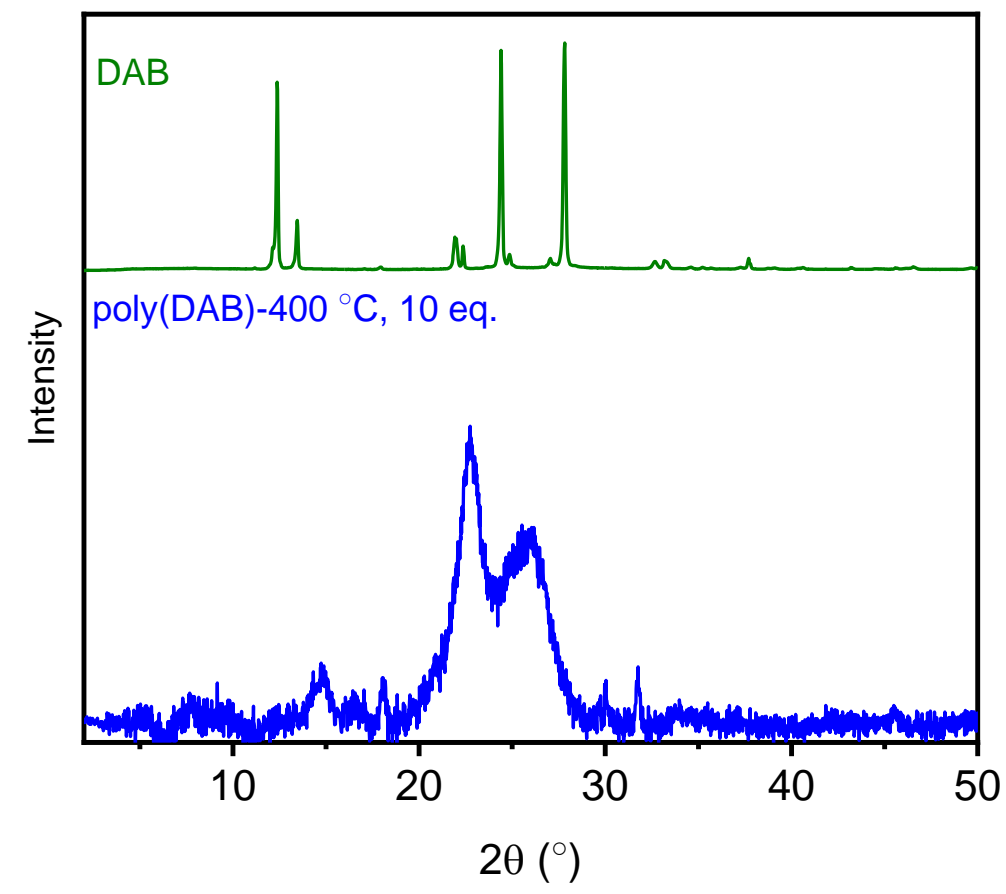

Figure S70. PXRD patterns of DAB and poly(DAB) synthesized at $400{ }^{\circ} \mathrm{C}$ with 10 equivalents of $\mathrm{ZnCl}_{2}$, indicating that poly(DAB) is an amorphous polymer.

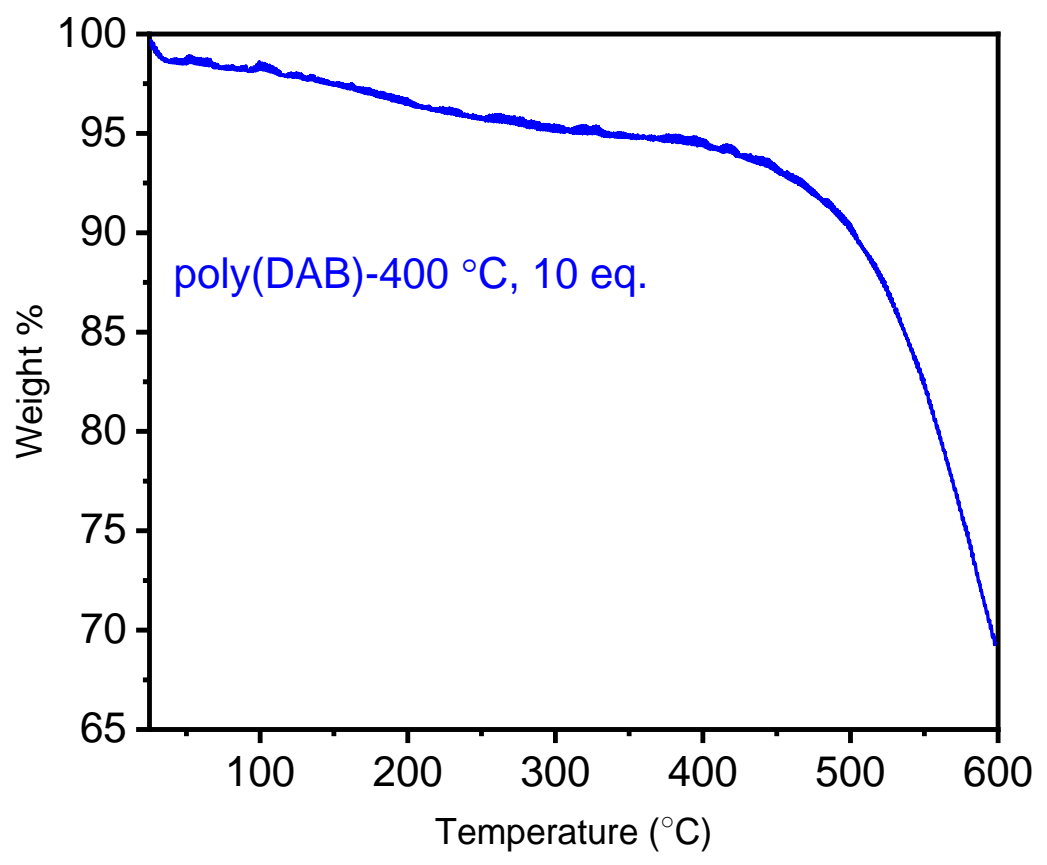

Figure S71. Decomposition profile of poly(DAB) synthesized at $400{ }^{\circ} \mathrm{C}$ with 10 equivalents of $\mathrm{ZnCl}_{2}$. 


\section{d. 4,4'-diacetylbiphenyl trimerization.}
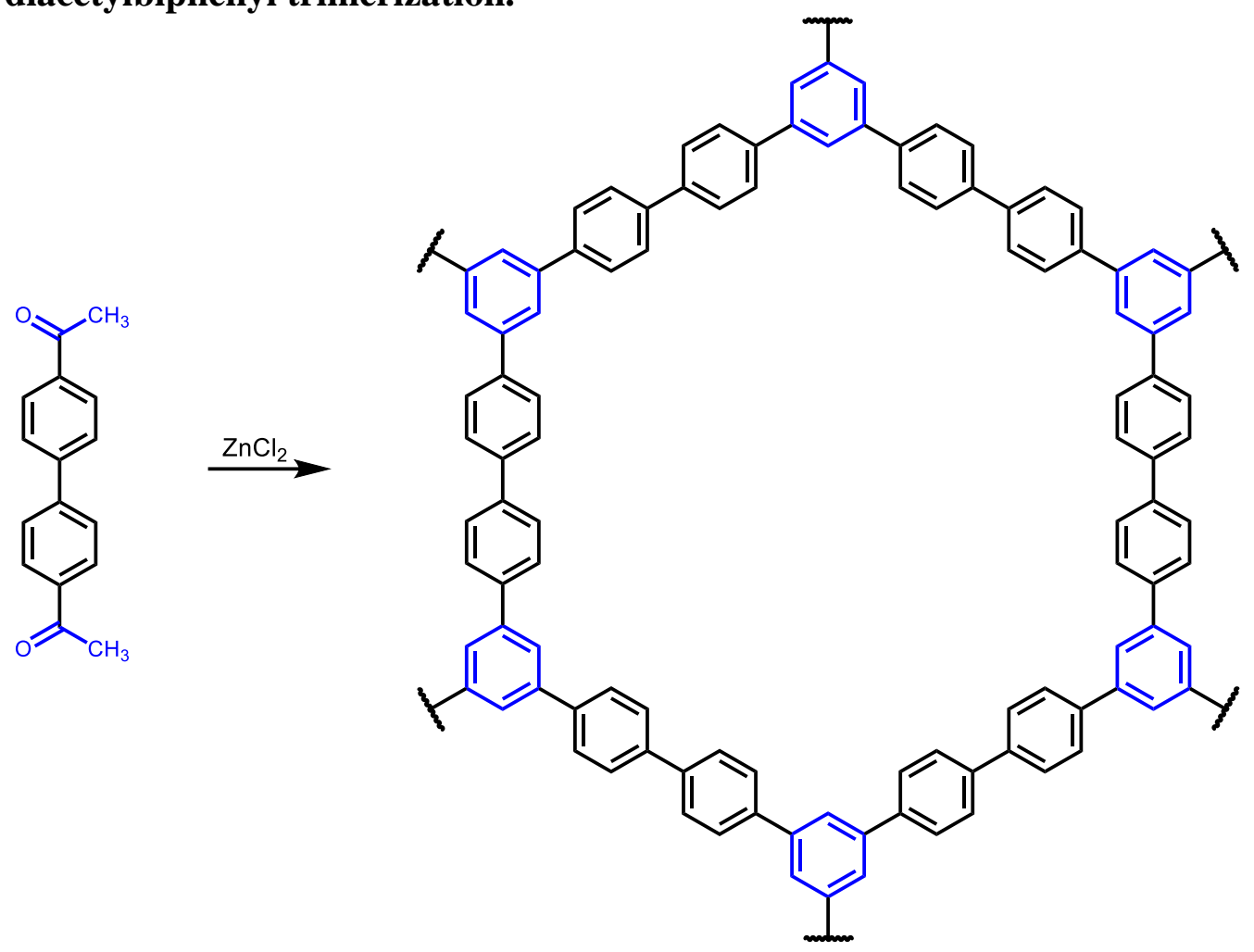

Figure S72. Synthesis of poly(DABP) from 4,4'-diacetylbiphenyl (DABP).

Following the general procedure, three tubes charged with 4,4'-diacetylbiphenyl (DABP) ( $40.0 \mathrm{mg}, 0.168 \mathrm{mmol}, 1.00$ eq.) and $\mathrm{ZnCl}_{2}(229 \mathrm{mg}, 1.68 \mathrm{mmol}, 10.0$ eq.) and the products were combined to yield poly(DABP) as a shiny black solid $(68.5 \mathrm{mg})$.

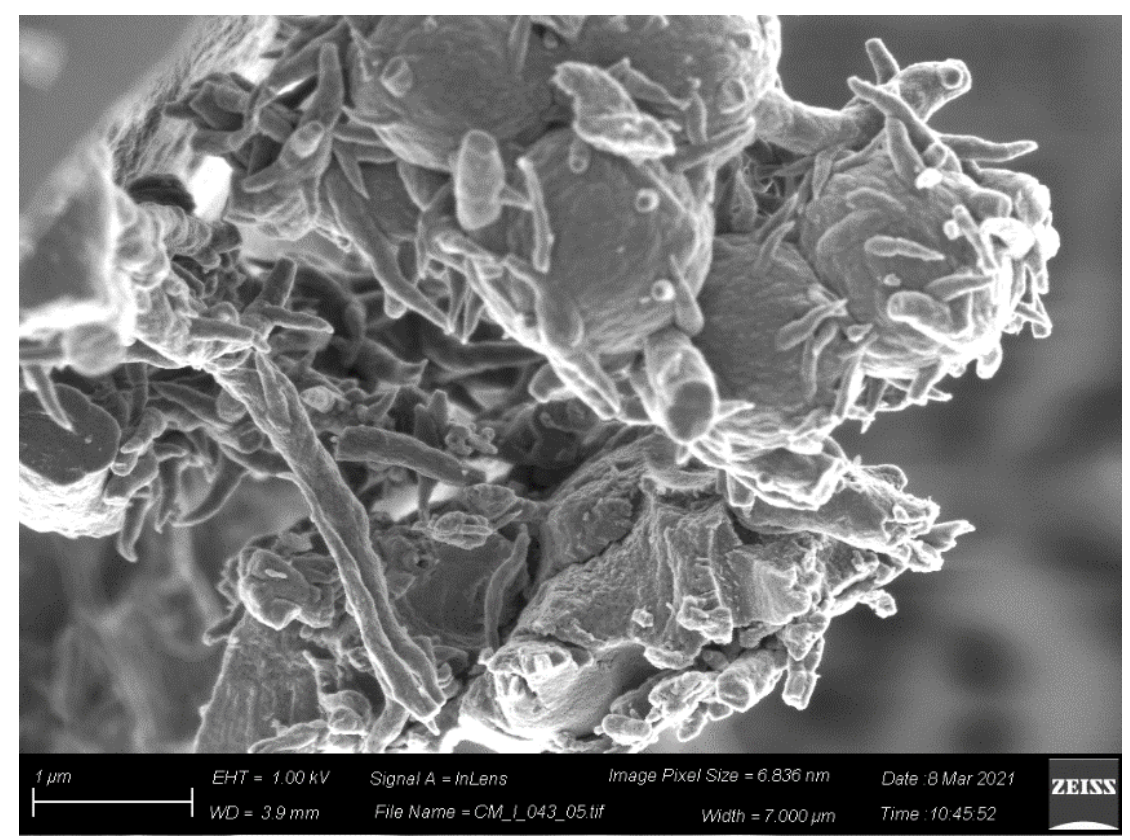

Figure S73. SEM image of poly(DABP) synthesized at $400{ }^{\circ} \mathrm{C}$ with 10 equivalents of $\mathrm{ZnCl}_{2}$. 


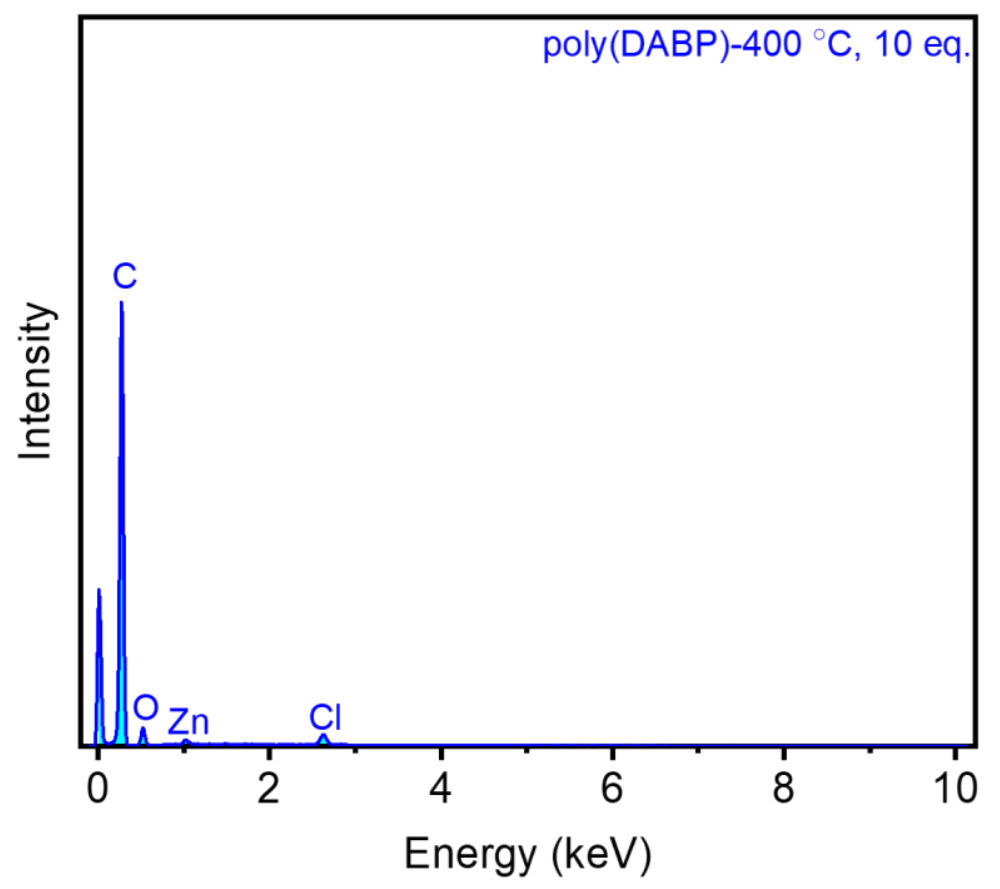

Figure S74. EDS data for poly(DABP) synthesized at $400{ }^{\circ} \mathrm{C}$ with 10 equivalents of $\mathrm{ZnCl}_{2}$.

Table S9. Tabulated EDS data for poly(DABP) synthesized at $400{ }^{\circ} \mathrm{C}$ with 10 equivalents of $\mathrm{ZnCl}_{2}$.

\begin{tabular}{|c|c|c|c|c|}
\hline Element & Line Type & Wt\% & Wt\% $\sigma$ & Atomic \% \\
\hline $\mathrm{C}$ & K series & 87.97 & 0.30 & 92.96 \\
\hline $\mathrm{O}$ & K series & 6.79 & 0.24 & 5.39 \\
\hline $\mathrm{Cl}$ & K series & 3.00 & 0.15 & 1.40 \\
\hline $\mathrm{Zn}$ & L series & 1.33 & 0.13 & 0.26 \\
\hline Total: & & 100.00 & & 100.00 \\
\hline
\end{tabular}




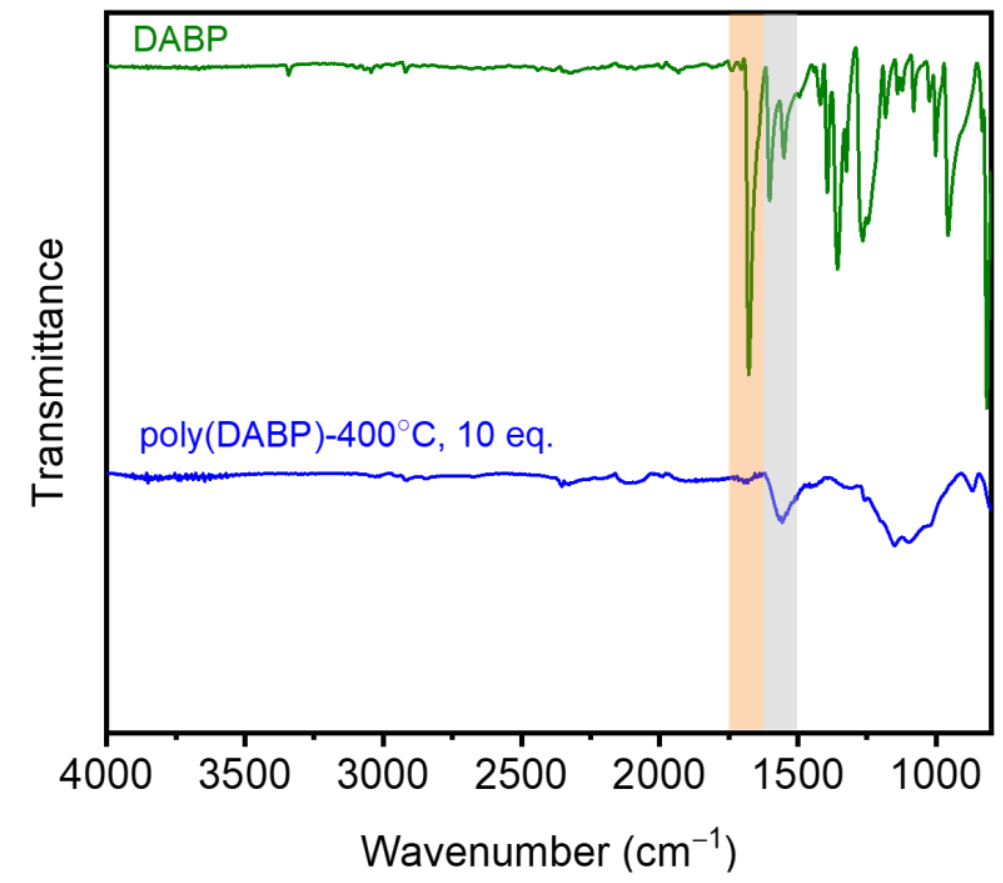

Figure S75. ATR IR spectra of DABP and poly(DABP) synthesized at $400{ }^{\circ} \mathrm{C}$ with 10 equivalents of $\mathrm{ZnCl}_{2}$.

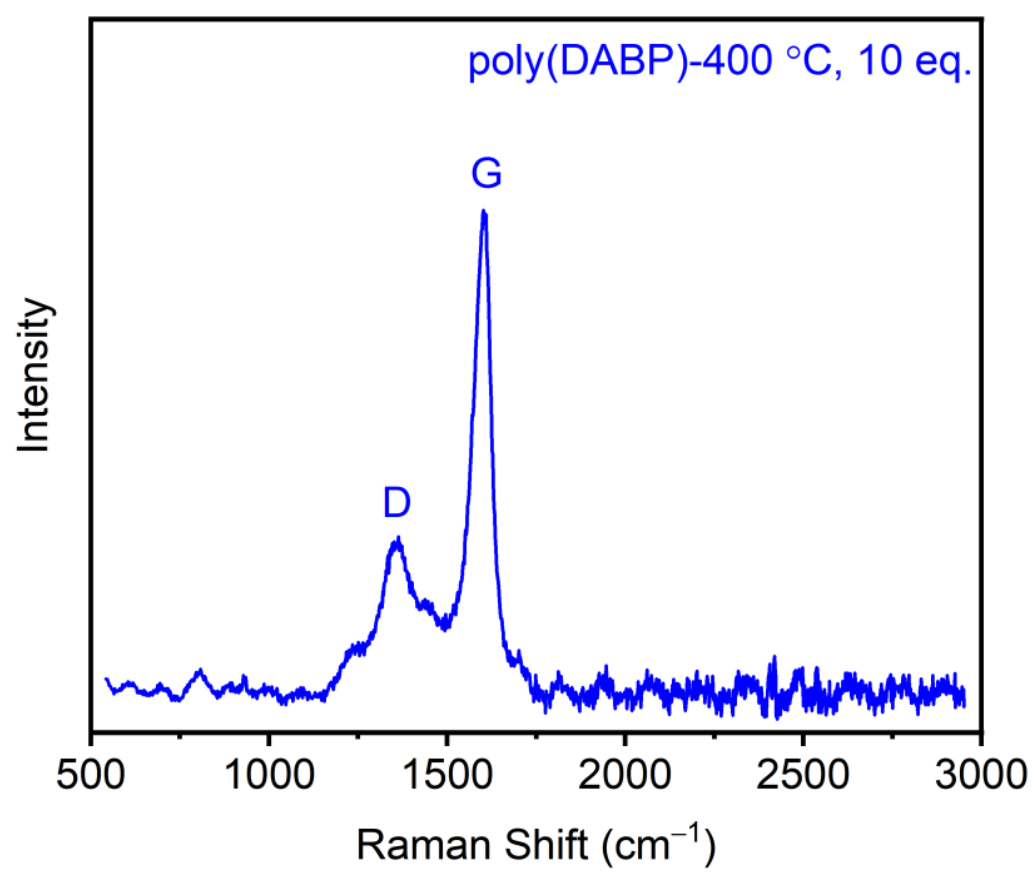

Figure S76. Raman spectrum of poly(DABP) synthesized at $400{ }^{\circ} \mathrm{C}$ with 10 equivalents of $\mathrm{ZnCl}_{2}$. $\mathrm{D}$ and $\mathrm{G}$ bands resembling those of graphene are labelled. ${ }^{4}$ 


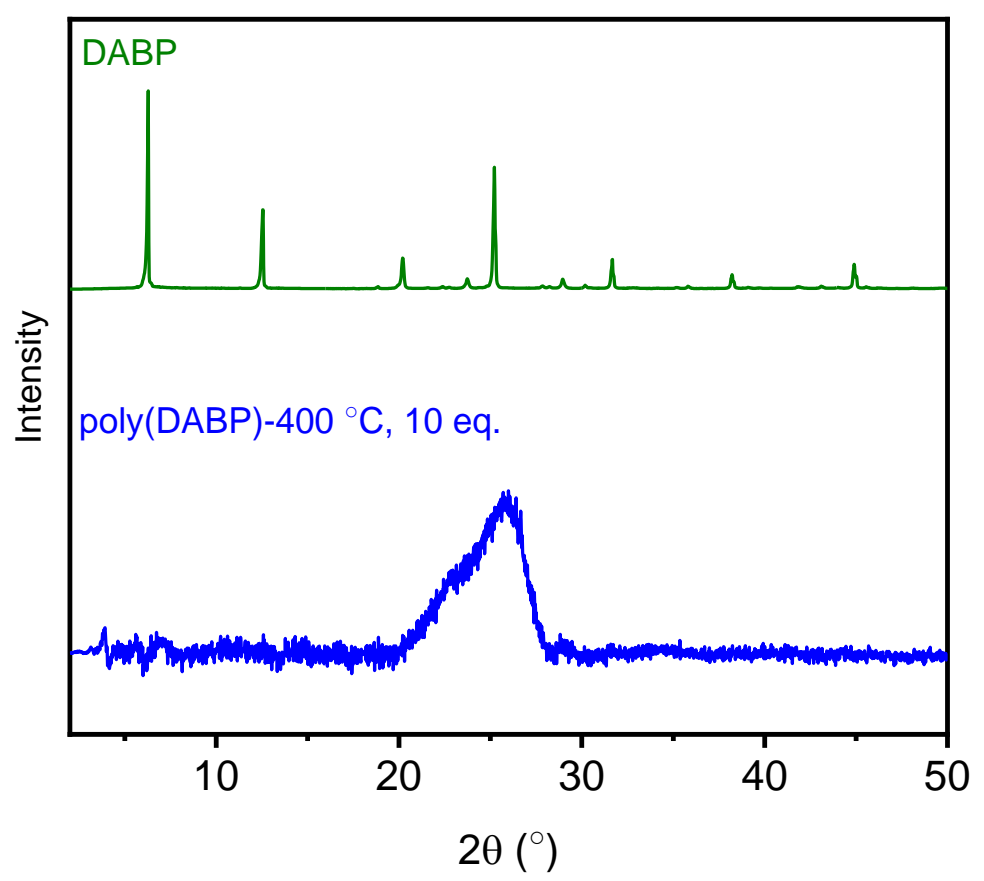

Figure S77. PXRD patterns of DABP and poly(DABP) synthesized at $400{ }^{\circ} \mathrm{C}$ with 10 equivalents of $\mathrm{ZnCl}_{2}$, indicating poly(DABP) is an amorphous polymer.

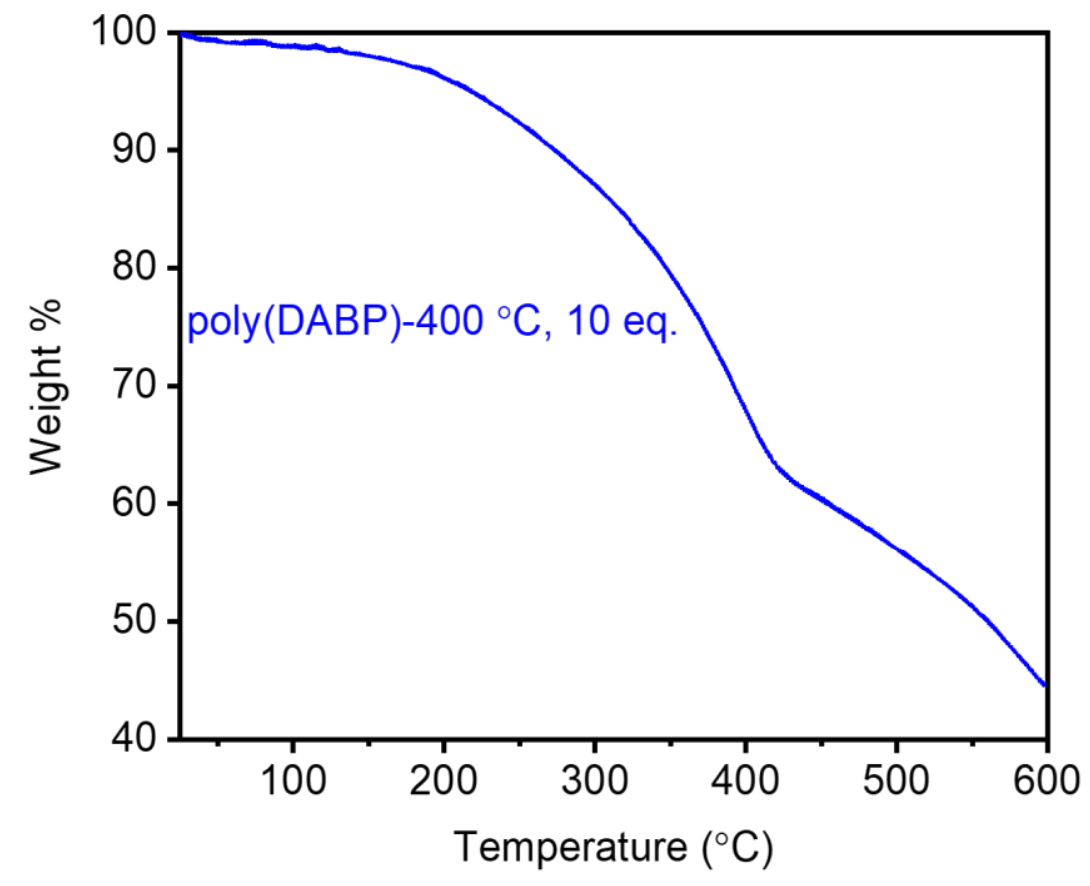

Figure S78. Decomposition profile of poly(DABP) synthesized at $400{ }^{\circ} \mathrm{C}$ with 10 equivalents of $\mathrm{ZnCl}_{2}$. 
<smiles>CC(=O)c1ccc(-c2cc(-c3ccc(C(C)=O)cc3)cc(-c3ccc(C(C)=O)cc3)c2)cc1</smiles>

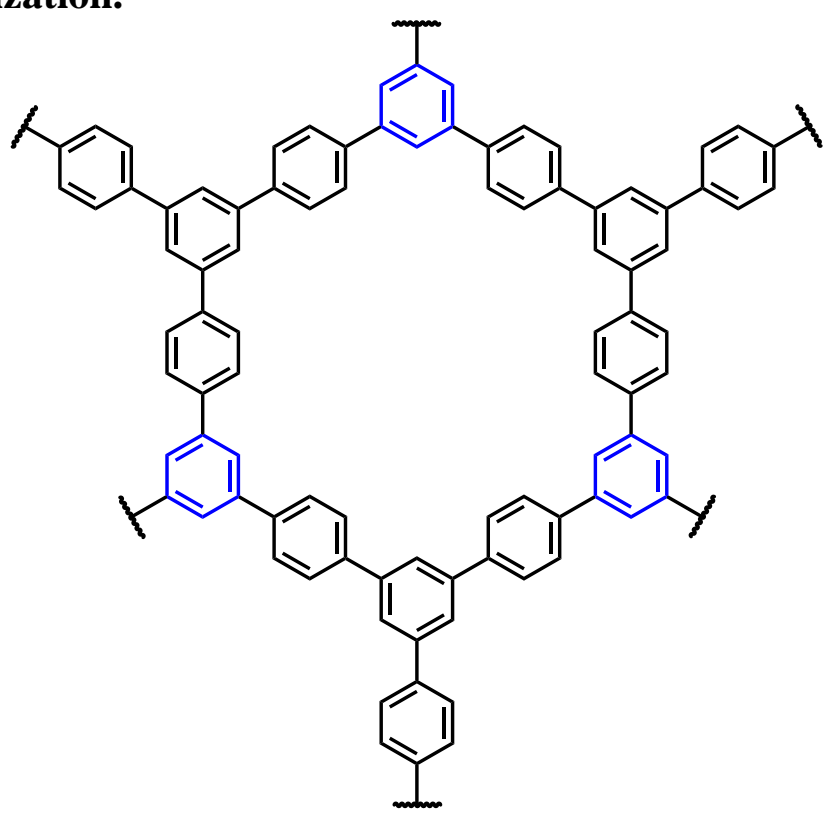

Figure S79. Synthesis of poly(TAPB) from 1,3,5-tris(4-acetylphenyl)benzene.

Following the general procedure, three tubes were charged with 1,3,5-tris(4acetylphenyl)benzene (TAPB) (40.0 mg, $0.168 \mathrm{mmol}, 1.00$ eq.) and $\mathrm{ZnCl}_{2}$ (229 mg, $1.68 \mathrm{mmol}$, 10.0 eq.) and the products were combined to yield poly(TAPB) as a shiny black solid (190 mg).

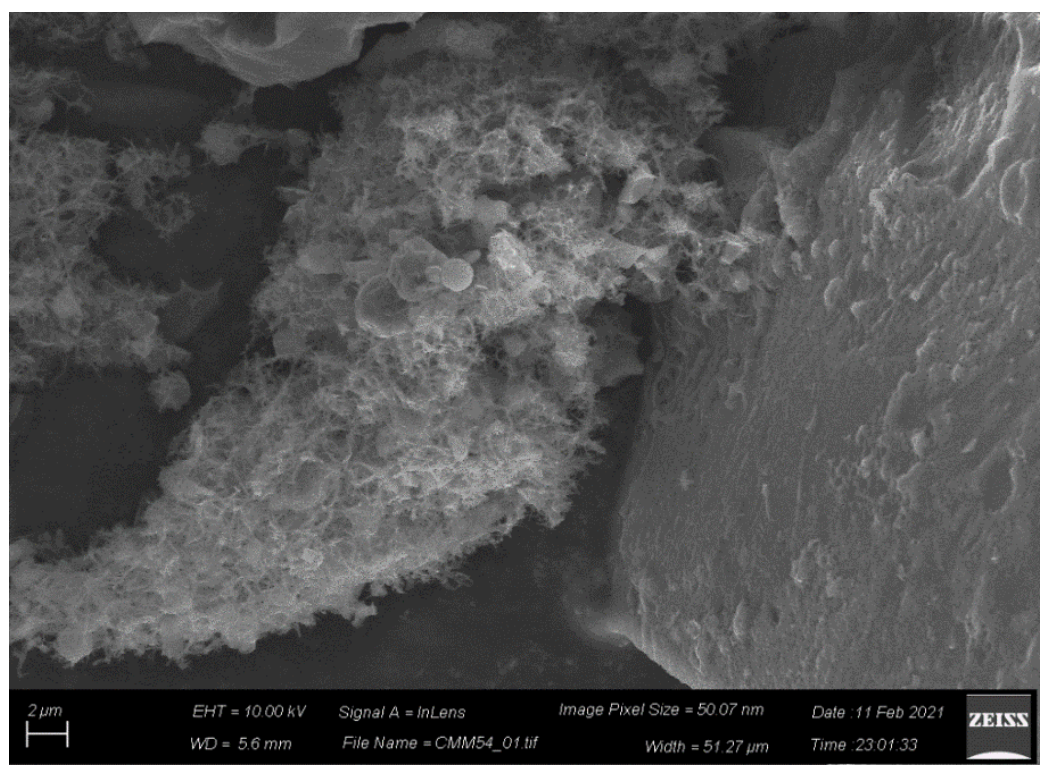

Figure S80. SEM image of poly(TAPB) synthesized at $400{ }^{\circ} \mathrm{C}$ with 10 equivalents of $\mathrm{ZnCl}_{2}$. 


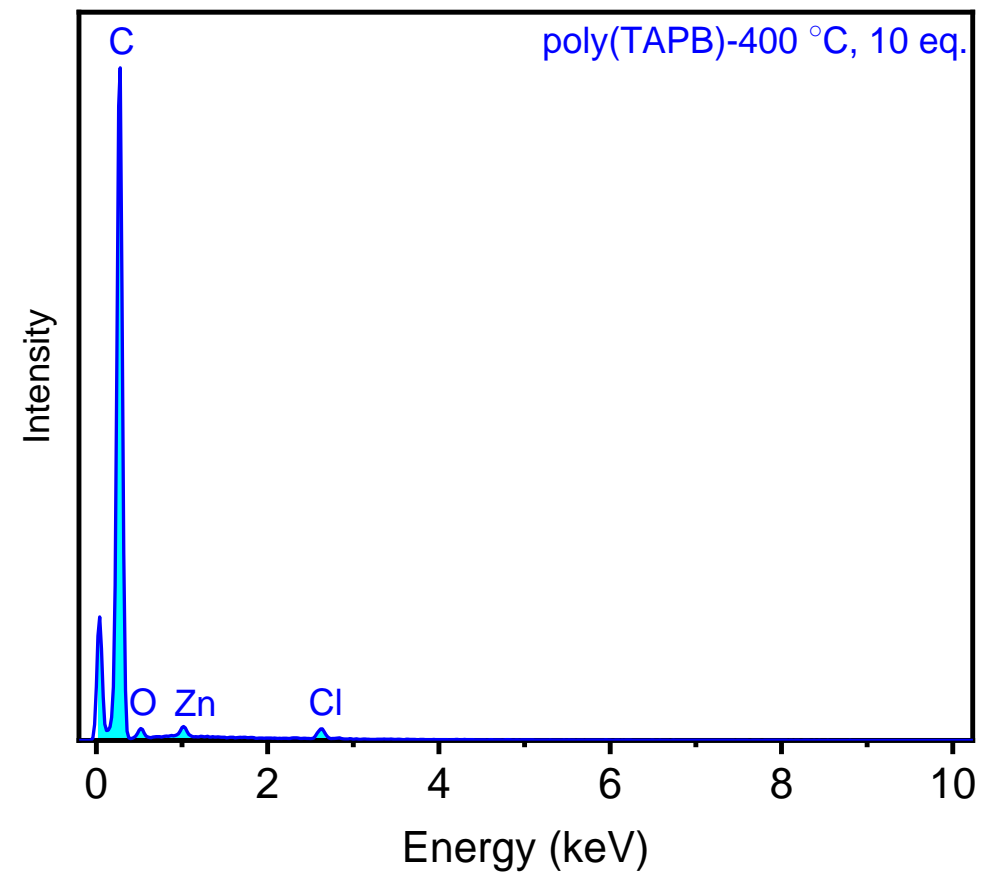

Figure S81. EDS data for poly(TAPB) synthesized at $400{ }^{\circ} \mathrm{C}$ with 10 equivalents of $\mathrm{ZnCl}_{2}$.

Table S10. Tabulated EDS data for poly(TAPB) synthesized at $400{ }^{\circ} \mathrm{C}$ with 10 equivalents of $\mathrm{ZnCl}_{2}$.

\begin{tabular}{|l|c|r|r|r|}
\hline \multicolumn{1}{|c|}{ Element } & Line Type & \multicolumn{1}{c|}{ Wt\% } & Wt\% $\sigma$ & Atomic \% \\
\hline $\mathrm{C}$ & K series & 32.66 & 0.20 & 96.59 \\
\hline $\mathrm{O}$ & K series & 0.98 & 0.06 & 2.18 \\
\hline $\mathrm{Cl}$ & K series & 0.86 & 0.04 & 0.86 \\
\hline $\mathrm{Zn}$ & L series & 0.68 & 0.06 & 0.37 \\
\hline Total: & & 35.18 & & 100.00 \\
\hline
\end{tabular}




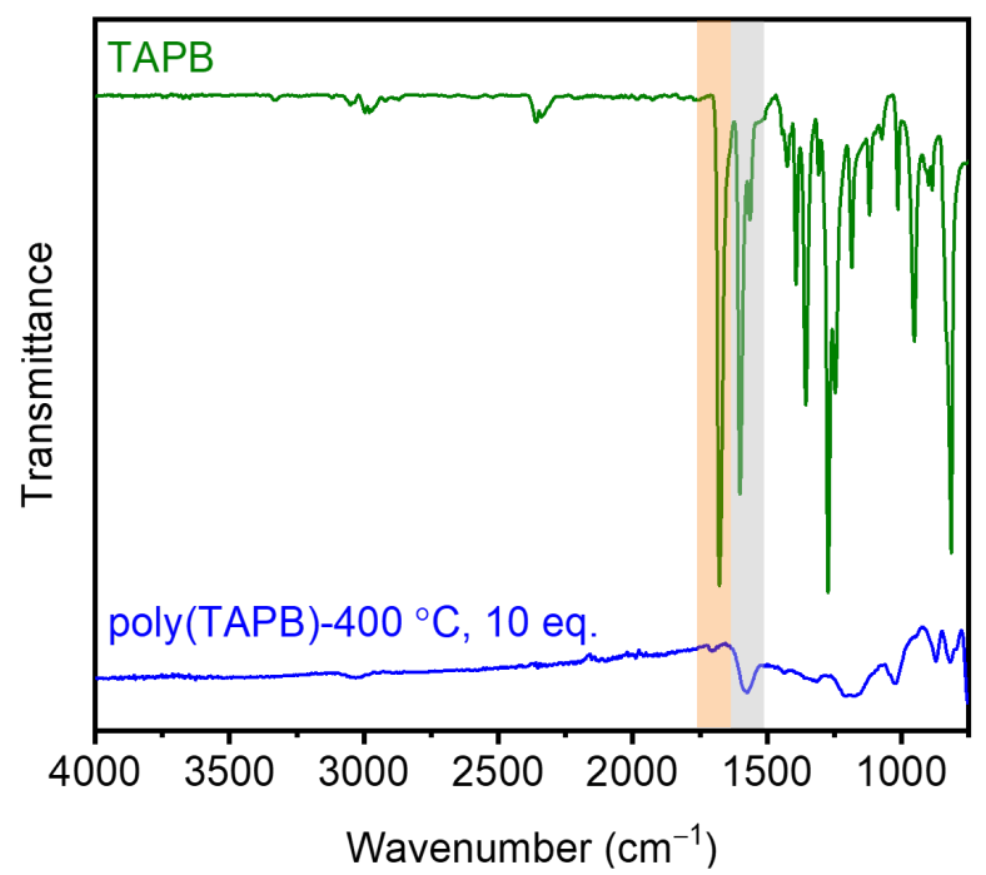

Figure S82. ATR IR spectra of TAPB and poly(TAPB) synthesized at $400{ }^{\circ} \mathrm{C}$ with 10 equivalents of $\mathrm{ZnCl}_{2}$.

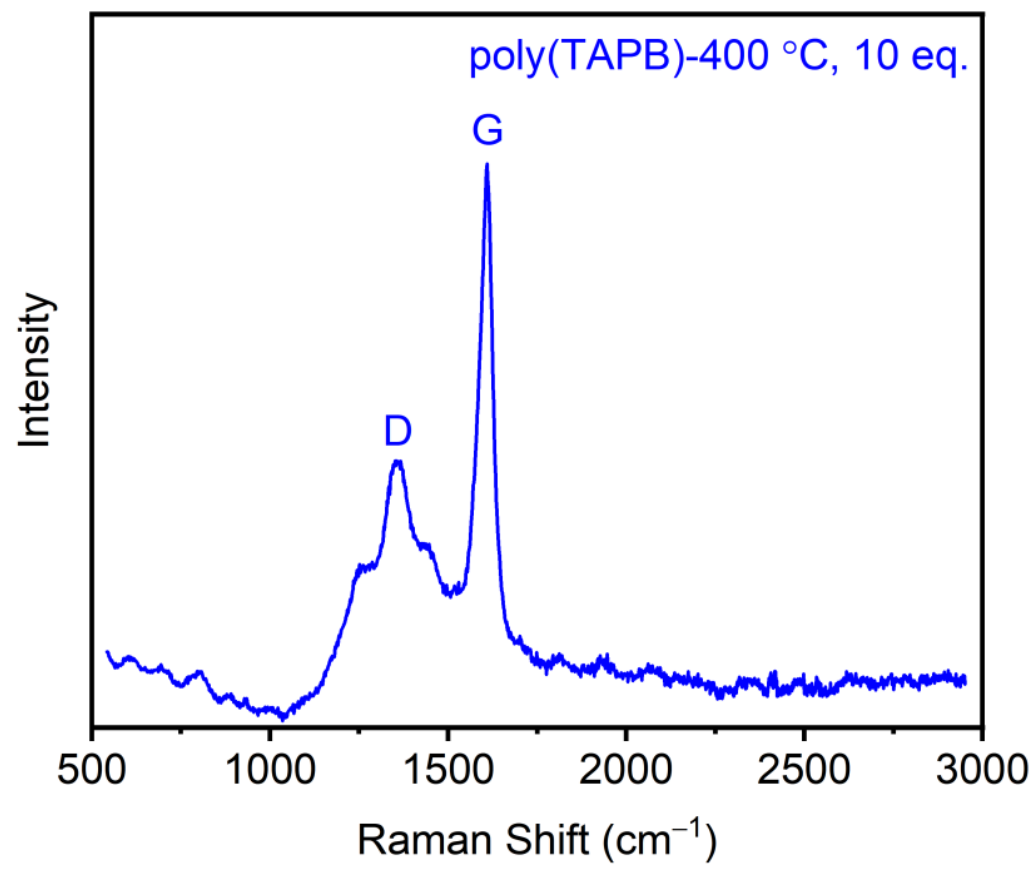

Figure S83. Raman spectrum of poly(TAPB) synthesized at $400{ }^{\circ} \mathrm{C}$ with 10 equivalents of $\mathrm{ZnCl}_{2}$. $\mathrm{D}$ and $\mathrm{G}$ bands resembling those of graphene are labelled. ${ }^{4}$ 


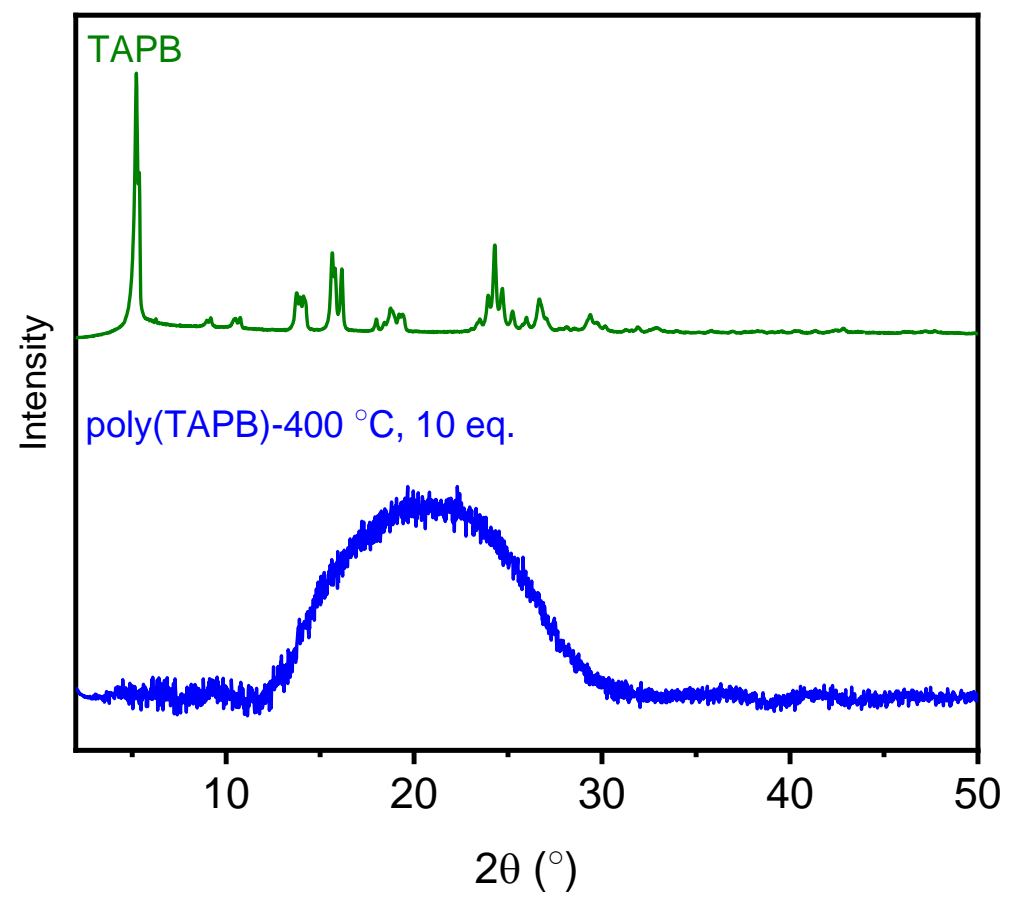

Figure S84. PXRD patterns of TAPB and poly(TAPB) synthesized at $400{ }^{\circ} \mathrm{C}$ with 10 equivalents of $\mathrm{ZnCl}_{2}$, indicating that poly(TAPB) is an amorphous polymer.

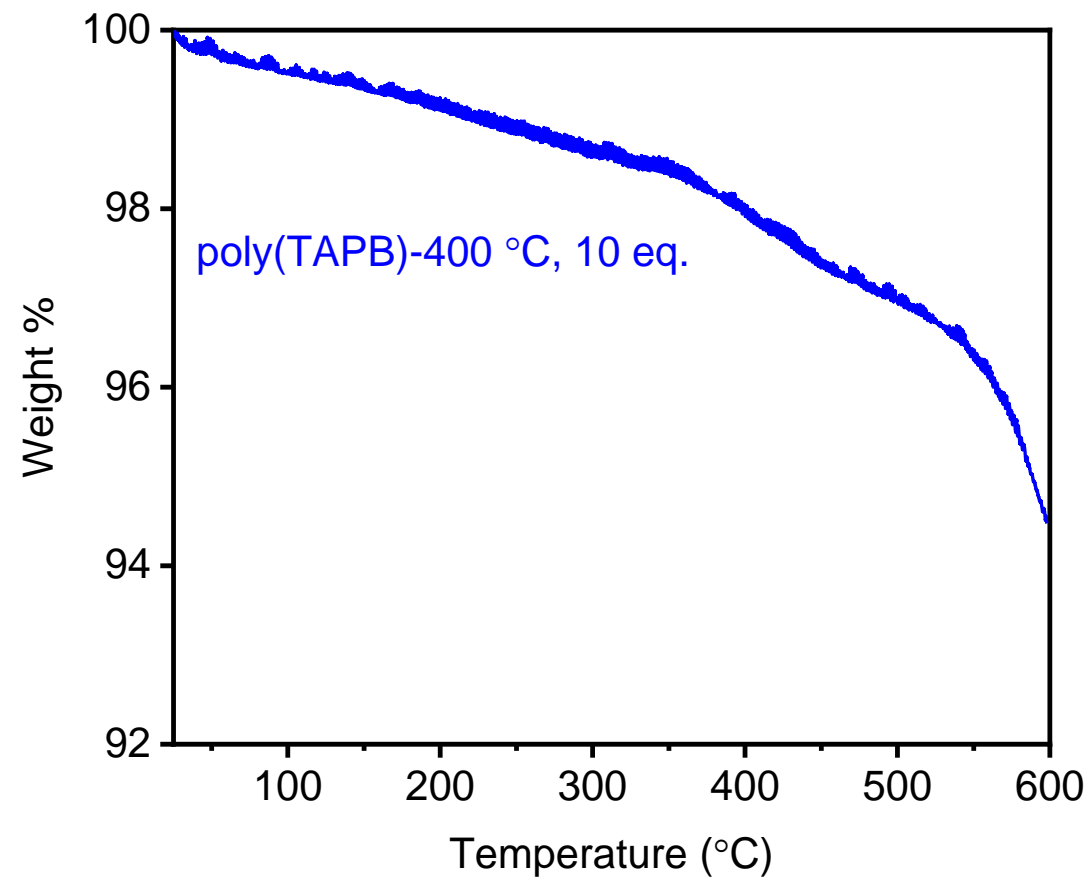

Figure S85. Decomposition profile of poly(TAPB) synthesized at $400{ }^{\circ} \mathrm{C}$ with 10 equivalents of $\mathrm{ZnCl}_{2}$. 


\section{f. 1,3,5-tris(4-acetylphenyl)-triazine trimerization.}<smiles>CC(=O)c1ccc(-c2nc(-c3ccc(C(C)=O)cc3)nc(-c3ccc(C(C)=O)cc3)n2)cc1</smiles><smiles>Cc1cc(-c2ccc(-c3nc(-c4ccc(-c5ccc(-c6ccc(C(C)C)cc6)cc5)cc4)nc(-c4ccc(-c5ccc(-c6ccc(C(C)C)cc6)cc5)cc4)n3)cc2)ccc1-c1ccc(-c2nc(-c3ccc(-c4ccc(C(C)C)cc4)cc3)nc(-c3ccc(C(C)C)cc3)n2)cc1</smiles>

Figure S86. Synthesis of poly(TAPT) from 1,3,5-tris(4-acetylphenyl)-triazine (TAPT) and $\mathrm{ZnCl}_{2}$.

Following the general procedure, three tubes were charged with 1,3,5-tris(4acetylphenyl)triazine (TAPT) $\left(40.0 \mathrm{mg}, 0.168 \mathrm{mmol}, 1.00\right.$ eq.) and $\mathrm{ZnCl}_{2}(229 \mathrm{mg}, 1.68 \mathrm{mmol}$, 10.0 eq.) and the products were combined to yield poly(TAPT) as a shiny black solid $(47.0 \mathrm{mg})$.

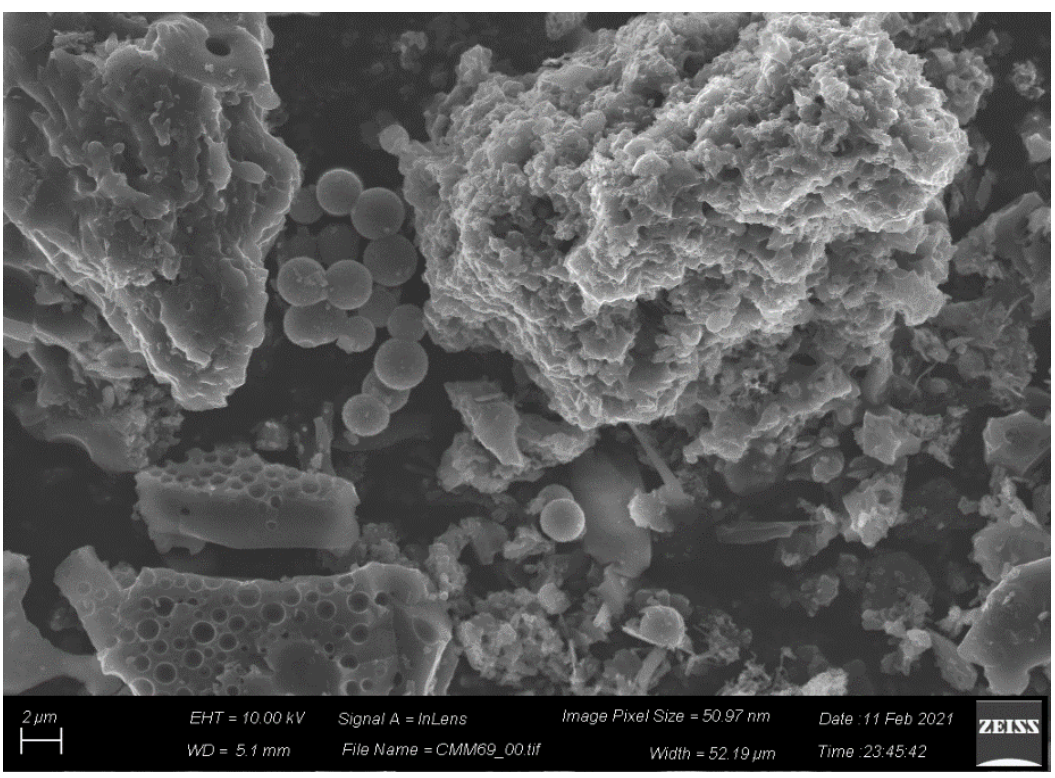

Figure S87. SEM image of poly(TAPT) synthesized at $400{ }^{\circ} \mathrm{C}$ with 10 equivalents of $\mathrm{ZnCl}_{2}$. 


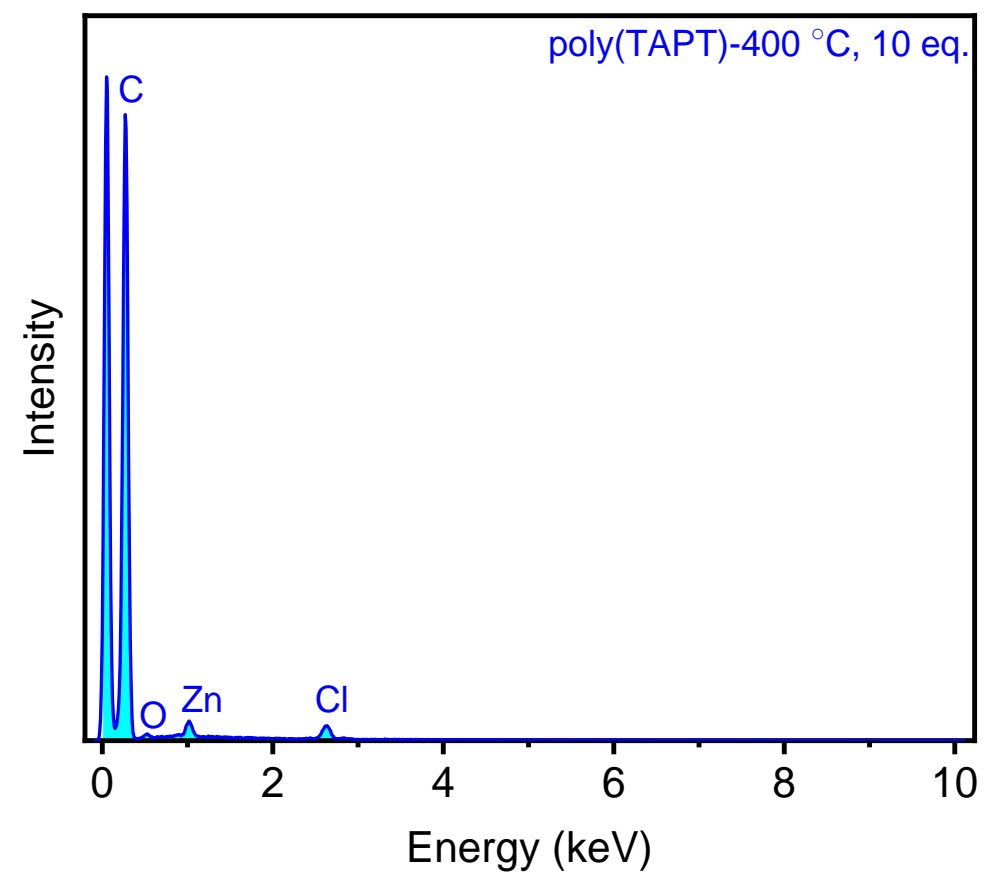

Figure S88. EDS data for poly(TAPT) synthesized at $400{ }^{\circ} \mathrm{C}$ with 10 equivalents of $\mathrm{ZnCl}_{2}$.

Table S11. Tabulated EDS data for poly(TAPT) synthesized at $400{ }^{\circ} \mathrm{C}$ with 10 equivalents of $\mathrm{ZnCl}_{2}$.

\begin{tabular}{|c|c|c|c|c|}
\hline Element & Line Type & Wt $\%$ & Wt $\% \sigma$ & Atomic $\%$ \\
\hline $\mathrm{C}$ & K series & 36.1 & 0.24 & 97.43 \\
\hline $\mathrm{O}$ & K series & 0.43 & 0.05 & 0.87 \\
\hline $\mathrm{Cl}$ & K series & 1.23 & 0.05 & 1.12 \\
\hline $\mathrm{Zn}$ & L series & 1.17 & 0.08 & 0.58 \\
\hline $\mathrm{N}$ & N/A & N/A & N/A & N/A \\
\hline Total: & & 9.21 & & 100.00 \\
\hline
\end{tabular}




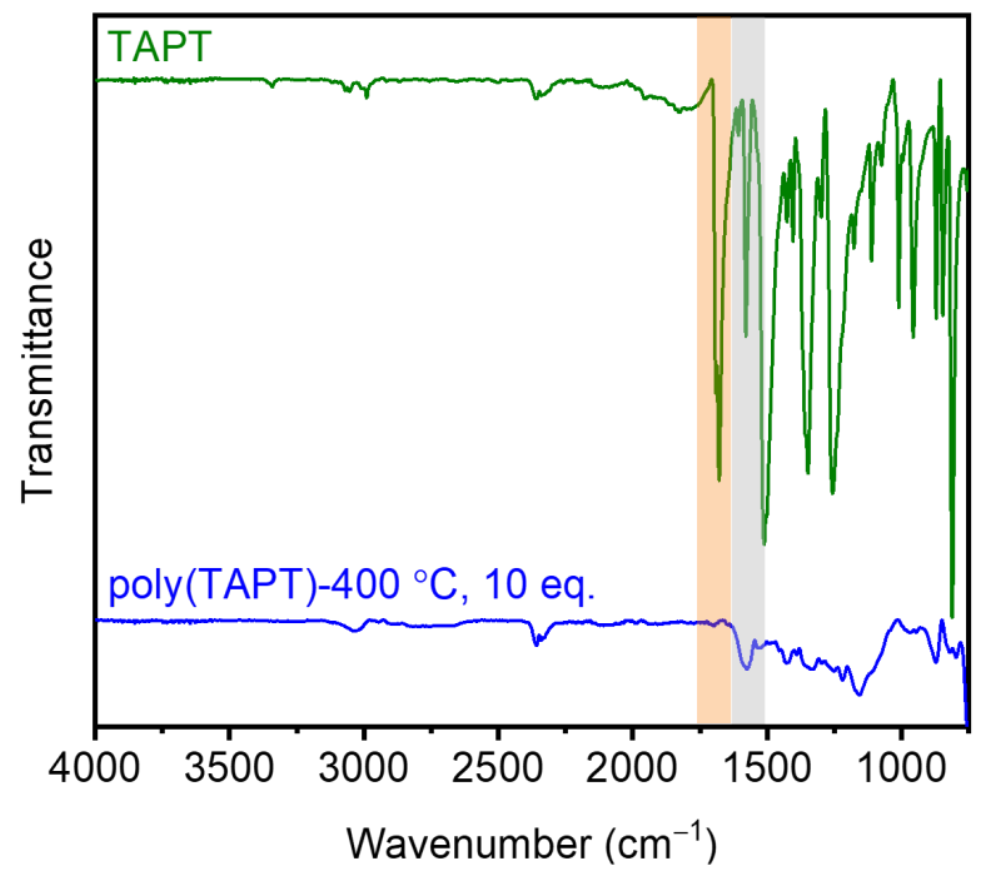

Figure S89. ATR IR spectra of TAPT and poly(TAPT) synthesized at $400{ }^{\circ} \mathrm{C}$ with 10 equivalents of $\mathrm{ZnCl}_{2}$.

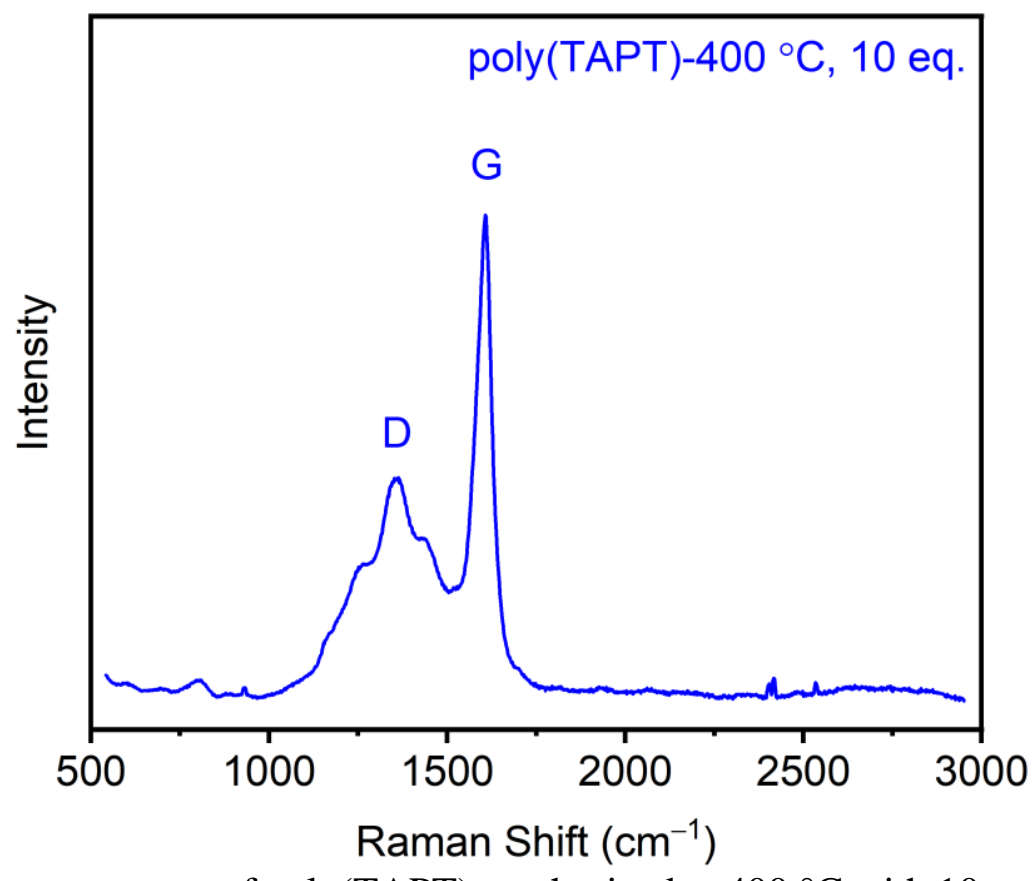

Figure S90. Raman spectrum of poly(TAPT) synthesized at $400{ }^{\circ} \mathrm{C}$ with 10 equivalents of $\mathrm{ZnCl}_{2}$. $\mathrm{D}$ and $\mathrm{G}$ bands resembling those of graphene are labelled. ${ }^{4}$ 


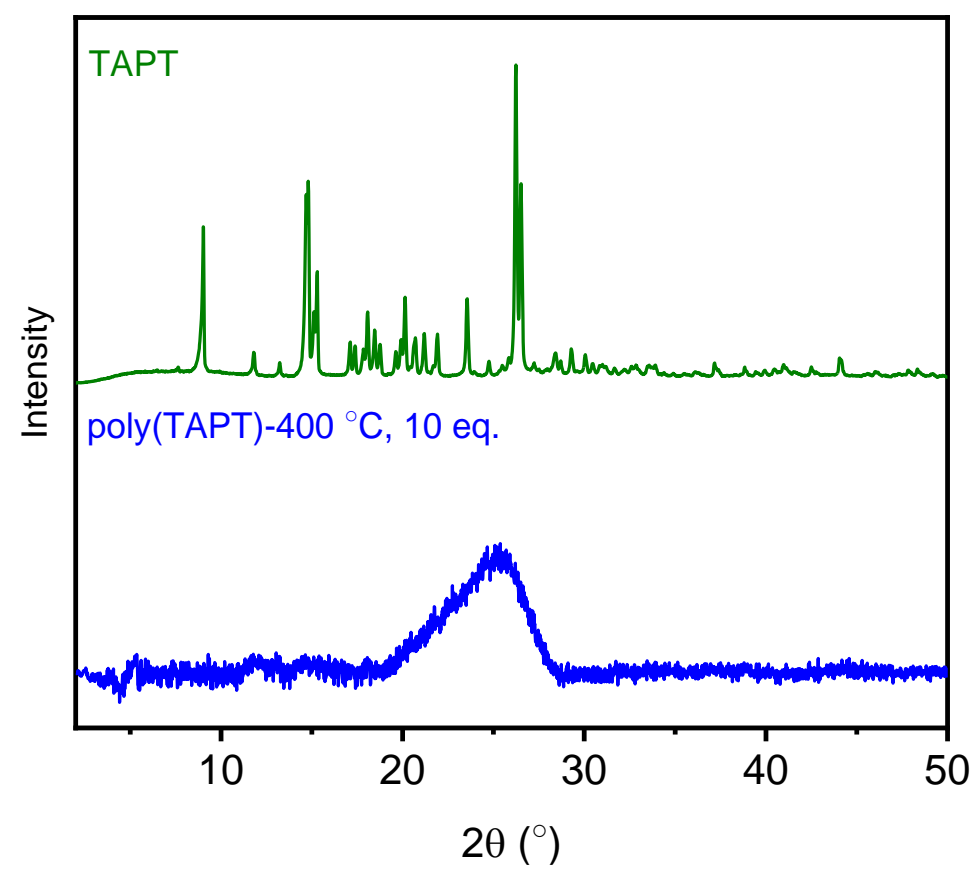

Figure S91. PXRD pattern of TAPT and poly(TAPT) synthesized at $400{ }^{\circ} \mathrm{C}$ with 10 equivalents of $\mathrm{ZnCl}_{2}$, indicating that poly(TAPT) is an amorphous polymer.

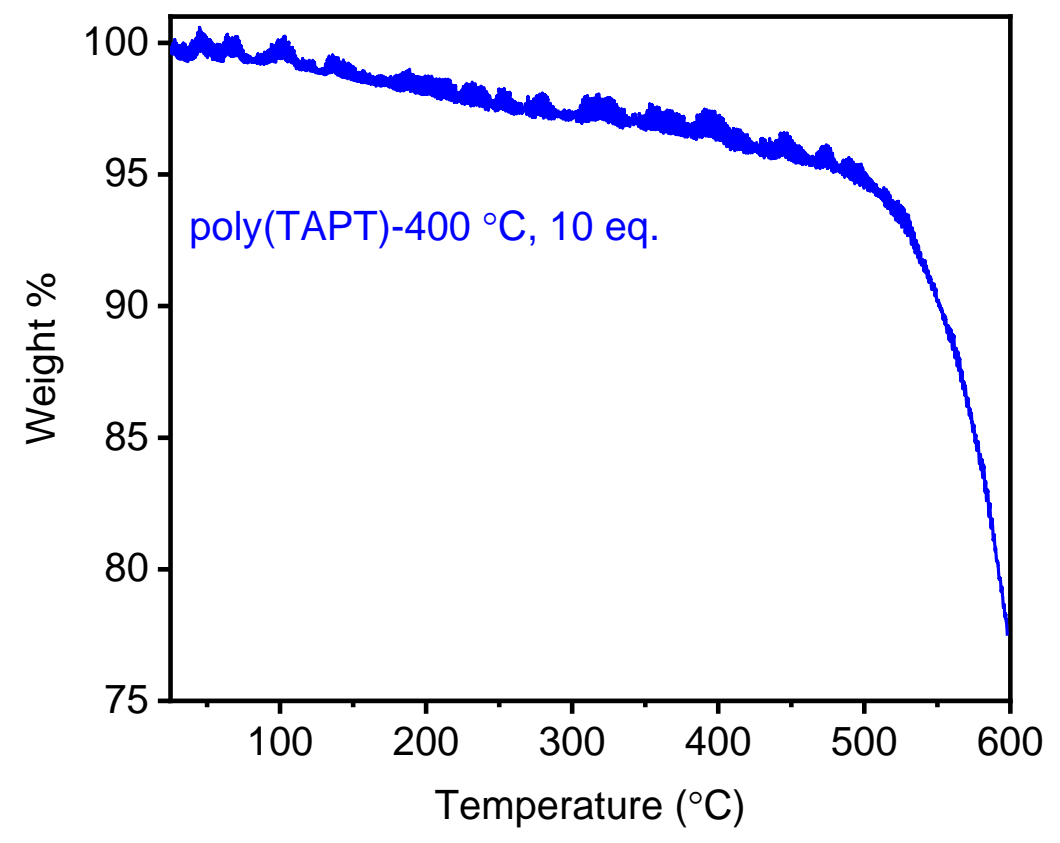

Figure S92. Decomposition profile of poly(TAPT) synthesized at $400{ }^{\circ} \mathrm{C}$ with 10 equivalents of $\mathrm{ZnCl}_{2}$ 


\section{Electrochemical Measurements of TAB-CMP-400 ${ }^{\circ} \mathrm{C}, 5.0 \mathrm{eq}$.}

\section{Electrode Preparation.}

The TAB-CMP-400 ${ }^{\circ} \mathrm{C}, 5.0$ eq. composite electrode was prepared by mixing the active material TAB-CMP- $400{ }^{\circ} \mathrm{C}, 5.0$ eq., Super P carbon, and polytetrafluoroethylene (PTFE) at a mass ratio of 80:10:10 in ethanol. The resulting paste was pressed onto a Ni foam current collector and dried at $110^{\circ} \mathrm{C}$ in a vacuum oven overnight. The dried electrodes were then pressed flat and used for electrochemical measurements. For comparison to commercial supercapacitor materials, composite electrodes were prepared following the same procedure with Supercapacitor Activated Carbon (MTI Corporation) as the active material.

Electrochemical measurements were performed in a three-compartment cell. The TAB-CMP$400{ }^{\circ} \mathrm{C}, 5.0$ eq. composite was used as the working electrode, with a $\mathrm{Ag} / \mathrm{AgCl}$ reference electrode and a Pt wire as the counter electrode. The electrolyte solution was $1.5 \mathrm{M}$ tetraethylammonium tetrafluoroborate in $\mathrm{MeCN}$. Prior to the measurements, the solution was degassed with Ar to remove dissolved oxygen. The electrochemical measurements were done using a Biologic SP200 potentiostat.

Cyclic voltammetry (CV) measurements were performed at scan rates from $0.5-20 \mathrm{mV} \mathrm{s}^{-1}$. Preliminary voltametric scans of the material were performed at $20 \mathrm{mV} \mathrm{s}^{-1}$ from which the highest capacitance potential range was identified $(-0.5$ to $-1.75 \mathrm{~V}$ vs. $\mathrm{Ag} / \mathrm{AgCl})$. This range was used as the potential cutoffs for further voltametric analysis. Capacitance values $(C)$ from $\mathrm{CV}$ were calculated by the following equation:

$$
C=\frac{i}{v \times m}
$$

where $i$ is the current, $v$ is the sweep rate in $\mathrm{V} \mathrm{s}^{-1}$, and $m$ is the mass of the active material.

Galvanostatic charge/discharge experiments were performed from -1.0 to $-1.8 \mathrm{~V}$ vs. $\mathrm{Ag} / \mathrm{AgCl}$ at current densities from $0.1-10 \mathrm{~A} \mathrm{~g}^{-1}$. Capacitance was evaluated from the discharge curve by the following equation:

$$
C=\frac{i \times t}{V \times m}
$$

where $i$ is the current, $t$ is the time of discharge, $\mathrm{V}$ is the voltage range $(0.8 \mathrm{~V})$, and $m$ is the mass of the active material.

Potentiostatic electrochemical impedance spectroscopy (PEIS) was conducted on fresh electrodes at $-1.0 \mathrm{~V}$ vs. $\mathrm{Ag} / \mathrm{AgCl}$. The frequency was swept from $100 \mathrm{kHz}$ to $10 \mathrm{mHz}$ using a 5 $\mathrm{mV}$ amplitude. The imaginary capacitance $\left(\mathrm{C}^{\prime \prime}\right)$ was evaluated by the following equation:

$$
C^{\prime \prime}=\frac{Z^{\prime}}{2 \pi f|Z|^{2}}
$$

where $f$ is the frequency in $\mathrm{Hz}, \mathrm{Z}^{\prime}$ is the real impedance, and $|\mathrm{Z}|$ is the magnitude of the impedance. 


\section{Conductivity Measurements.}

The conductivity of TAB-CMP-400 ${ }^{\circ} \mathrm{C}, 5.0$ eq. was measured using the two-point probe method. Approximately $30 \mathrm{mg}$ of TAB-CMP- $400{ }^{\circ} \mathrm{C}, 5.0$ eq. was placed between two stainless steel probes with a contact area (A) of $0.792 \mathrm{~cm}^{2}$ held together in a Teflon tube encasing. A series of small potential pulses $(2-20 \mathrm{mV})$ were applied across the sample, and from the current response, an I-V curve was generated, from which a slope was extracted to provide the resistance $(\mathrm{R})$ of the sample (Figure S78). The conductivity $(\sigma)$ was calculated using the following equation:

$$
\sigma=\frac{t}{R \times A}
$$

where $t$ is the thickness of the active material between the two metal probes, $\mathrm{R}$ is the resistance, and $\mathrm{A}$ is the contact area. The conductivity of the sample was determined to be $5.7 \times 10^{-5} \mathrm{~S} \mathrm{~cm}^{-1}$. The above procedure was followed for OFC-1b and tri-PPN as well (Figure S102 and Figure S109).

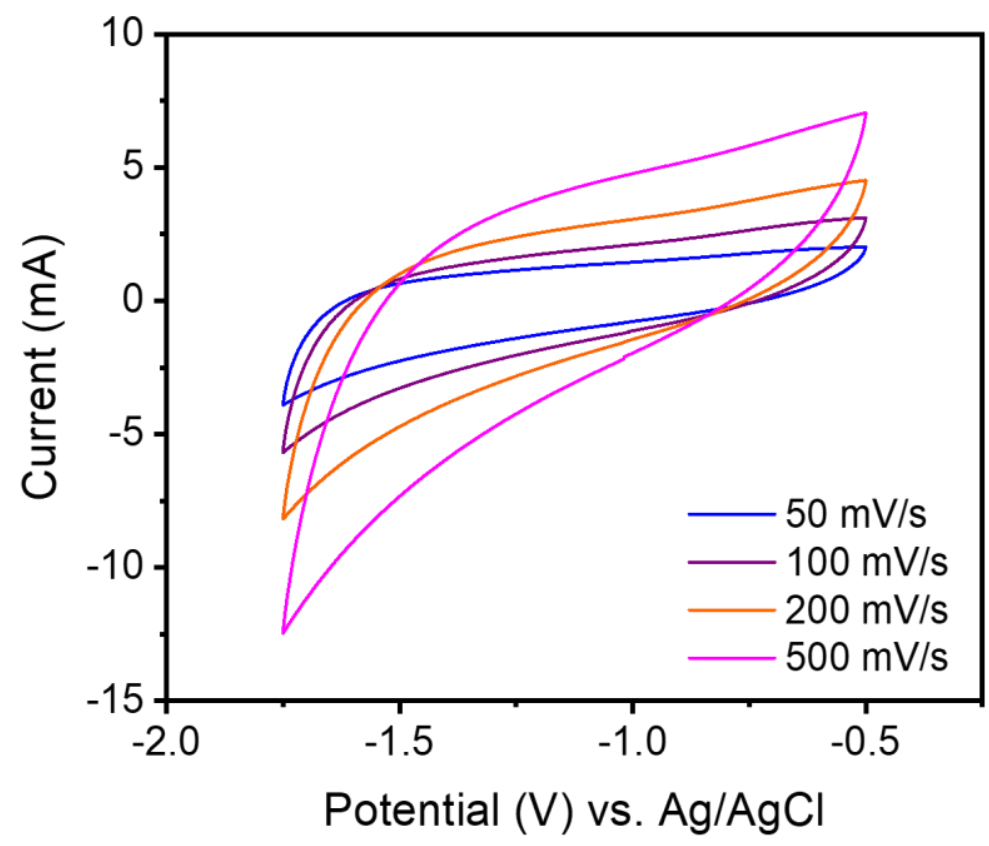

Figure S93. CV measurements of TAB-CMP-400 ${ }^{\circ} \mathrm{C}, 5.0$ eq. at fast sweep rates. At fast sweep rates, the capacitive contribution to the current will dominate the observed current response, while diffusion-limited processes will be suppressed. 


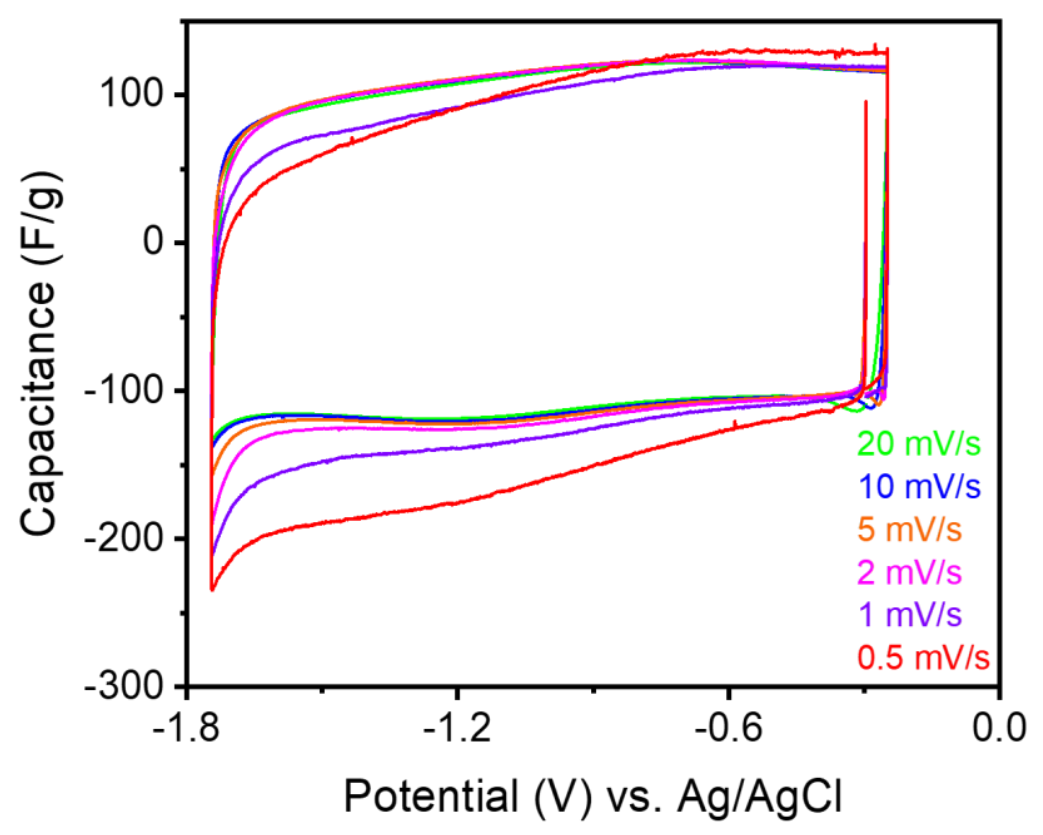

Figure S94. Cyclic voltammetry (CV) measurements of Supercapacitor Activated Carbon (MTI Corporation) at different sweep rates.
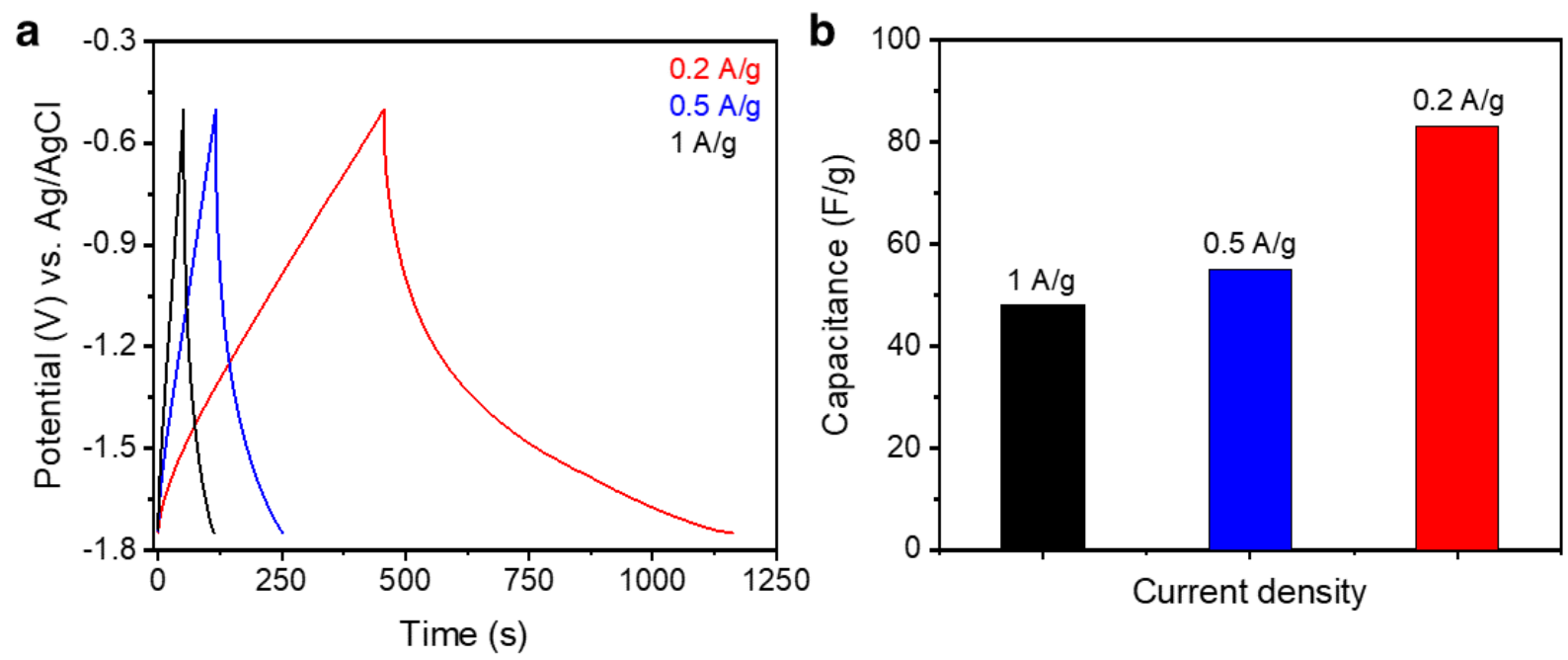

Figure S95. a) Galvanostatic charge-discharge measurements of TAB-CMP- $400{ }^{\circ} \mathrm{C}, 5.0$ eq. carried out over a wider potential window than the measurements in Figure 7 of the main text. b) Capacitances determined from charge-discharge measurements. 

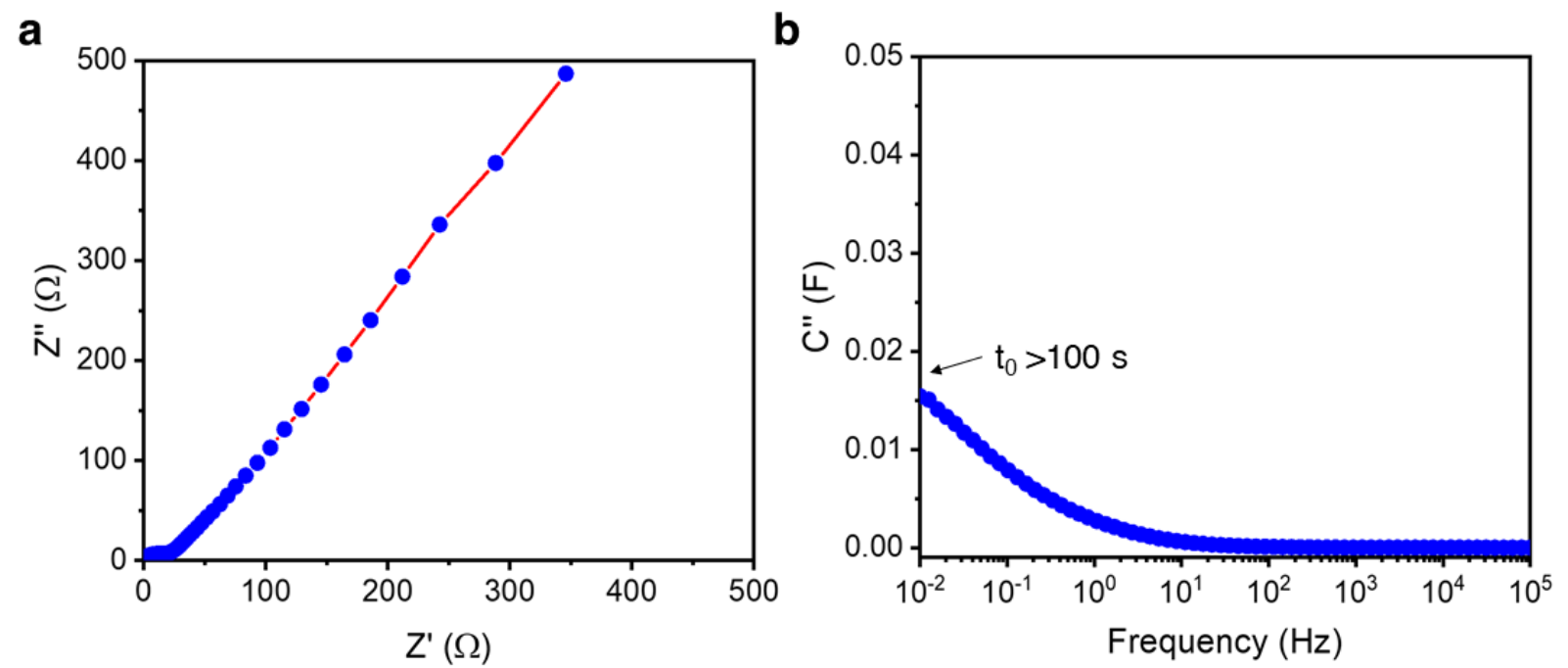

Figure S96. PEIS spectroscopy measurements of TAB-CMP-400 ${ }^{\circ} \mathrm{C}, 5.0$ eq. at $-1.0 \mathrm{~V}$ vs. $\mathrm{Ag} / \mathrm{AgCl}$. a) Nyquist plot and b) plot of imaginary component of the capacitance $\left(\mathrm{C}^{\prime \prime}\right) \mathrm{vs}$. $\mathrm{AC}$ frequency. $t_{0}$ represents the minimum time required to reach $50 \%$ of the material's maximum capacitance.
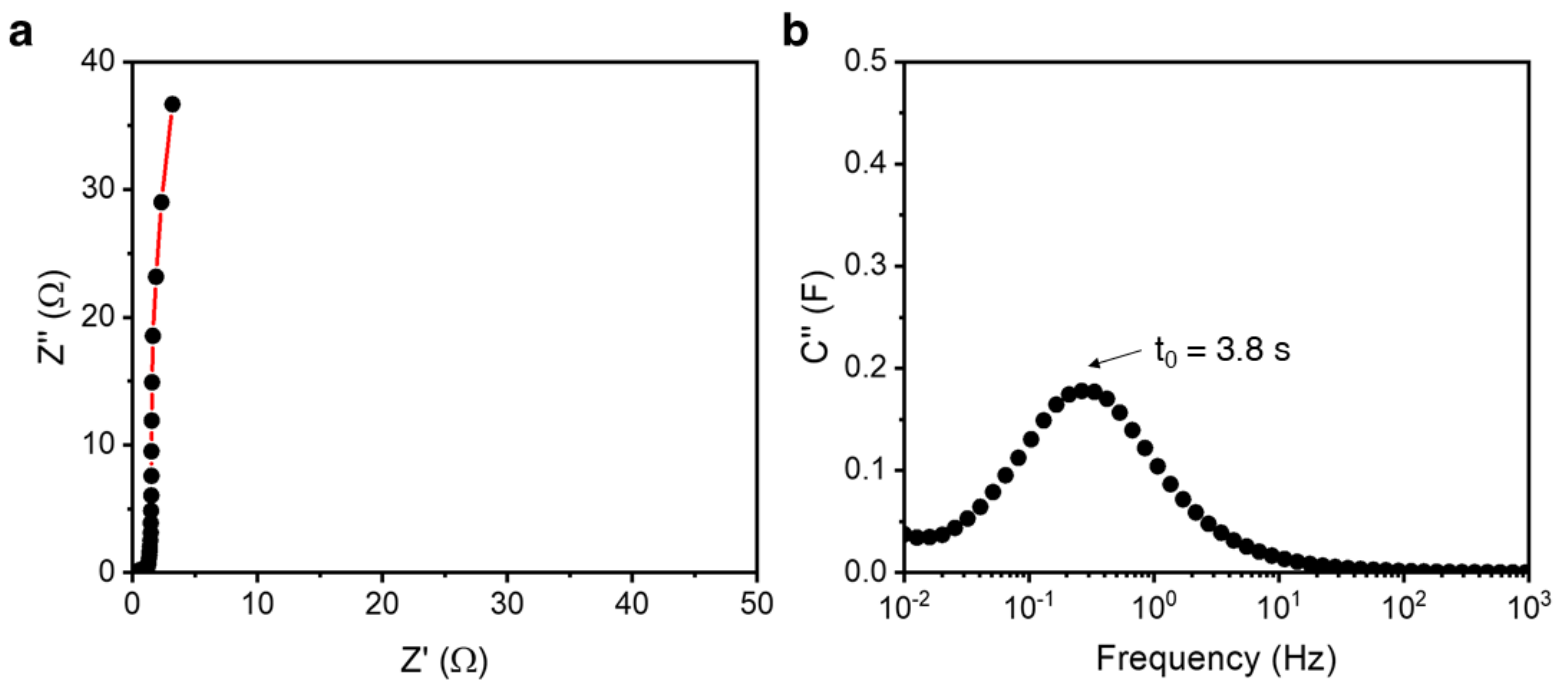

Figure S97. Potentiostatic electrochemical impedance spectroscopy measurements of Supercapacitor Activated Carbon (MTI Corporation). to represents the minimum time required to reach $50 \%$ of the material's maximum capacitance. 


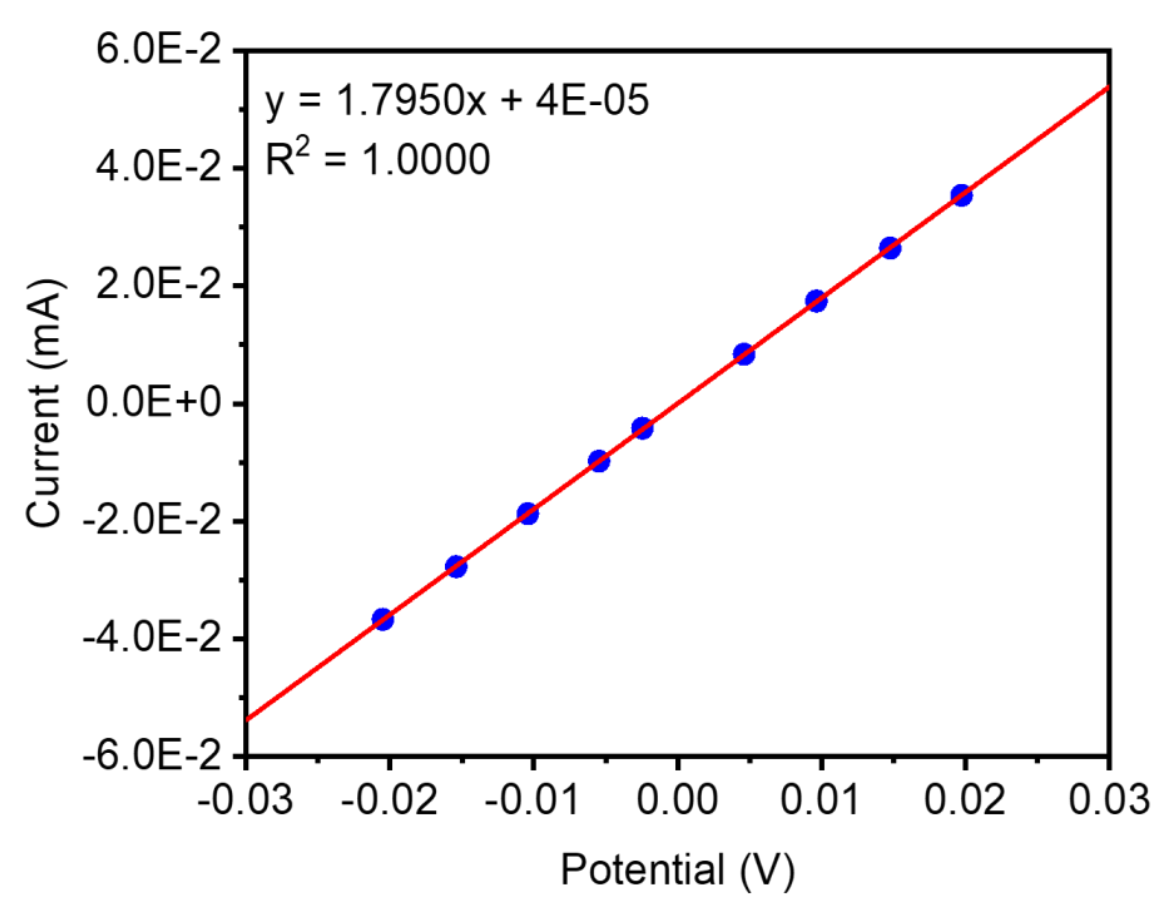

Figure S98. Two-point probe conductivity measurement of TAB-CMP-400 ${ }^{\circ} \mathrm{C}, 5.0$ eq., indicating that this material displays Ohmic conductor behavior with a resistance of $560 \Omega$. This results in a conductivity of $5.7 \times 10^{-5} \mathrm{~S} / \mathrm{cm}$ for the apparatus that squeezed the powder to dimensions of 0.25 $\mathrm{mm}$ in length and $10.04 \mathrm{~mm}$ in diameter. 


\section{Synthesis and characterization of $\mathrm{OFC}-1 \mathrm{~b}$.}

OFC-1b was prepared according to a modified literature procedure. ${ }^{5}$ Three $12 \mathrm{~mm}$ diameter borosilicate glass tubes were each charged with 1,4-diacetylbenzene $(40.0 \mathrm{mg}, 0.247 \mathrm{mmol}, 1.00$ eq.) and $p$-toluenesulfonic acid monohydrate $(469 \mathrm{mg}, 2.47 \mathrm{mmol}, 10.0 \mathrm{eq}$.). The tubes were evacuated ( $<100 \mathrm{mTorr}$ ), and then flame-sealed under high vacuum using a natural gas torch and a custom-built apparatus (Figure S13). The tubes were placed in an oven and heated at $110{ }^{\circ} \mathrm{C}$ for $72 \mathrm{~h}$. The tubes were cooled to room temperature and were snapped into two pieces using a glass tube cutter. The dark red reaction mixture was scraped out of the tubes with a Hayman Style spatula, using water $(10 \mathrm{~mL})$ to help slide the mixture off the tube walls. The reaction mixtures from all three tubes were combined in a $100 \mathrm{~mL}$ jar and suspended in $3 \mathrm{M} \mathrm{HCl}(40 \mathrm{~mL})$. The suspension was allowed to stir for $48 \mathrm{~h}$. The heterogeneous mixture was filtered, and the resulting dark red solid was rinsed with water $(3 \times 5 \mathrm{~mL})$ and THF $(3 \times 5 \mathrm{~mL})$. The solid was transferred to a $20 \mathrm{~mL}$ scintillation vial filled with THF and allowed to stand for $24 \mathrm{~h}$ at room temperature, after which the THF was decanted off and replaced with fresh THF. This soaking process was repeated two more times for a total of three THF soaks. After the third THF soak, the THF was decanted from the solid and replaced with acetone. The vial was allowed to stand for $24 \mathrm{~h}$ at room temperature, after which the acetone was decanted from the solid and replaced with fresh acetone. This soaking process was repeated two more times for a total of three acetone soaks. The acetone was decanted, and the red solid $(107 \mathrm{mg})$ was oven-dried at $120{ }^{\circ} \mathrm{C}$ for $6 \mathrm{~h}$ and then allowed to cool to room temperature. 


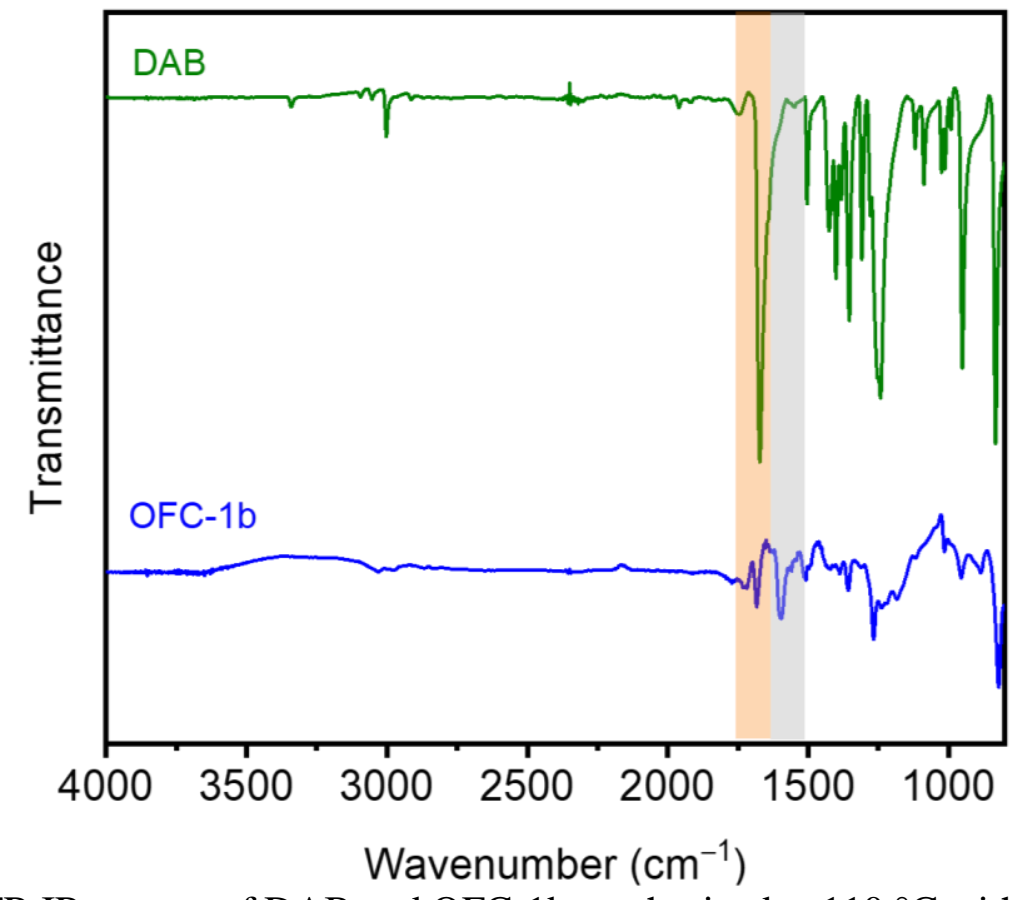

Figure S99. ATR IR spectra of DAB and OFC-1b synthesized at $110^{\circ} \mathrm{C}$ with 10 equivalents of $p$ toluenesulfonic acid monohydrate, indicating the significant presence of residual carbonyl groups.

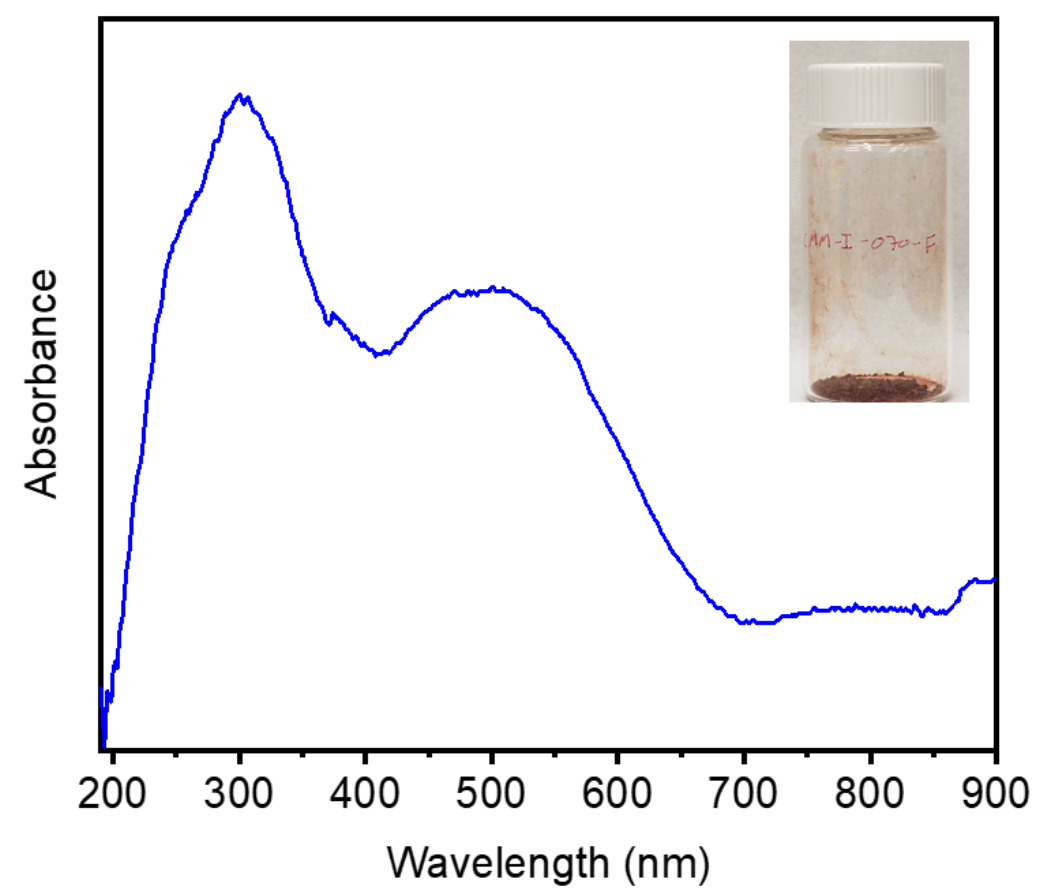

Figure S100. Solid-state UV-Vis absorption spectrum of OFC-1b synthesized at $110{ }^{\circ} \mathrm{C}$ with 10 equivalents of $p$-toluenesulfonic acid monohydrate. Inset: image of OFC-1b, which is a red solid. 


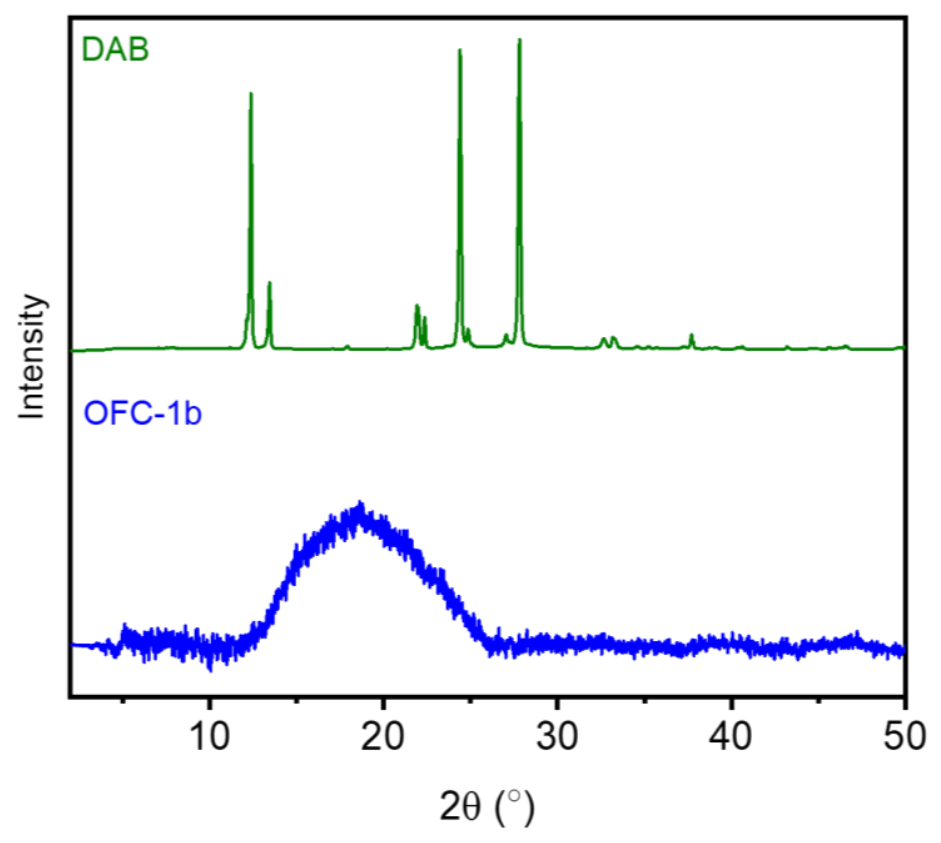

Figure S101. PXRD patterns of DAB and OFC- $1 \mathrm{~b}$ synthesized at $110{ }^{\circ} \mathrm{C}$ with 10 equivalents of $p$-toluenesulfonic acid monohydrate, indicating that $\mathrm{OFC}-1 \mathrm{~b}$ is an amorphous polymer.

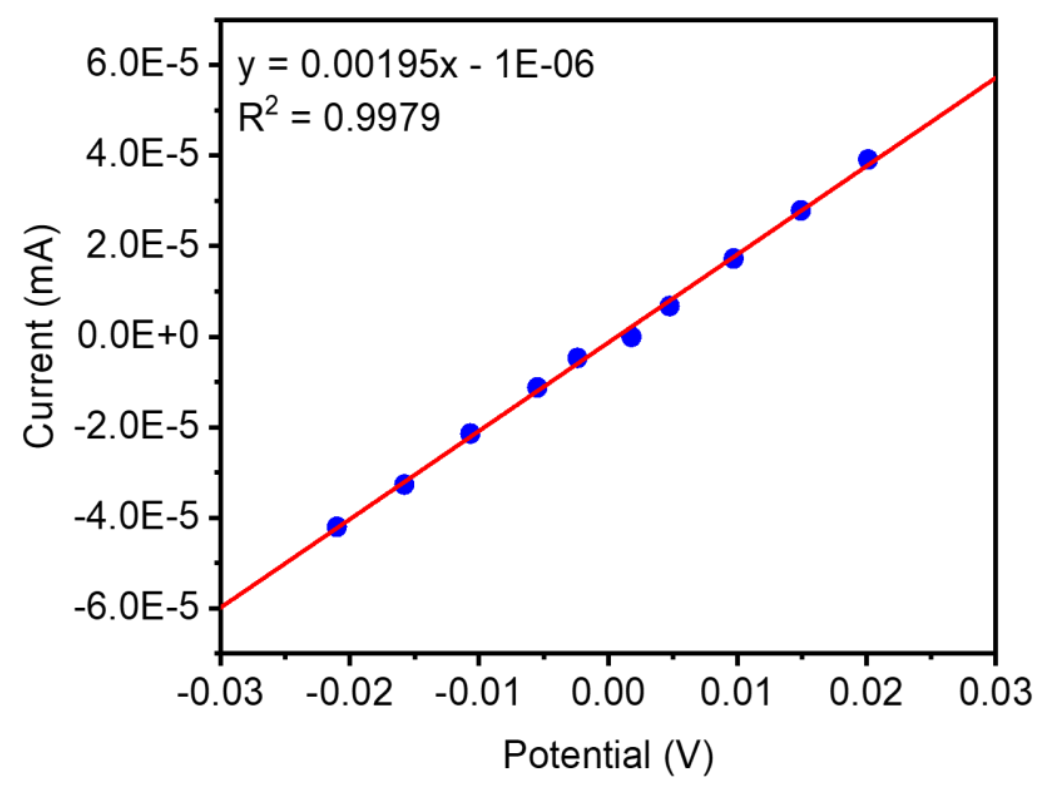

Figure S102. Two-point probe conductivity measurement of OFC-1b, indicating that this material displays Ohmic conductor behavior with a resistance of 510,000 $\Omega$. This results in a conductivity of $2.2 \times 10^{-7} \mathrm{~S} / \mathrm{cm}$ for the apparatus that squeezed the powder to dimensions of $0.90 \mathrm{~mm}$ in length and $10.04 \mathrm{~mm}$ in diameter. 


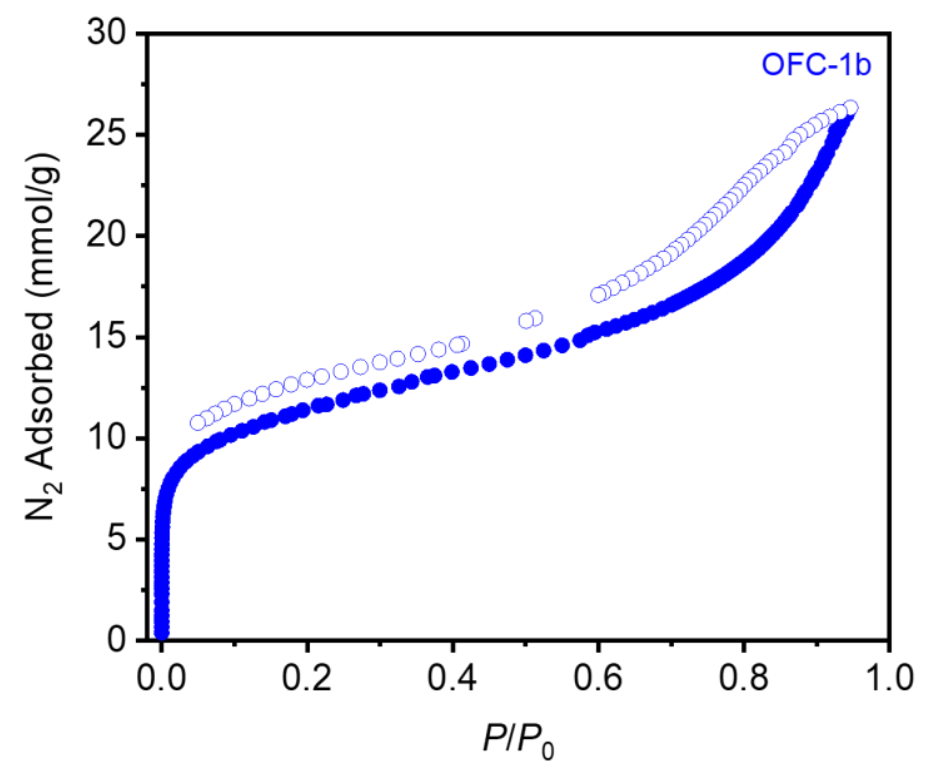

Figure S103. $77 \mathrm{~K} \mathrm{~N}_{2}$ adsorption (filled circles) and desorption (open circles) isotherm for OFC$1 \mathrm{~b}$ synthesized at $110{ }^{\circ} \mathrm{C}$ with 10 equivalents of $p$-toluenesulfonic acid monohydrate. The Brunauer-Emmett-Teller (BET) and Langmuir surface areas were determined to be $900 \pm 5 \mathrm{~m}^{2} / \mathrm{g}$ and $2126 \pm 168 \mathrm{~m}^{2} / \mathrm{g}$, respectively.

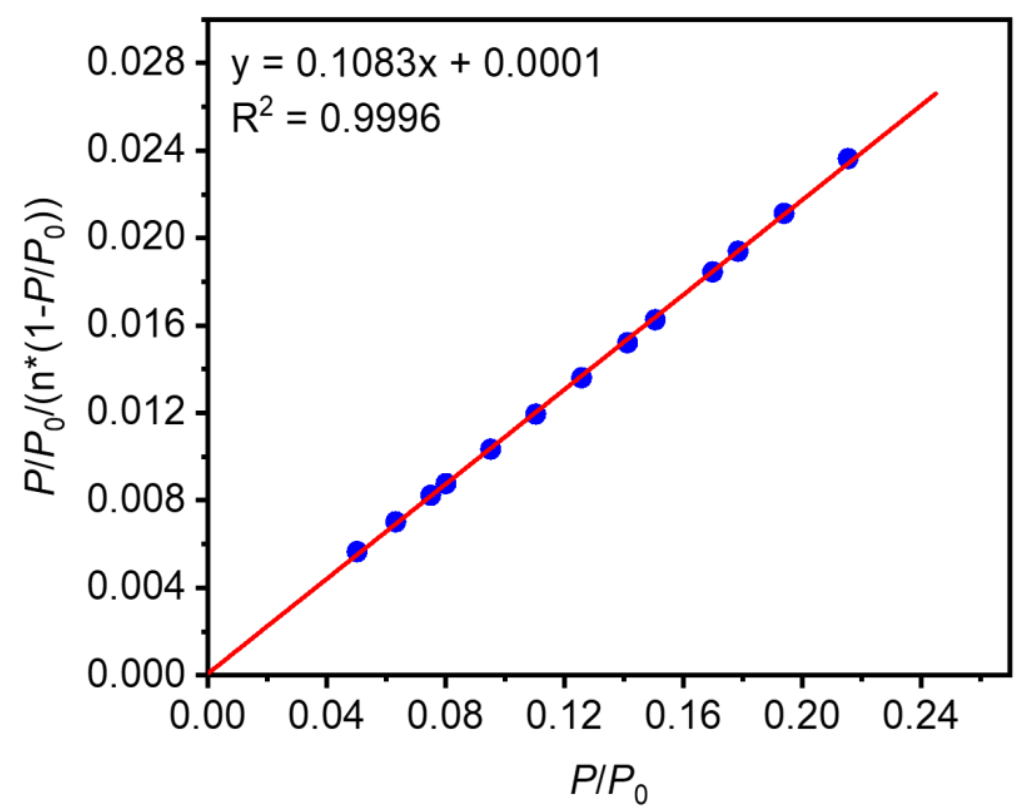

Figure S104. Linearized BET plot of OFC-1b made at $110{ }^{\circ} \mathrm{C}$ with 10 equivalents of $p$ toluenesulfonic acid monohydrate. 


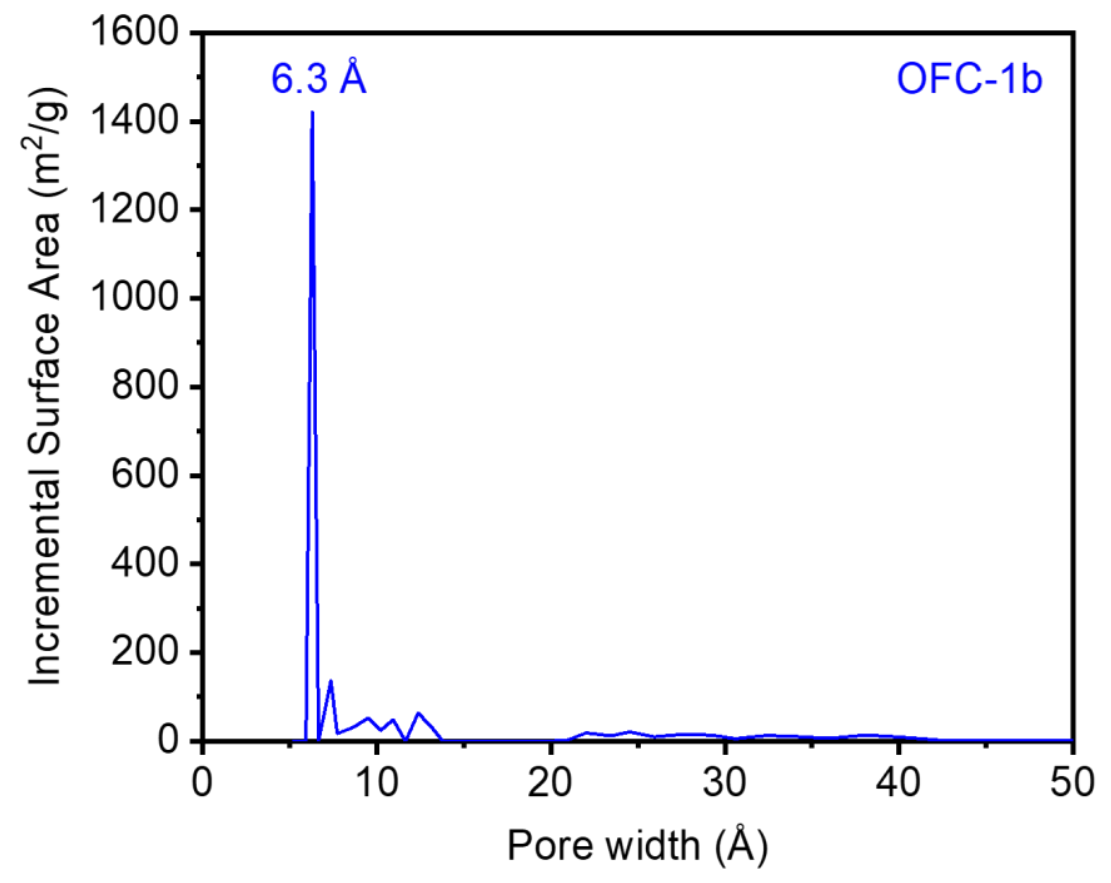

Figure S105. $\mathrm{N}_{2}$-Tarazona NLDFT-calculated pore size distribution for OFC-1b prepared at 110 ${ }^{\circ} \mathrm{C}$ with 10 equivalents of $p$-toluenesulfonic acid monohydrate, assuming a cylindrical pore geometry. 


\section{Synthesis and characterization of tri-PPN.}

The bulk powdered form of tri-PPN was prepared according to literature procedure. ${ }^{6,7}$ A 20 $\mathrm{mL}$ scintillation vial was charged with 1,3,5-triacetylbenzene $(240 \mathrm{mg}, 1.17 \mathrm{mmol}, 1.00$ eq.) and methanesulfonic acid $\left(0.763 \mathrm{~mL}, 11.7 \mathrm{mmol}, 10.0\right.$ eq.). The mixture was heated at $110{ }^{\circ} \mathrm{C}$ for 12 $\mathrm{h}$. The reaction mixture was allowed to cool to room temperature and filtered. The resulting solid was thoroughly rinsed with copious amounts of deionized water. The resultant brown solid was Soxhlet extracted with $95 \%$ ethanol for $24 \mathrm{~h}$ and allowed to dry under vacuum at $120^{\circ} \mathrm{C}$ for $12 \mathrm{~h}$, yielding a brown solid $(216 \mathrm{mg})$.

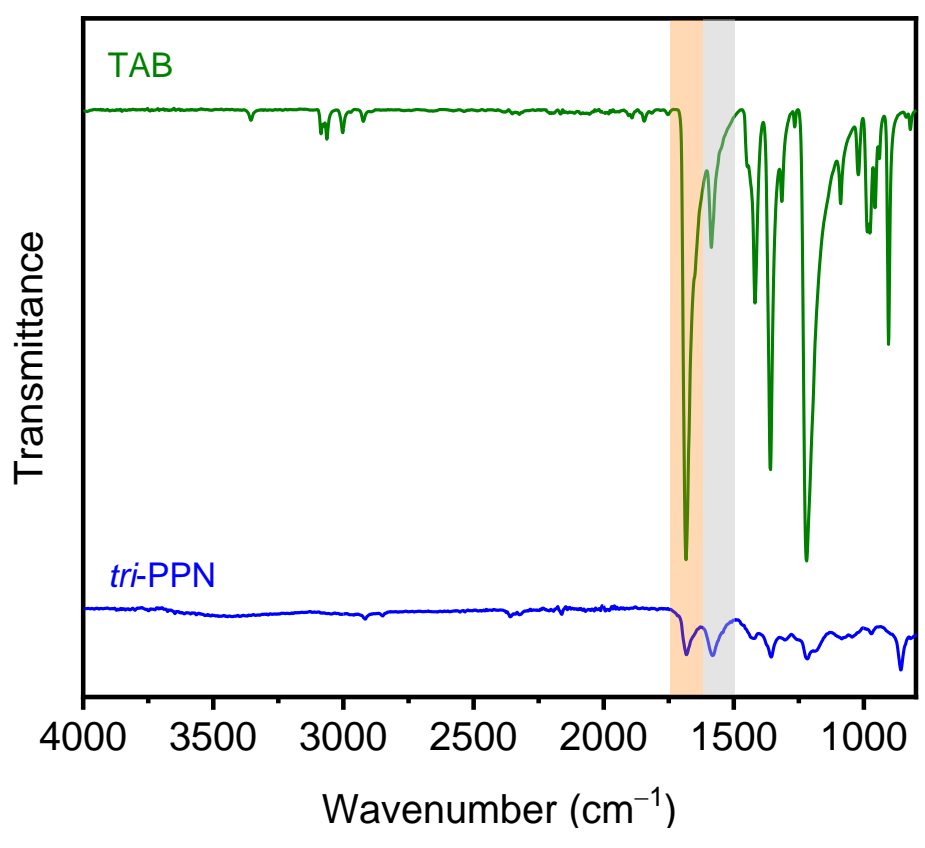

Figure S106. ATR IR spectra of TAB and tri-PPN synthesized at $110{ }^{\circ} \mathrm{C}$ with 10 equivalents of methanesulfonic acid, indicating the significant presence of residual carbonyl groups. 


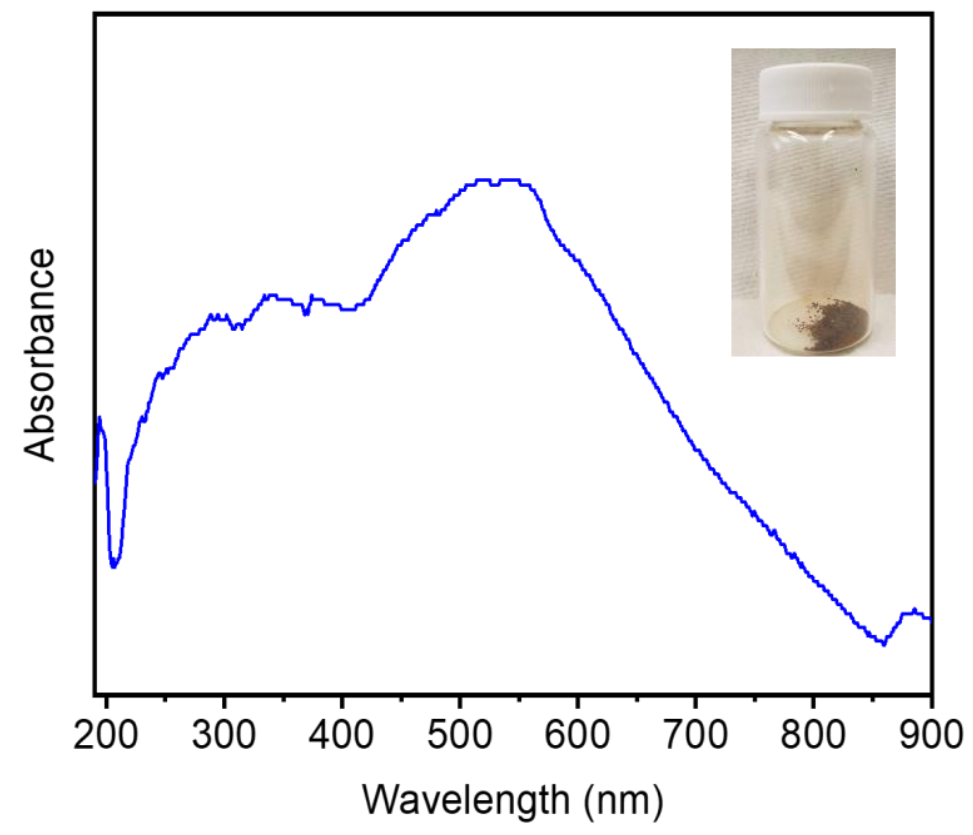

Figure S107. Solid-state UV-Vis absorption spectrum of tri-PPN synthesized at $110{ }^{\circ} \mathrm{C}$ with 10 equivalents of methanesulfonic acid monohydrate. Inset: image of tri-PPN, which is a brown solid.

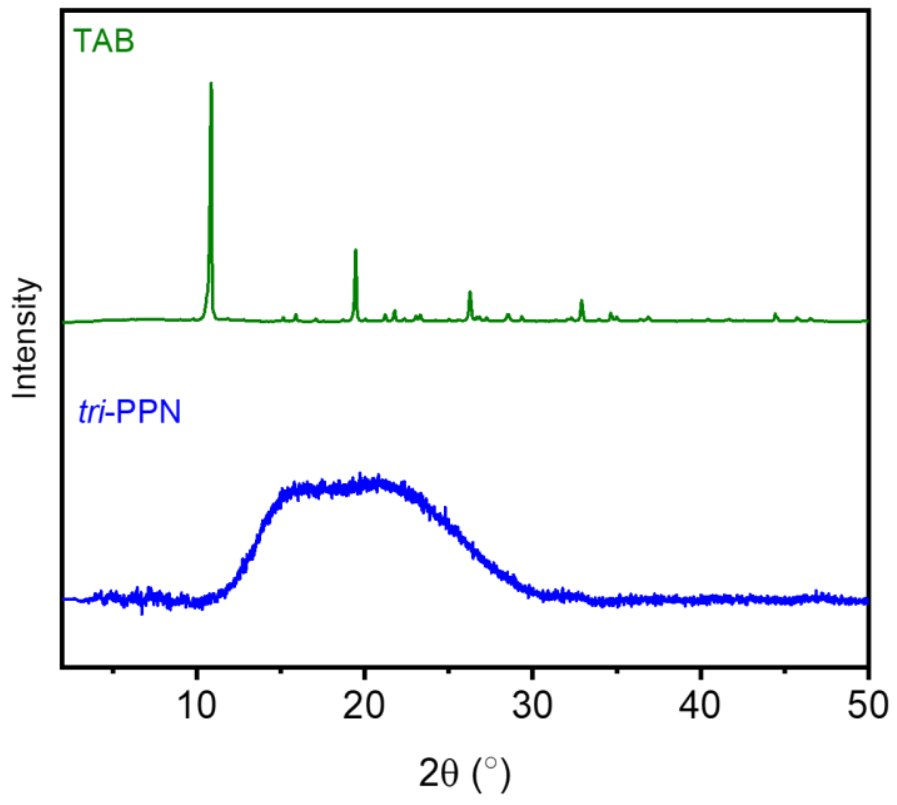

Figure S108. PXRD patterns of TAB and tri-PPN synthesized at $110{ }^{\circ} \mathrm{C}$ with 10 equivalents of methanesulfonic acid, indicating that tri-PPN is an amorphous polymer. 


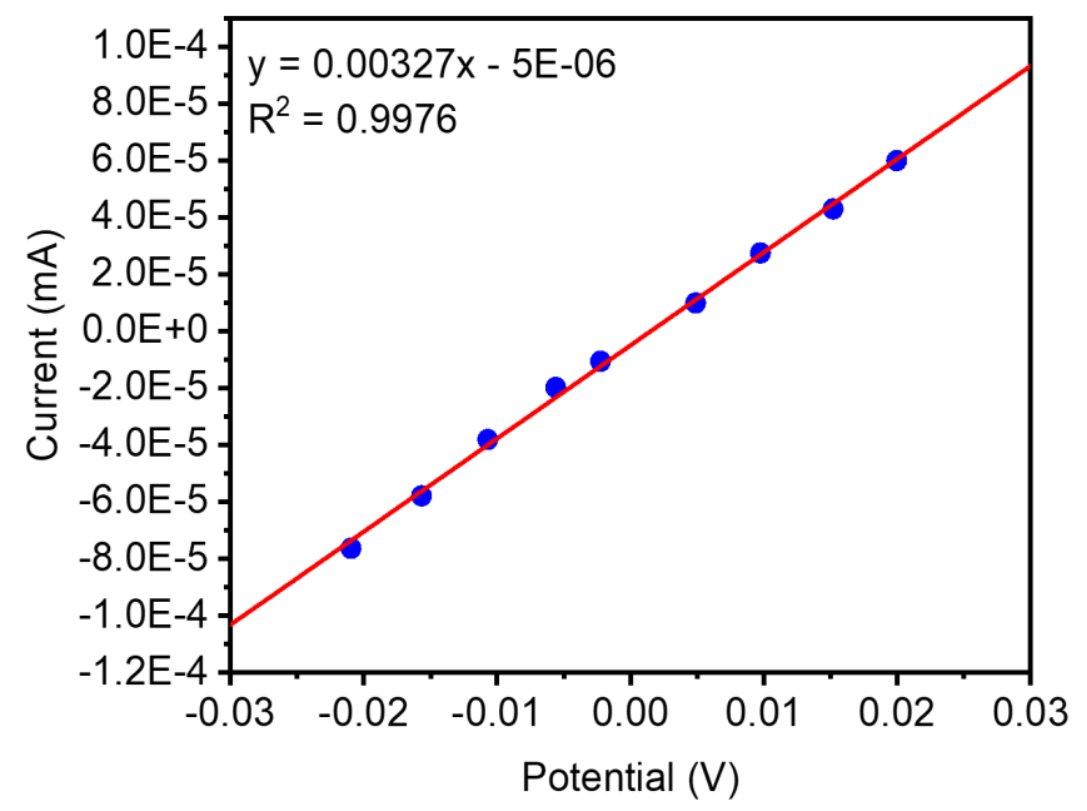

Figure S109. Two-point probe conductivity measurement of tri-PPN, indicating that this material displays Ohmic conductor behavior with a resistance of $310,000 \Omega$. This results in a conductivity of $2.9 \times 10^{-7} \mathrm{~S} / \mathrm{cm}$ for the apparatus that squeezed the powder to dimensions of $0.70 \mathrm{~mm}$ in length and $10.04 \mathrm{~mm}$ in diameter.

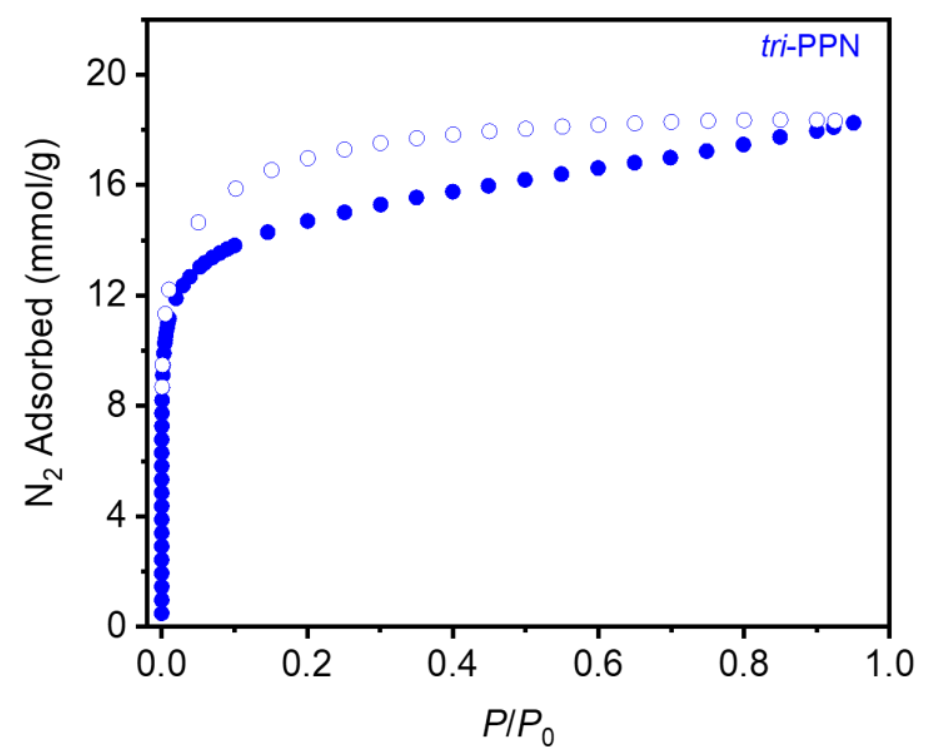

Figure S110. $77 \mathrm{~K} \mathrm{~N}_{2}$ adsorption (filled circles) and desorption (open circles) isotherm for triPPN synthesized at $110{ }^{\circ} \mathrm{C}$ with 10 equivalents of methanesulfonic acid. The Brunauer-EmmettTeller (BET) and Langmuir surface areas were determined to be $1221 \pm 6 \mathrm{~m}^{2} / \mathrm{g}$ and $1750 \pm 19$ $\mathrm{m}^{2} / \mathrm{g}$, respectively. 


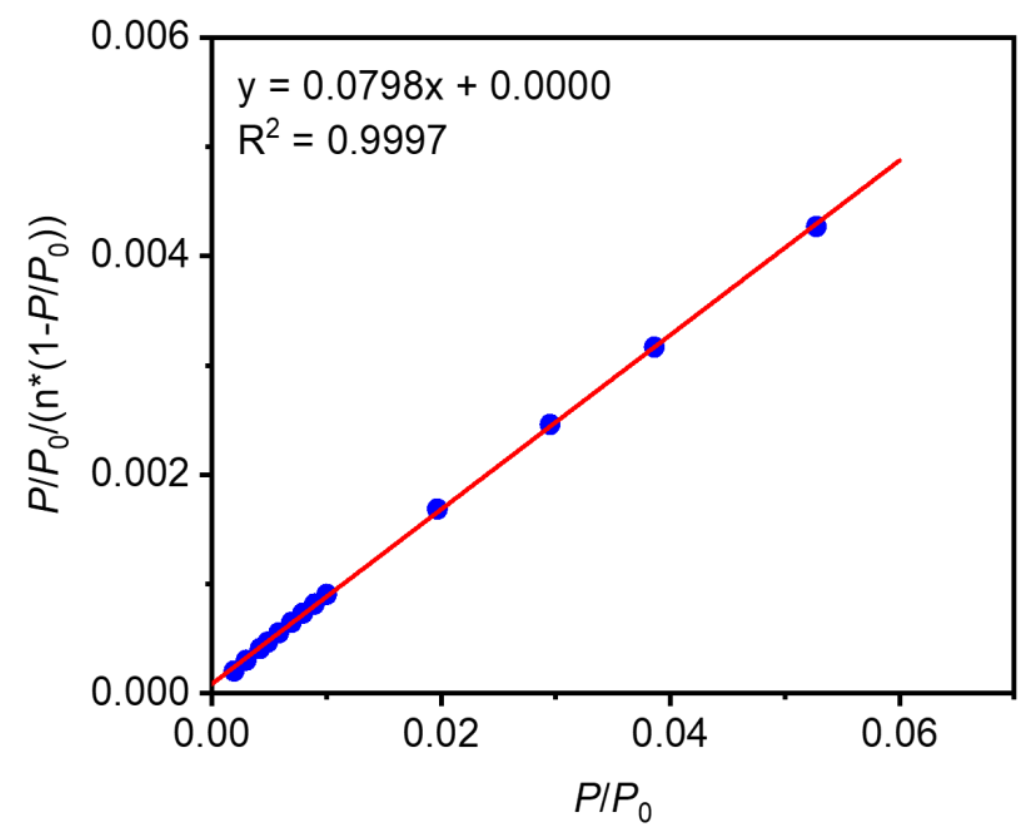

Figure S111. Linearized BET plot of tri-PPN made at $110{ }^{\circ} \mathrm{C}$ with 10 equivalents of methanesulfonic acid.

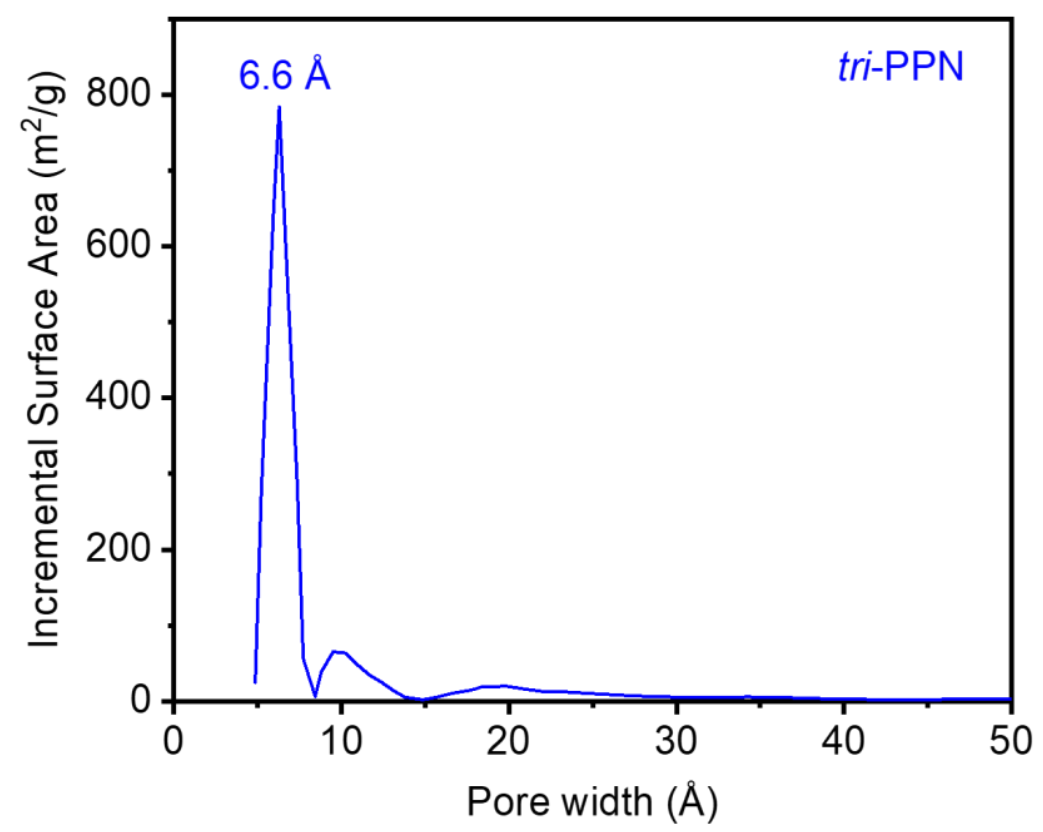

Figure S112. $\mathrm{N}_{2}$-Tarazona NLDFT-calculated pore size distribution for tri-PPN prepared at 110 ${ }^{\circ} \mathrm{C}$ with 10 equivalents of methanesulfonic acid, assuming a cylindrical pore geometry. 


\section{Control experiments}

a. Attempted trimerization of 1,3,5-triethylbenzene.

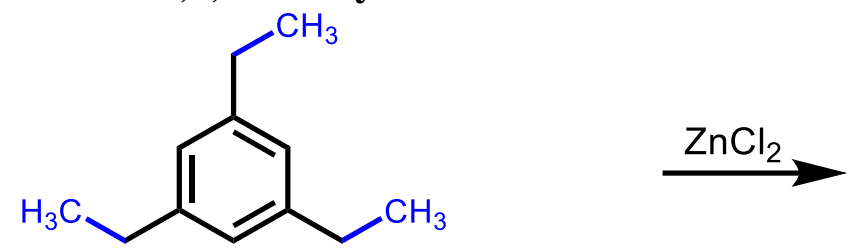

Figure S113. Control reaction of TEB with zinc chloride.

Following the general procedure, three tubes were each charged with 1,3,5-triethylbenzene (TEB) (80.0 mg, $0.168 \mathrm{mmol}, 1.00$ eq.) and $\mathrm{ZnCl}_{2}$ (229 mg, $1.68 \mathrm{mmol}, 5.00$ eq.), and the products were combined to yield a small amount of a shiny black solid (23 mg). This solid was confirmed to be non-porous by gas sorption analysis.

b. Solid state ${ }^{1} \mathrm{H}$ NMR comparison with other carbon materials.

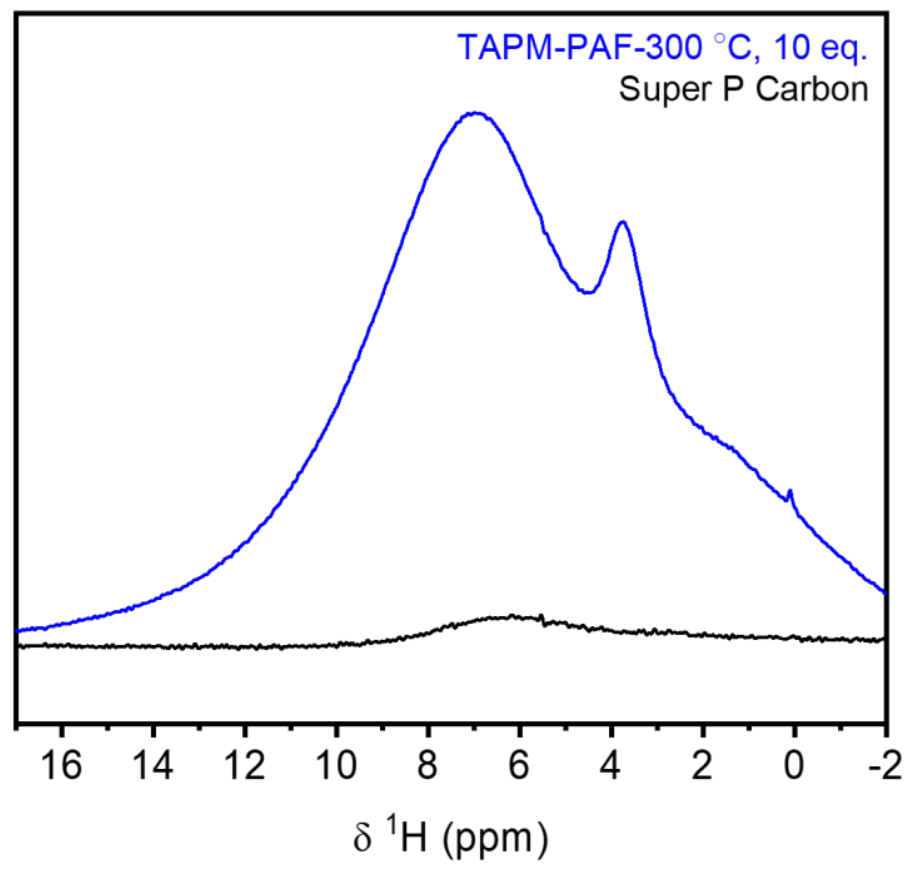

Figure S114. MAS ${ }^{1} \mathrm{H}$ SSNMR (500 MHz) spectra of commercial Super-P carbon and TAPMPAF synthesized at $300{ }^{\circ} \mathrm{C}$ with 10 equivalents of $\mathrm{ZnCl}_{2}$, collected at a spinning speed of $20 \mathrm{kHz}$. 

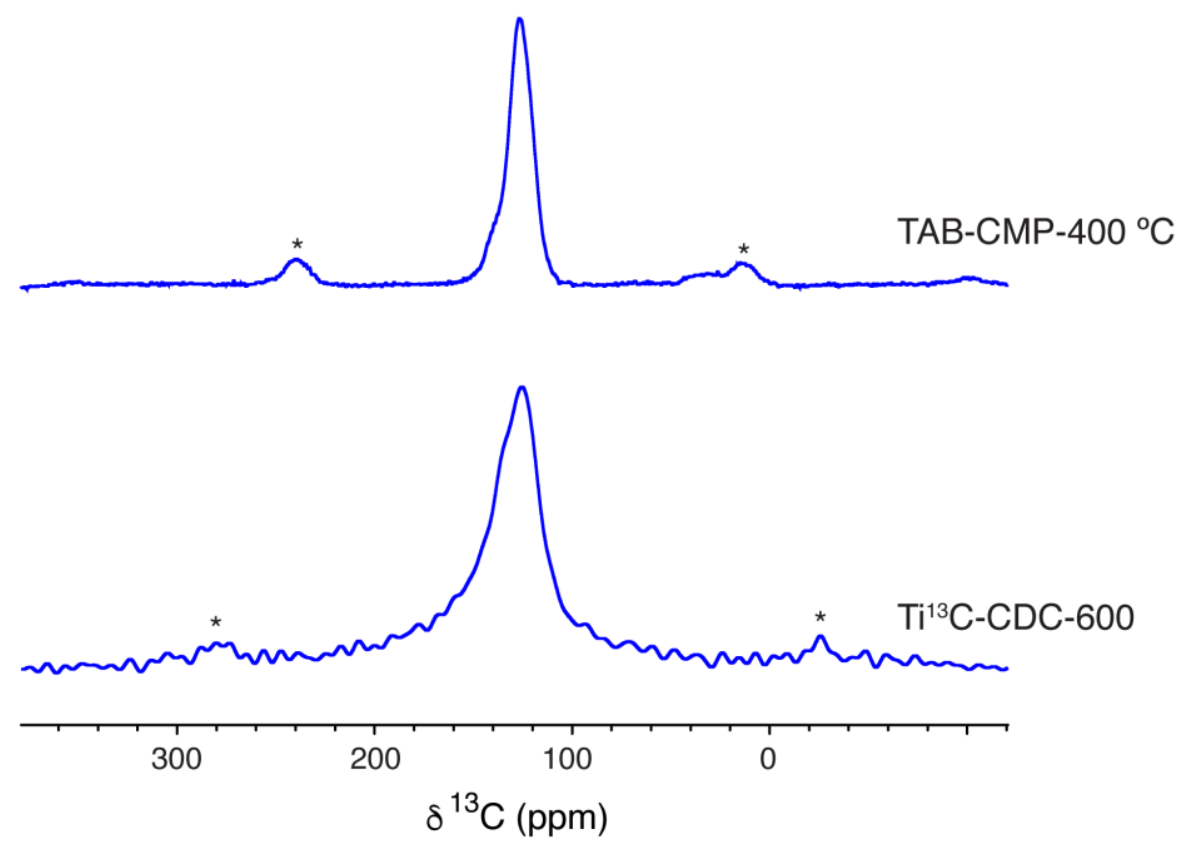

Figure S115. Comparison of ${ }^{13} \mathrm{C}$ NMR spectra (700 MHz and $400 \mathrm{MHz}$ respectively) for TAB$\mathrm{CMP}-400{ }^{\circ} \mathrm{C}$ and a porous carbon material, $\mathrm{Ti}^{13} \mathrm{C}-\mathrm{CDC}-600$. For TAB-CMP-400 ${ }^{\circ} \mathrm{C}$, NMR data were collected at $16.4 \mathrm{~T}$, with a MAS rate of $20 \mathrm{kHz}$, and cross polarization was used with a contact time of $1 \mathrm{~ms}$. Data for $\mathrm{Ti}^{13} \mathrm{C}-\mathrm{CDC}-600$ is from a previously published study, with data acquisition at $9.4 \mathrm{~T}$, with a MAS rate of $15 \mathrm{kHz}$, and with direct acquisition (i.e. pulse-acquire). ${ }^{8}$ Asterisks mark spinning sidebands. 

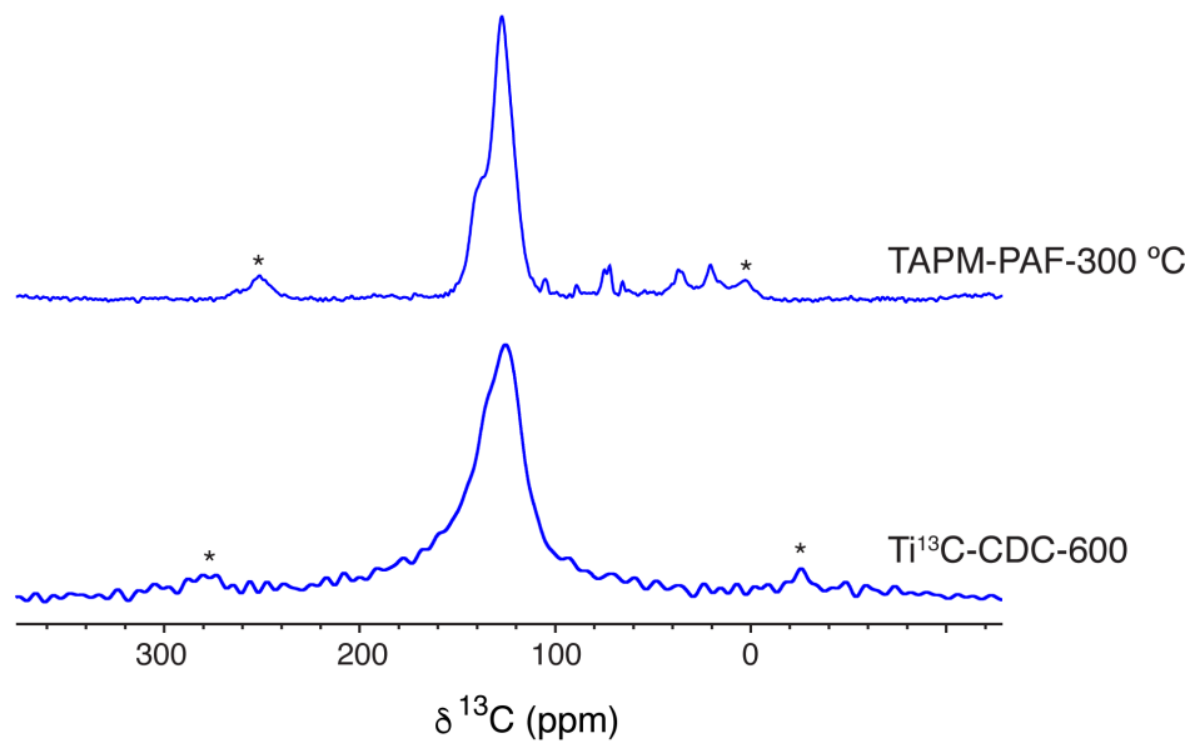

Figure S116. Comparison of ${ }^{13} \mathrm{C}$ NMR spectra for TAPM-PAF-300 ${ }^{\circ} \mathrm{C}$ and a porous carbon material, $\mathrm{Ti}^{13} \mathrm{C}-\mathrm{CDC}-600$. For TAPM-PAF- $300^{\circ} \mathrm{C}$, NMR data were collected at $9.4 \mathrm{~T}$, with a MAS rate of $12.5 \mathrm{kHz}$, and cross polarization was used with a contact time of $2 \mathrm{~ms}$. Data for $\mathrm{Ti}^{13} \mathrm{C}-\mathrm{CDC}$ 600 is from a previously published study, with data acquisition at $9.4 \mathrm{~T}$, with a MAS rate of 15 $\mathrm{kHz}$, and with direct acquisition (i.e. pulse-acquire). ${ }^{8}$ Asterisks mark spinning sidebands. 
9. Calculated Structural Models of CORN-CMP-1 and CORN-PAF-1.

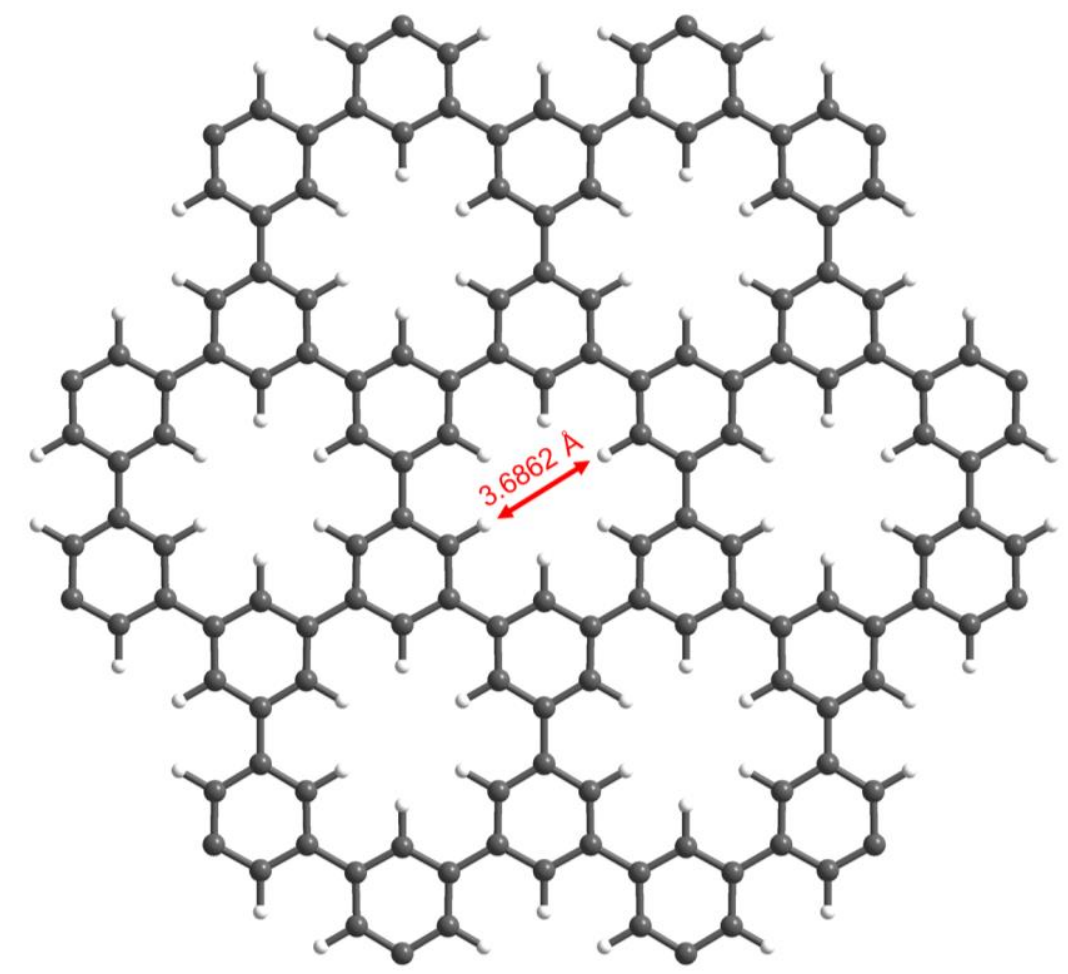

Figure S117. Calculated planar structural model of CORN-CMP-1, which has a calculated approximate pore size $(\mathrm{H} \cdots \mathrm{H}$ cross pore distance) of $3.69 \AA$. Due to $\mathrm{H}-\mathrm{H}$ repulsion, CORN-CMP1 is unlikely to be planar, which will increase the size of the micropores.

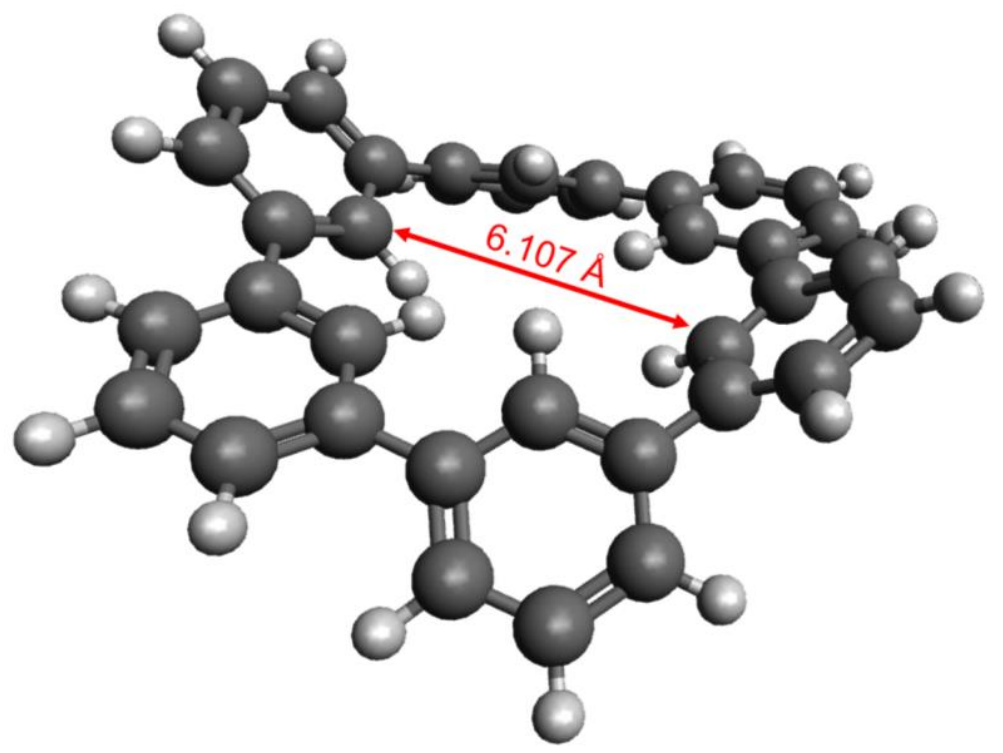

Figure S118. Calculated structural model of a non-planar fragment of CORN-CMP-1, which has a calculated pore size $(\mathrm{C} \cdots \mathrm{C}$ cross pore distance) of $6.107 \AA$. This pore size is more consistent with that measured by $77 \mathrm{~K} \mathrm{~N}_{2}$ adsorption measurements (Figure $3 b$ ). 


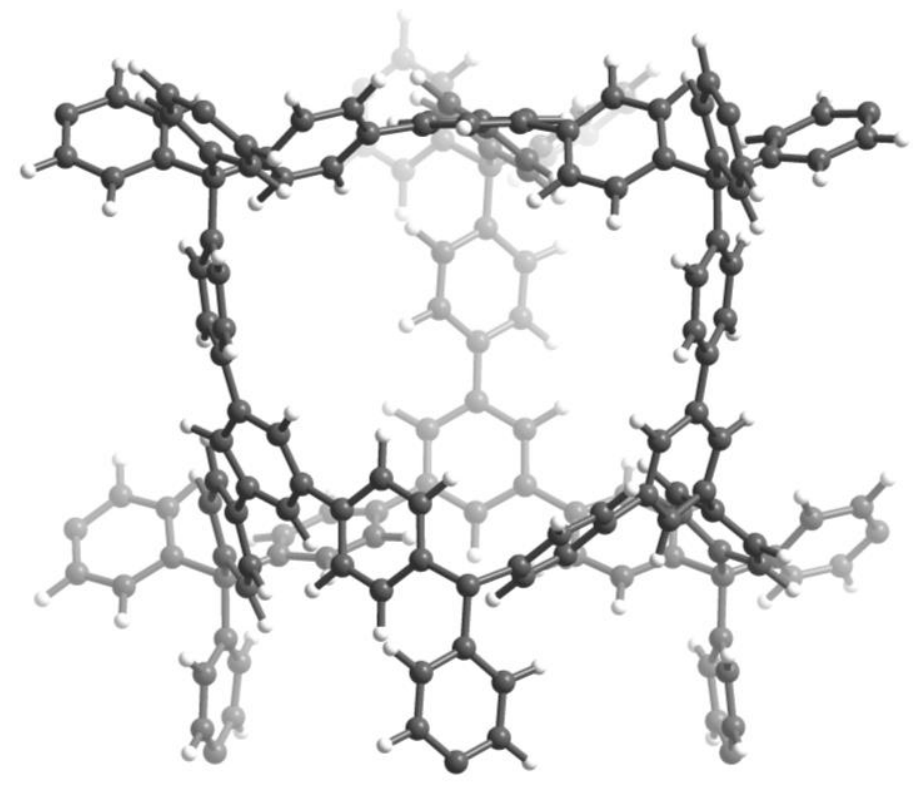

Figure S119. Calculated structural model of CORN-PAF-1 synthesized from tetrakis(4acetylphenyl)methane (TAPM). 


\section{References.}

(1) Plietzsch, O.; Schilling, C. I.; Tolev, M.; Nieger, M.; Richert, C.; Muller, T.; Bräse, S. FourFold Click Reactions: Generation of Tetrahedral Methane- and Adamantane-Based Building Blocks for Higher-Order Molecular Assemblies. Org. Biomol. Chem. 2009, 7 (22), 4734-4743. https://doi.org/10.1039/b912189g.

(2) Zimmermann, T. J.; Freundel, O.; Gompper, R.; Müller, T. J. J. Synthesis and Electronic Properties of Tetrakis[4-(Pyrimidyl)Phenyl]Methanes - A Novel Class of Electronically Active Nanometer-Sized Scaffolds. European J. Org. Chem. 2000, No. 19, 3305-3312. https://doi.org/10.1002/1099-0690(200010)2000:19<3305::AID-EJOC3305>3.0.CO;2-C.

(3) Zentner, C. A.; Lai, H. W. H.; Greenfield, J. T.; Wiscons, R. A.; Zeller, M.; Campana, C. F.; Talu, O.; Fitzgerald, S. A.; Rowsell, J. L. C. High Surface Area and Z' in a Thermally Stable 8-Fold Polycatenated Hydrogen-Bonded Framework. Chem. Commun. 2015, 51 (58), 11642-11645. https://doi.org/10.1039/c5cc04219d.

(4) Lalwani, G.; Xing, W.; Sitharaman, B. Enzymatic Degradation of Oxidized and Reduced Graphene Nanoribbons by Lignin Peroxidase. J. Mater. Chem. B 2014, 2 (37), 6354-6362. https://doi.org/10.1039/c4tb00976b.

(5) Rose, M.; Klein, N.; Senkovska, I.; Schrage, C.; Wollmann, P.; Böhlmann, W.; Böhringer, B.; Fichtner, S.; Kaskel, S. A New Route to Porous Monolithic Organic Frameworks via Cyclotrimerization. J. Mater. Chem. 2011, 21 (3), 711-716. https://doi.org/10.1039/c0jm02998j.

(6) Guo, Z. H.; Wang, C.; Zhang, Q.; Che, S.; Zhou, H. C.; Fang, L. Cost-Effective Synthesis and Solution Processing of Porous Polymer Networks through Methanesulfonic AcidMediated Aldol Triple Condensation. Mater. Chem. Front. 2018, 2 (2), 396-401. https://doi.org/10.1039/c7qm00485k.

(7) Wang, C.; Li, C.; Rutledge, E. R. C.; Che, S.; Lee, J.; Kalin, A. J.; Zhang, C.; Zhou, H. C.; Guo, Z. H.; Fang, L. Aromatic Porous Polymer Network Membranes for Organic Solvent Nanofiltration under Extreme Conditions. J. Mater. Chem. A 2020, 8 (31), 15891-15899. https://doi.org/10.1039/c9ta10190j.

(8) Forse, A. C.; Presser, V.; Gogotsi, Y.; Grey, C. P. Ring Current Effects: Factors Affecting the NMR Chemical Shift of Molecules Adsorbed on Porous Carbons. J. Phys. Chem. C 2014, 118 (14), 7508-7514. https://doi.org/10.1021/jp502387x. 